LIBRARY OF THE COOPER-HEWITT MUSEUM OF DESIGN - SMITHSONIAN INSTITUTION •

Bequest from

Estate of Marian Hague 




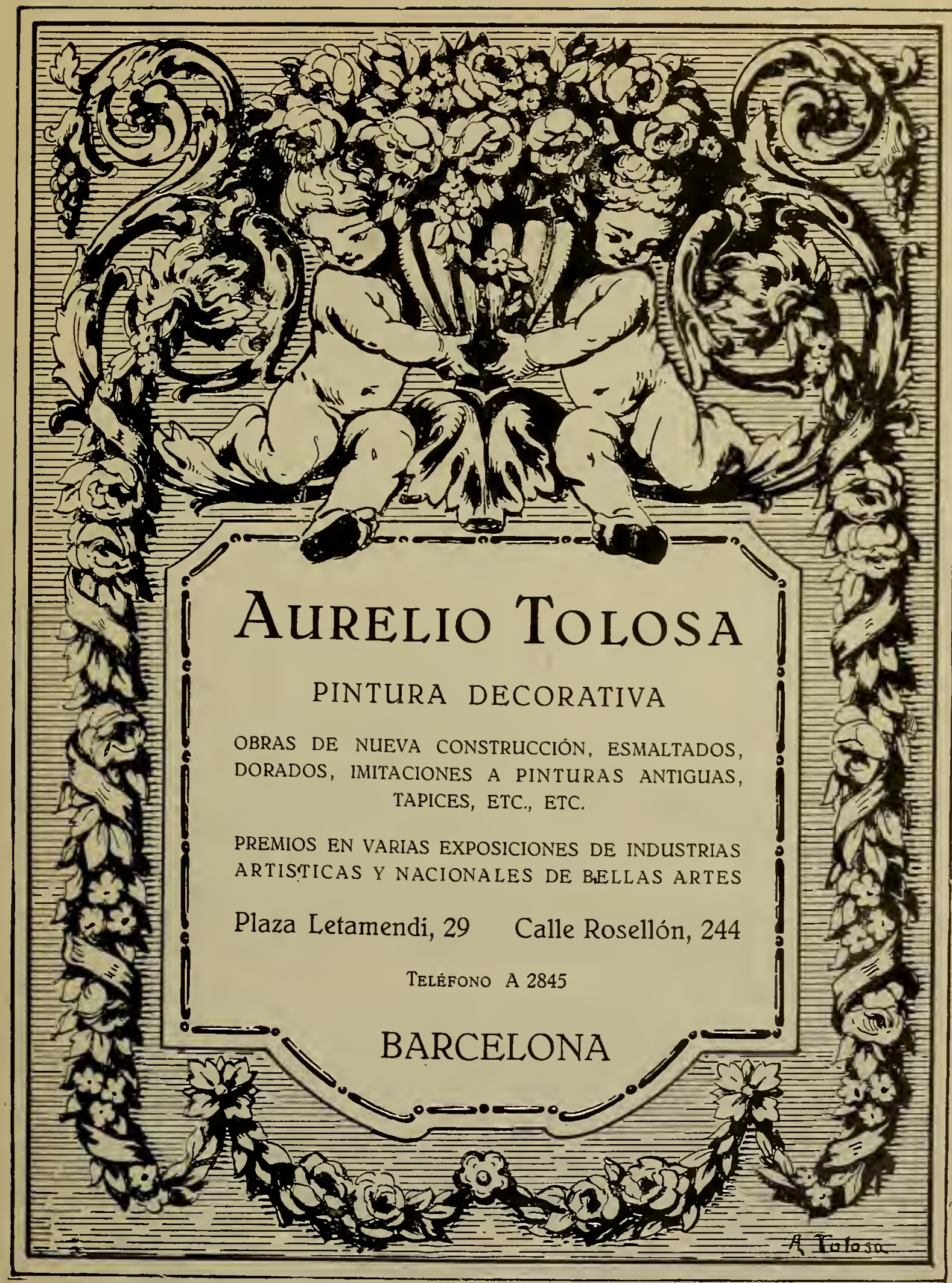


回回回回回回回回回回回回回回回回回 回 回

回

回

回

回

回

回

回

回

回

回

回

回

回

回

回

回

回

回

回

回

回

回

回

回

回

回

回

回

回

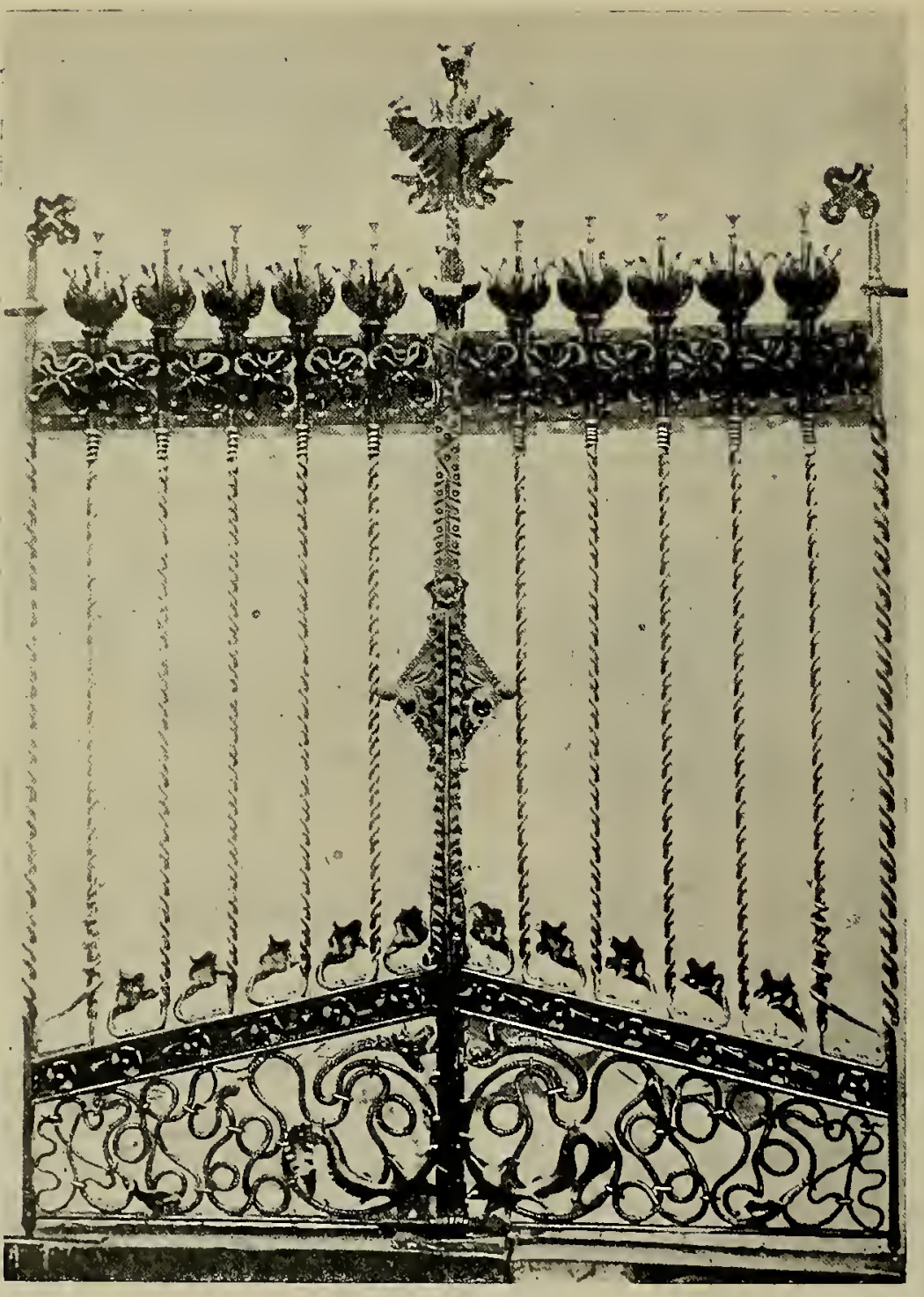

回

回

回

回

回

回

回

回

回

回

回

回

回

回

回

回

回

回

回

回

回

回

回

回

Cerrajería de FLINCH 回 FUNDADA EN 1884

回

PELIGRO，7，Y LIBERTAD，6 回

BARCELONA (GRACIA) 回

回

回

回回回回回回回回回回回回回回回回回回回 


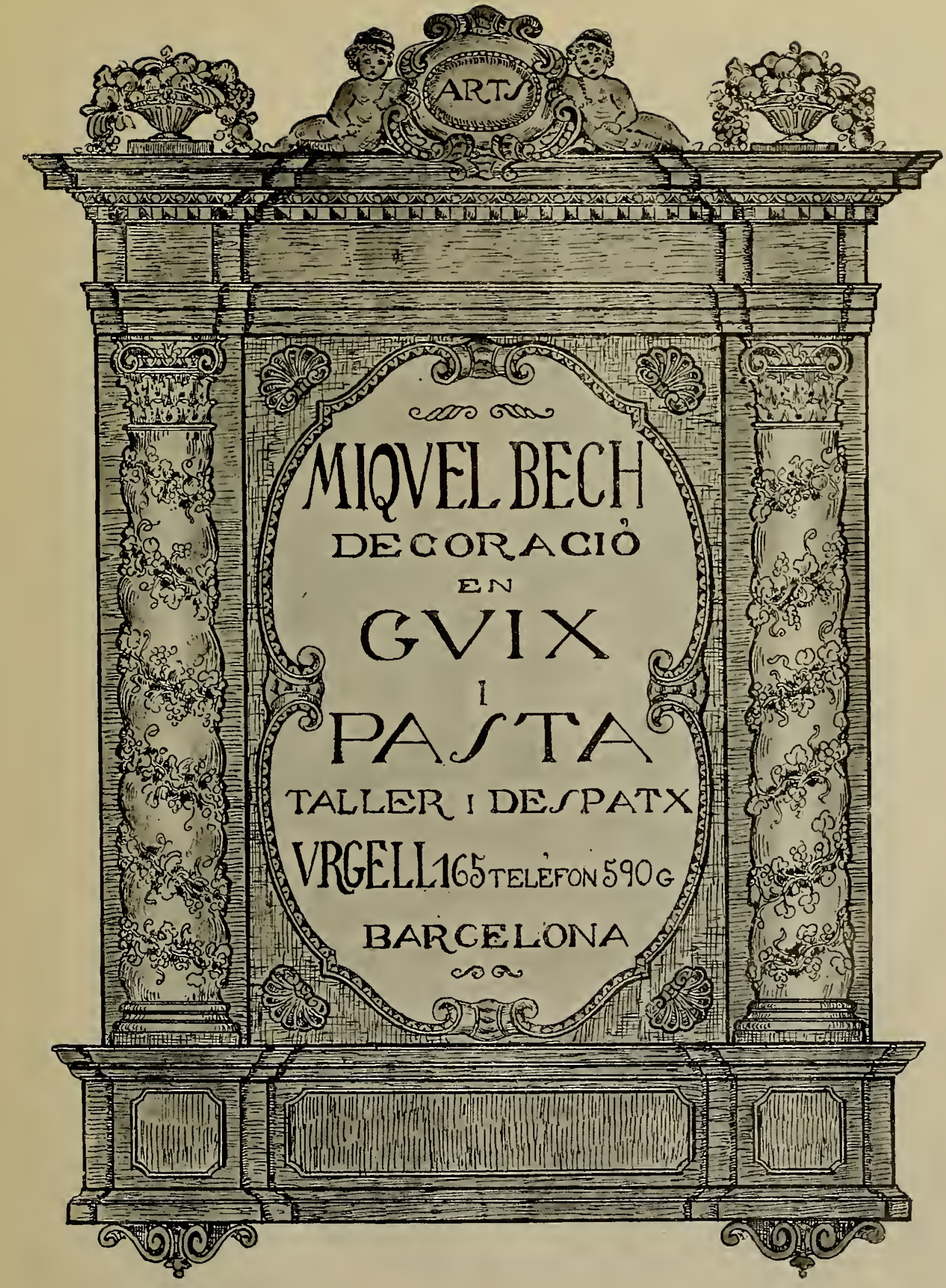




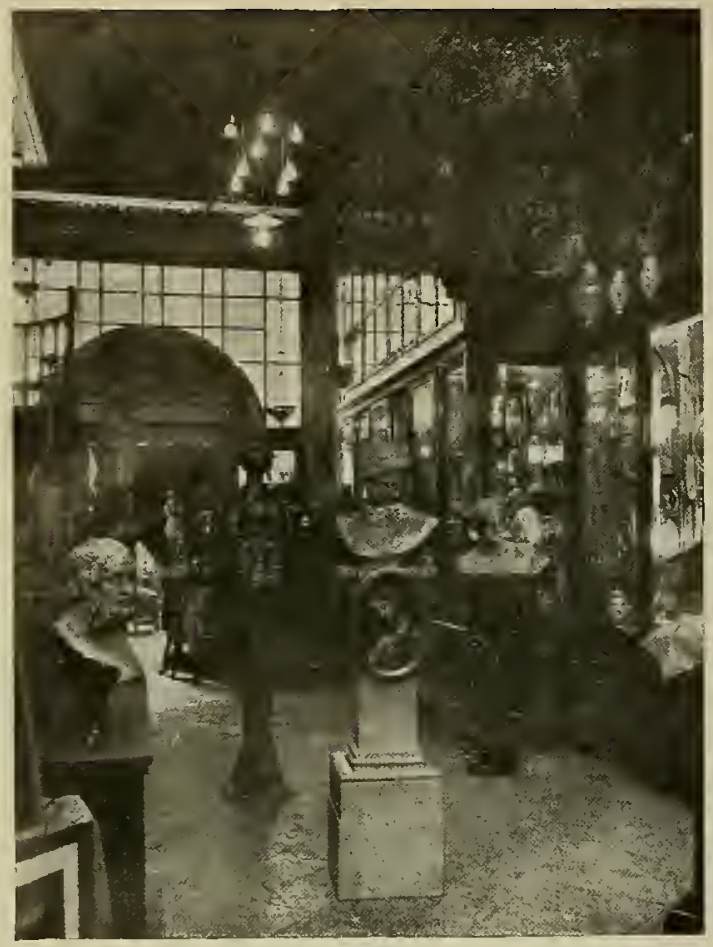

$\underline{\mathrm{R}} \mathrm{E} \mathbf{N} \mathrm{A} \mathbf{R}$

ARTE DECORATIVO :: PINTURA Y ESCULTURA :: REPRODUCCIONES :: MARCOS Y DECORACIÓN POLICROMA GRABADOS Y FOTOGRAFÍAS ALTARES E IMÁGENES

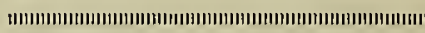

Representación de la casa DOMENICO ANDERSON Editor-Fotógrafo, de Roma

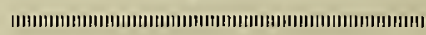

Diputación, 271 (Entre Paseo Gracia y Claris) BARCELONA

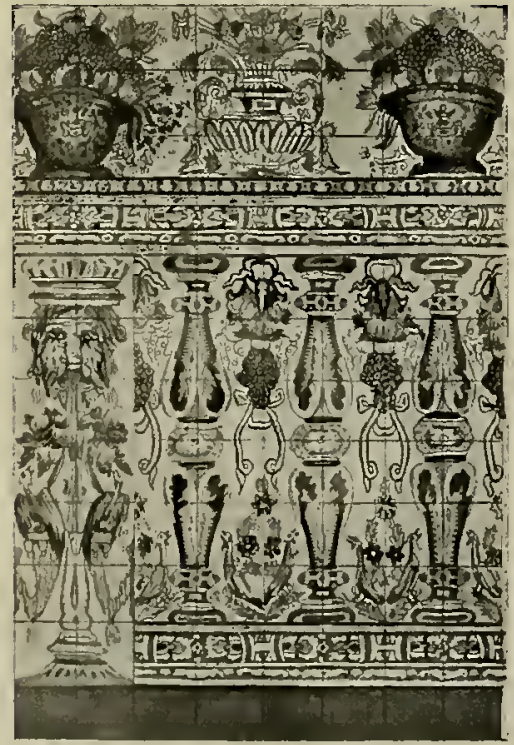

\section{CASIMIRO VICENS}

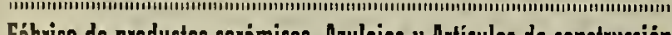
Fábrica de productos cerámicos, Azulejos y Articulos de construcción BARCELONA

Despacho: CALle de TALLERS, 72 :-: Teléfono 5090 A. Fábrica: Calle benavent, próxima a Travesera; Sans
Sociedad Anónima

\section{Ballarín}

Aceros y Hierros forjados y moldeados : Fundición de Hierro, Bronces y Aleaciones : Cerrajería artistica : Construcciones metálicas : Prensas para cartas : Básculas y balanzas : Pesas y medidas : Básculas medicales y Pesa-bebes sistema Ballarín : Artículos de ferretería: Herrajes modernos y de estilo

TALLERES:

Córcega, frente Bruch - Teléfono $640 \mathrm{G}$. DESPACHO:

Diagonal, 402 - Teléfono $1824 \mathrm{G}$. BARCELONA 


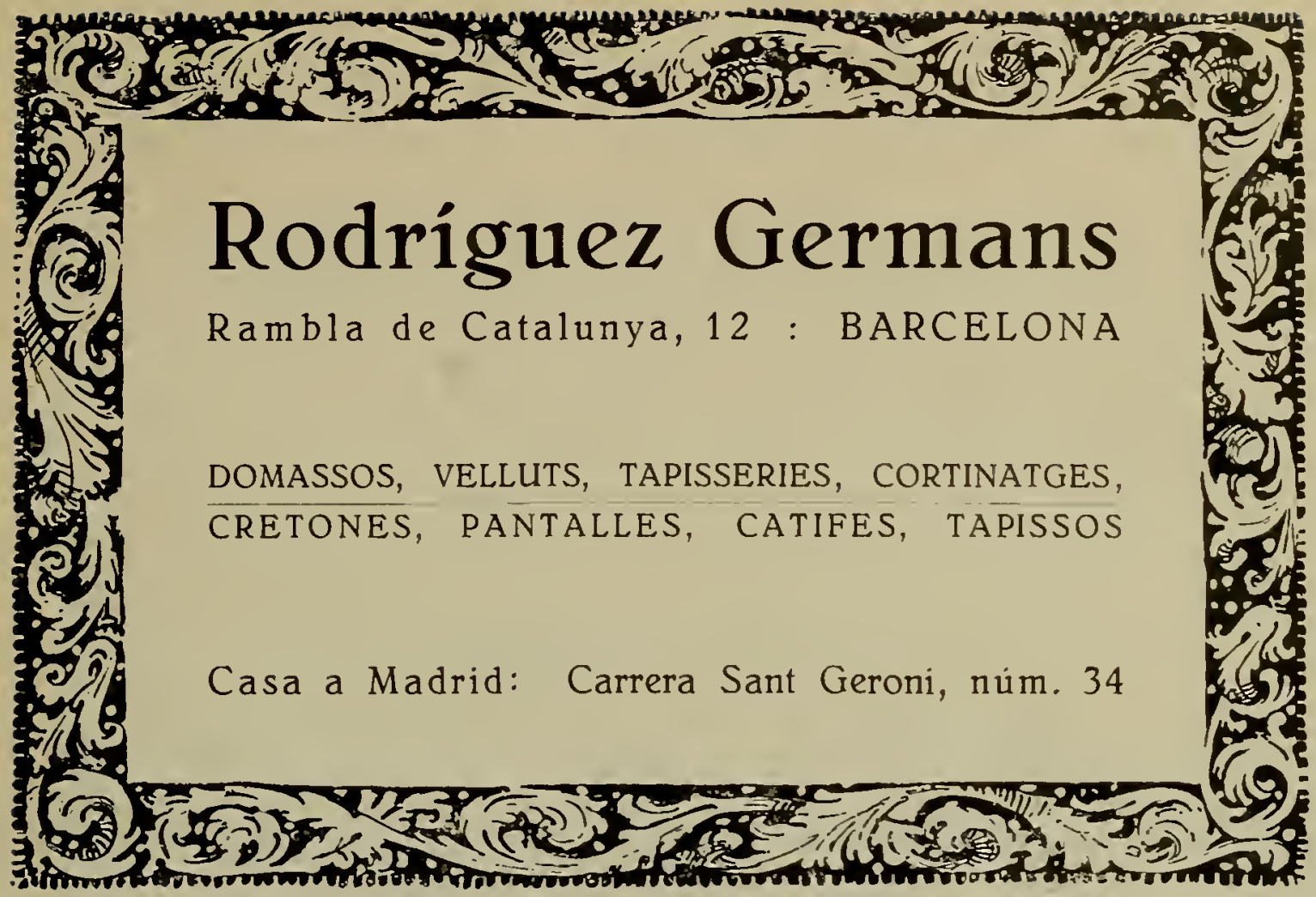

\section{Arte Moderno}

ARTICULOS PARA

LAS BELLAS ARTES

OBJETOS DE ESCRITORIO

CARMEN, 13 - MADRID

\section{AGUA FARGAS}

NATURAL NO GASEOSA

Con protector DE ESTAÑO

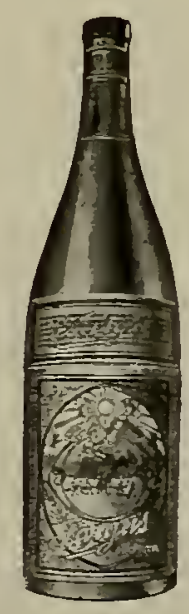

SIN TAPÓN DE CORCHO

La mejor agua de mesa n. Admón. en Barcelona: LAURIA, 60, pral. 


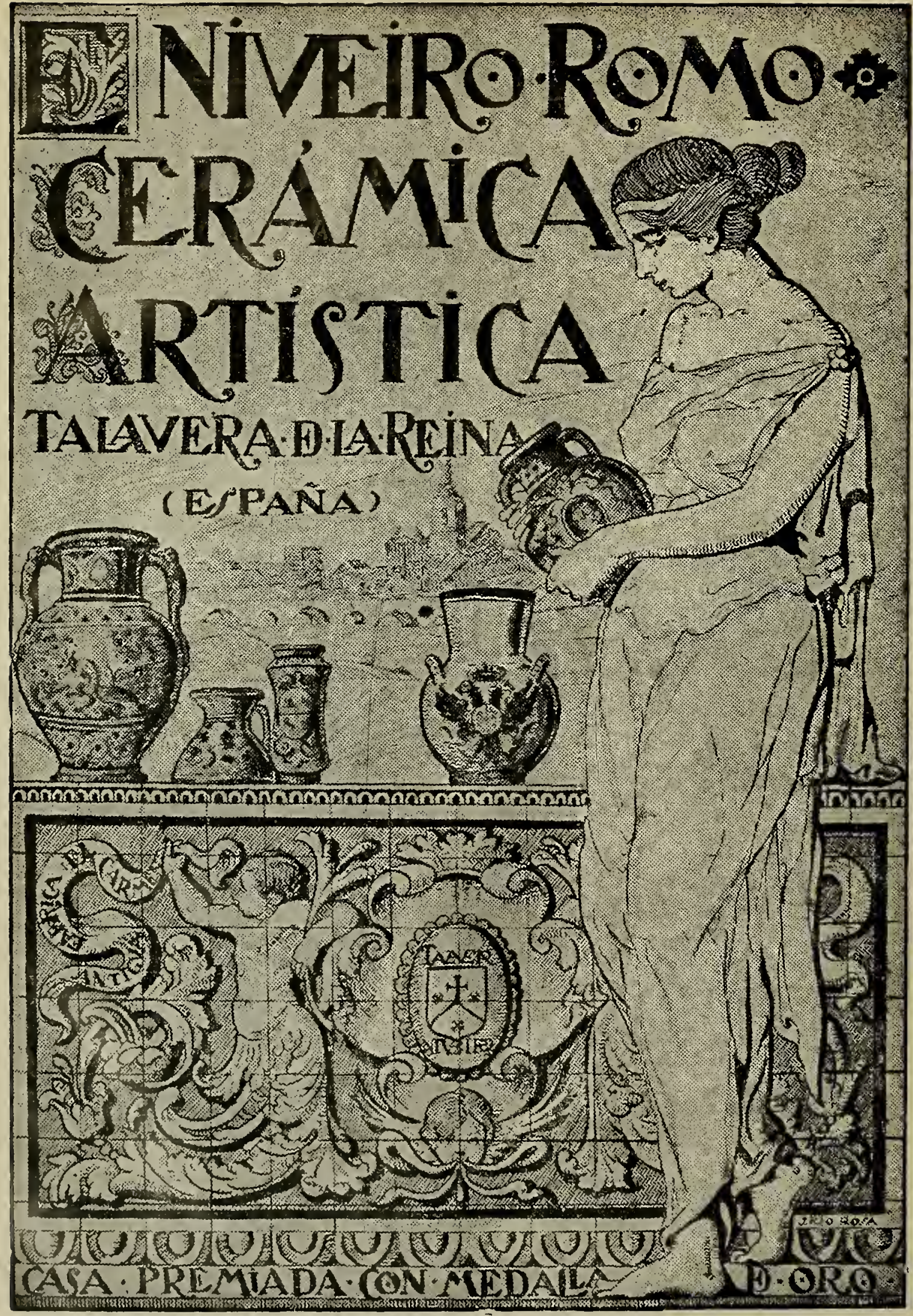




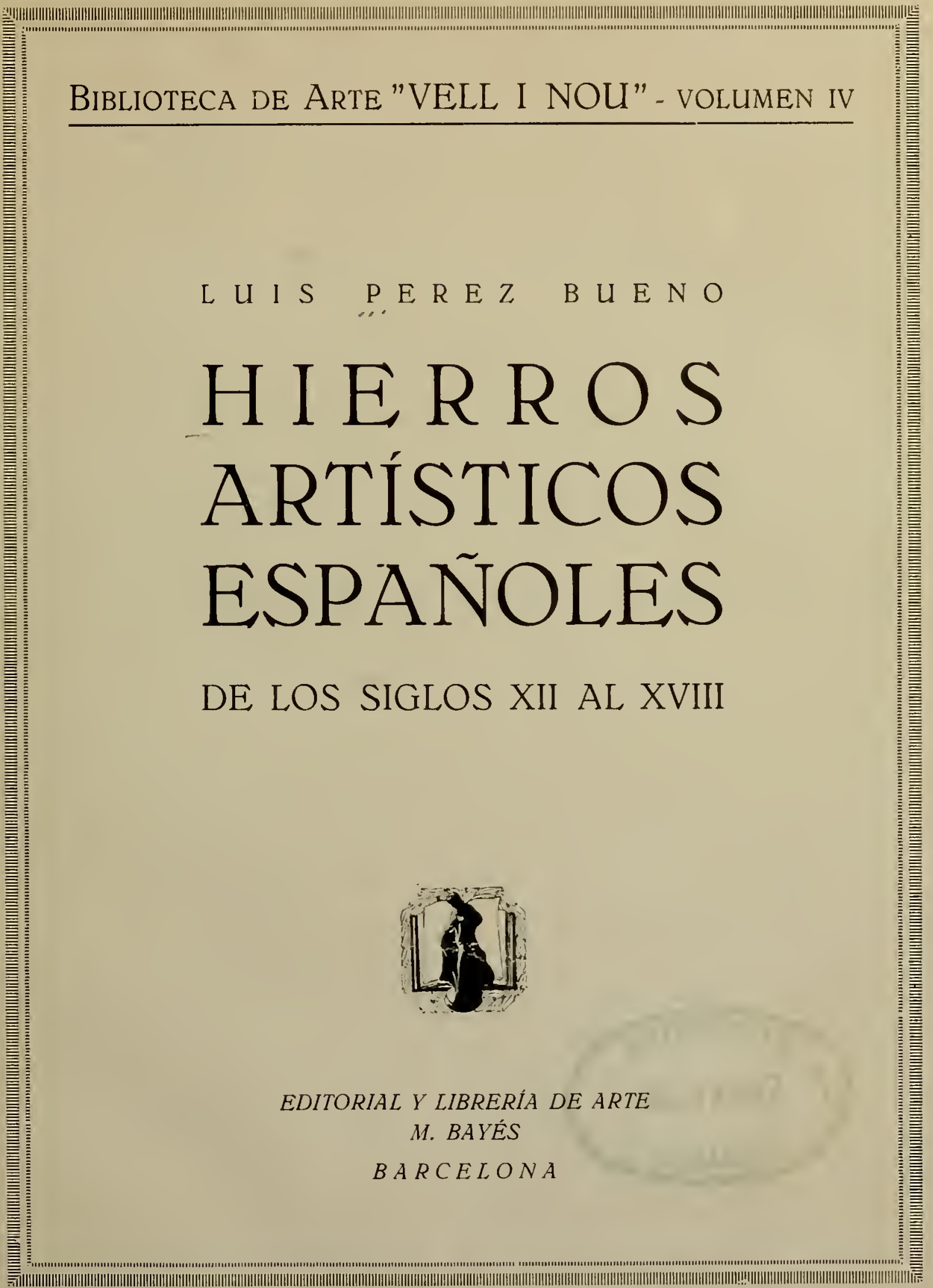


401475 


\section{Hierros artísticos españoles de los siglos XII al XVIII}

Finalizando el siglo xIX comenzó a manifestarse en España un creciente interés por los estudios de las artes industriales.

En monografias, folletos, libros y conferencias, demostraron sus autores, con más o menos éxito, pero siempre con esfuerzo plausible, la finalidad que persiguieron, los medios de investigación de que se habian valido y el punto de vision que tuvieron del problema, bien tratando de resolverlo en un sentido puramente erudito, de aportación documental, o histórico, por su desarrollo evolutivo, o eminentemente práctico analizando las diversas técnicas o procedimientos de ejecución, según el material empleado y sus aplicaciones artístico-industriales. Estos esfuerzos, un tanto aislados, permitirán seguramente en época no lejana el que puedan unificarse o complementarse dando la resultante que todos anhelamos: el que la historia de las artes industriales en España, en toda la amplitud del concepto, sea un hecho. Actualmente, si aún ofrece muchas interrogantes, quedan fuentes todavía no exploradas en las que podrán hallarse las contestaciones.

Los Centros de Estudios de Cataluña y el muy notable en todos sus aspectos "Centro de Estudios Históricos de Madrid"y otros focos de laboriosa y constante investigación que en muchos lugares de España realizan hombres beneméritos, llevarán a término esa compleja labor, cuyo encauzamiento formal y metódico, aquí como en otras naciones, es de una relativa modernidad.

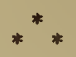

De todas las industrias Nacionales, la del hierro es la que más poderosamente ha resurgido trayendo hermanada, para satisfacer una necesidad sentida, la publicación de obras dedicadas a presentar ejemplos de los variadisimos trabajos artísticos que se realizaron con el hierro en los pasados siglos. Las artes gráficas prestan a la idea su poderoso y eficaz auxilio. Y de esta suerte se va encaminando, en cuanto es posible, la fidelidad de las reproducciones de los artísticos hierros antiguos, sirviendo como radicales elementos de inspiración para otras formas y para otras aplicaciones.

Raro es hallar alguna publicación española que anteriormente al siglo xvin trate de las labores artisticas del hierro.

Es ineludible, si se quiere conocer algo referente a esa materia, el tener que dedicarse a la paciente búsqueda de manuscritos e impresos, para que la suerte, de vez en vez, depare alguna nota interesante o curiosa que, como pequeña luminaria se destaca entre el inmenso fárrago de los inventarios, testamentos, reglamentaciones gremiales, Cédulas de tasas, convenios, y pactos, y escrituras y asientos de artífices herreros con los Cabildos de las Santas Iglesias. Todo eso y aún más está diseminado, hasta que en el siglo xvir se dan a la estampa obras de compilación. de conjunto, redactadas con relativo orden, conteniendo noticias relacionadas con la materia de hierros y otras industrias artísticas. Entre aquellas se significan: las "Memorias históricas" de Capmany de Montpalau; las "Memorias Políticas y Económicas" de Larruga; el "Semanario Erudito" de Valladares de Sotomayor; el "Viaje de España" de Ponz; el "Diccionario de Bellas Artes" de Cean Bermúdez y los discursos de Campomanes. 
Salvo las obras de Alquimia, cuya antigüedad venía de la Edad Media y cuyos tratados avanzando el siglo xvil siguieron consultándose, [como el del sabio médico y astrónomo Árabe, Geber - Giaber] (1), la bibliografía extranjera no acusa hasta fines del primer tercio del siglo xvi obras importantes en el arte del hierro. Fué la primera y más extendida por toda Europa en repetidas ediciones "De Re Metallica" del Doctor Jorge Agricola, al que llegaron a llamar "padre de la metalurgia». Realmente la fama lograda fué justa; "De Re Metallica" (2) recopila y expone cuanto en el arte de trabajar el hierro se conocía en los comienzos del siglo xvi, principalmente en Alemania, Francia y España. Es la bella época del progreso, en la que la fuerza hidráulica es el motor que lanza el viento y trabaja con el martillo, libertando a la mano del hombre de una ruda esclavitud. Enseña Agrícola paso a paso desde la obtención del metal hasta convertirlo en barras, la manera de darle temple; y cuando la fundición del mineral era dificil, el procedimiento del tostado; y la obtención del acero, etc. Por el año 1540 la imprenta de Venecia publicó la obra de Vanoccio Biringuccio (de la Pirotechnia) producción igualmente notable, con la ventaja de estar su texto en italiano, lo que permitía en la cuenca del Mediterráneo mayor divulgación de conocimientos, que no el texto de la de Agrícola escrito en latín, por cierto un poco enrevesado.

Del contenido de esas dos obras maestras y fundamentales en las artes del hierro, ha podido inferirse que en España, señaladamente en las regiones de Cataluna, de tan ilustre abolengo mundial por sus fraguas, y las Vascongadas, los métodos de elaboración y los productos obtenidos, no eran superados ni aún igualados en determinados casos por los de otros países (3); sin duda conservó y mejoró su gran arte celtíbero.

El último tercio del siglo xv y gran parte del

(1) Geberi Phisolophi ac AIchimistae maximi, de Alchimia.

(2) Ediciones en Basilea - 1530 en $8 .^{\circ}$ - en folio en 1549, 1556, 1561 con grabados en madera. Reimpresiones en 1621 y 1657 . - Traducida al italiano en 1563 , etc.

(3) Es notable lo escrito sobre este tema por el distinguido arqueólogo e Ingeniero Industrial D. Pedro M. de Artiñano en su sIntroducción al Estudio del trabajo del hierro en Españan. Madrid, 1919. siglo xvi comprende el más alto grado de esplendor en las obras de forja de los herreros, maravillosos transmutadores que con el martillo, el cincel y la lima, modelan y afiligranan el tosco metal hasta convertirlo en materia más preciada que el oro.

Del hierro fundido, de su fabricación, se tienen pocos antecedentes con anterioridad al siglo xvI. A las ventajas de la fundición, como era el licuarse y moldearse con facilidad, se oponía su natural condición quebradiza e indócil para el trabajo de arte. Así lo debieron entender con el alto sentido que tienen todos los creadores de belleza, aquellos ferreros que trabajando el metal, no hurtaron el esfuerzo, aún cuando lo pudieron eludir y falsear empleando la fundición. De aquí las pocas obras en hierro fundido de caracter artístico que han llegado hasta nosotros. Si en los pasados siglos hubiese estado en predicamento el exceso de fines utilitarios que hoy padecemos, se hubiesen trocado los efectos y hoy las obras antiguas de forja serían casi desconocidas. Muchos tratadistas, culpan a la fundición de la actual decadencia de la herrería verdaderamente artística.

Como ocurre con algunos inventos datados en remotas fechas, en este de la fundición del hierro nada de cierto se sabe de donde y cuando fué logrado; aunque nunca falten sabios a quien atribuírselos, que, para estos casos, son como valores representativos del amor propio colectivo de una Nación. Tanto monta haya sido Inglaterra, como Alemania, o los Paises Bajos. Hecho cierto es que, sin encaminarnos hacia la China, que es la región inventora por excelencia, al decir de algunos historiadores, lo que representa un método de investigación bien sencillo, en Europa se conservan algunas obras de fundición de fines del siglo xIV y en España en los finales del siglo xv, - dice el Sr. Artiñano-(1) “se establece en Navarra con caracter francamente industrial la primera fábrica de balas o bombas fundidas; en los principios del siglo xvI la industria se extiende a las provincias Vascongadas y Santander, y en dias de Doña Juana primero, y del Emperador

(1) Obra ya citada. 
después, se obtienen para Granada, en hierro fundido las primeras piezas ornamentales, que son fondos de chimenea trabajados por moldeo del hierro líquido por fusión». De estas placas de fondos de chimeneas y de hogares, de formas rectangulares o rematadas en medio punto y con relieves con el escudo del Emperador Carlos y sus descendientes, hasta la extinción de la dinastía de los Austrias en España, hemos podido ver buen número de ejemplares, en las regiones de Extremadura y Castilla la Vieja especialmente.

Terminemos este apunte teniendo un recuerdo para el poeta francés Nicolás Bourbon (1) que en el primer tercio del siglo xvı compuso en latín un poema, detallando con toda exactitud el trabajo del hierro en su tiempo. El poeta nos dice como habiéndosele aparecido Vulcano, el dios le ordena que cante en versos la dura labor del hierro a la que se consagra con sus cíclopes. $Y$ obediente al mandato, el poeta cumple bien su misión descriptiva, no difícil en verdad, porque el padre de Bourbon poseía una fragua, explotaba los bosques para el carboneo y realizaba cuantas operaciones eran necesarias hasta lograr fundir el hierro, fabricando bombas y cañones. Pero no es todo estrepitoso y guerrero en su poema, pues entremezcla con el tráfago de las labores, como buen Virgiliano, la alegría y el regocijo de los obreros cuando terminado el trabajo y cobrado el jornal, comen y beben con sus familias en plena fiesta campestre entre la grata sombra de las frondas.

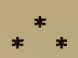

El hierro es el metal que más servicios ha prestado al hombre, satisfaciendo con sus variadas aplicaciones muchas de sus necesidades. La riqueza minera de España era tan famosa como conocida en el mundo antiguo y tan pródiga en mineral de hierro que pocas zonas de su territorio no han tenido su beneficio. Antes de finar el siglo xin, en que las reglamentaciones gremiales con motivo de sus ordenamientos trabaron en parte

(1) Nacido en Vaudeuvre (Champaña) la libertad del trabajo, sometiendo a preceptos a los ferreros y sus obras, los obreros artistas viviendo y trabajando aislados generalmente-por excepción existían núcleos de ese arte en Vizcaya, Cataluña, Cuenca y Toledo-sabían muy bien según la procedencia de origen, qué metal era bueno o agrio y por lo tanto qué trato tenían que darle con la forja y el martillo, con más o menos caldas, hasta conseguir su doma y servirse de él como si de la materia más dúctil y maleable se tratase. Es posible que en las fragosidades de las serranias o en los más apartados lugares de la Peninsula, se conservase como reliquia salvadora contra las constantes invasiones que padecia nuestro solar, aquella sabiduría celtibérica, creadora de armas ofensivas no superadas en muchos siglos en fortaleza y temple, elogiadas por Marcial y utilizadas por los ejércitos romanos.

La no interrumpida práctica de esta técnica, debió de aumentar y enriquecerse con los conocimientos que en la materia trajeron los Árabes al tiempo de su conquista. Cierto es que, aunque se sirvieron del hierro, de su herrería artística no nos legaron, quizás por practicarla menos, tan gran número de obras como las realizadas en bronce y en azofar, pero en el conocimiento de las ciencias y en todas las artes industriales les somos deudores. Perduraron en nuestra patria, en cuanto a la cerrajería artística se refiere, los tipos de fallebas, cerrojos, llamadores, clavos, etc., con aquel su peculiar estilo, pleno de sutiles elegancias, de trazas geométricas, y tan viril como enérgico, aún cuando lo apliquen en preciadas ataujias de oro y plata a sus armas y arreos.

Vivió la alta Edad Media en continuas luchas; la guerra, la barbarie y la ignorancia fueron sus características y como natural consecuencia los trabajos en hierro debieron quedar reducidos y sintetizados en dos grupos de elementos armónicos con ese medio ambiente: los que tenían por objeto guardar y defender las posibles entradas al interior de los edificios, (puertas y ventanas) cuyos huecos o vanos eran de reducidas dimensiones, y los referentes a elementos ofensivos, comprendiendo en ellos la labor de todo género 
de armas. Lapso es éste anterior al siglo xil, en que parecen dadas al olvido las prácticas de los hierros artísticos, ante la imperiosa ley de la necesidad. Los centros productores de esas armas blancas, en el logro de su mayor resistencia y poder ofensivo, son probablemente los que dieron origen a las famosas escuelas de espaderos y cuchilleros españoles; venero de enseñanzas, lo mismo para realizar menudas y filigranadas obras que como férreo encaje forman cresterias o ciñen $\mathrm{y}$ cubren los cofrecillos y arquetas del siglo $\mathrm{xv}$ que, para los maestros ejecutores de aquellas bellísimas y monumentales rejas, asombro de los tiempos presentes y gloria de la época de oro de nuestra insuperable rejeria, que comprende, desde mediados del siglo $\mathrm{xv}$, hasta tines del. siglo xvi.

Tratando esta materia habrá que recordar con gratitud lo que escribieron, ensalzando justamente las artes Patrias, con grandes enseñanzas para todos, hombres eminentísimos, como Rico Rinobas historiando la cuchillería y el Conde de Valencia de Don Juan, reconstituyendo, formando, dando nueva vida, con labor tan paciente como sábia, a la armería de Nuestros Reyes, quizás la mejor en calidad que hoy existe en el mundo; y D. Juan F. Riaño, el primero que nosotros sepamos, que publicó sumada a la investigación propia, una ordenada compilación histórica de nuestras artes industriales. Relacionado con la materia anterior, escribió el erudito Palomares en el año 1760 una muy curiosa "Memoria sobre la Espaderia Toledana” extendiéndose a defender la buena calidad de los aceros de Mondragon, a los que calumniaron algunas gentes de ese tiempo, tachándoles de agrios, tercos e indóciles.

¡Decir mal de Mondragon y de sus armas, de aquellos aceros batidos en el yunque siguiendo el ritmo de una canturia, en la que el nombre de Dios y santos conceptos, eran medidas de tiempo para las diversas maniobras! De aquellos aceros que habian empuñado los paladines de nuestro romancero y a los que alabaron los poetasmedioevales! Bien hizo Palomares en defenderlos contra los malsines de su tiempo.
De acuerdo con el orden de presentación de los gráficos, haremos unos breves comentarios respecto a lo que ha sido el arte del hierro en España desde el siglo $x 11$ (d. J. C.) hasta comienzos del xvur, en que ya iniciada la decadencia en todas las artes industriales, se va perdiendo nuestra personalidad artística, como sucedió en las Naciones Europeas mas en contacto con Francia, .por el influjo del arte de los Luises. Influencia mayor aún en España, desde que comenzó a reinar la dinastía de Borbón. No está suficientemente esclarecido si esas influencias fueron buenas o perversas, pero es innegable el constante interés y la voluntad que al servicio del resurgimiento de las artes industriales españolas, pusieron, alentando hasta con donaciones y premios de su particular peculio, Monarcas como Felipe V, Fernando VI y Carlos III.

Sabemos todos que los llamados estilos no pueden contenerse dentro de fechas, que puedan determinar su nacimiento y desaparición. La evolución, la transformación en las formas, decoración y aspectos que puede presentar un arte industrial, es dinámica, constante; muchas veces será lenta en tan alto grado que el observador podrá no llegar a percibir los cambios sufridos; será éste uno de tantos casos en que la vida del observador fué corta; pero la evolución no se habrá paralizado.

De la mayoría de los objetos del pasado, hoy existentes, podremos no saber ni el día ni el año en que se dieron por terminados, pero sus caracteres externos de forma, decoración, técnica, y aplicación útil presumible, nos permitirá el que los podamos considerar incluidos, con relativa certidumbre, dentro de un grupo perteneciente a un modo artístico que tuvo existencia en tal periodo o época de la vida. Tampoco hemos de desconocer que las artes industriales, y entre ellas significadamente las del hierro, son leales servidoras y auxiliares de la Arquitectura. No habrá por tanto necesidad de demostrar que siendo la Arquitectura la que va fijando en el curso del 
tiempo las aspiraciones colectivas de cada pueblo, segun se sucedan o alternen los predominios religiosos o civiles, del Poder de la Realeza, de los Nobles o del estado llano, así se irán traduciendo en las construcciones, y asi el arte del hierro irá amoldándose a lo que en cada caso necesite de él la Arquitectura.

Como hemos indicado, presentamos ejemplos de obras ejecutadas desde el siglo xII (periodo Románico) hasta los comienzos del siglo xviI, ya olvidada la belleza de lo plateresco y la sobriedad Herreriana. Puede verse en el siglo xII la característica de que en los trabajos en hierro, a la idea de práctica utilidad se va añadiendo la de embellecimiento por medio de algunas decoraciones a base de unidades y composiciones geométricas. La idea inicial (1) puede determinarse con una estilización floral de un vástago (primitivo barrote en las rejas anteriores) en el que a distancias reguladas brotan como hojas que van recogidas, unidas $\mathrm{y}$ remachadas al barrote con espiras en " $\mathrm{C}$ ", o sean dobles espiras (2) que, emparejadas por oposición, en serie y superpuestas, llenan los espacios comprendidos entre cada dos barrotes, formando su conjunto una completa composición decorativa. Estos elementos decorativos pueden verse aplicados a rejas de ventanas, de capillas, barandas de escalera, braseros, herrajes de puerta, etc. etc. La ejecución de estas labores no requería grandes conocimientos técnicos, pues las cintas de hierro, eran fácilmente enrolladas por el forjador. Estas cintas, delgadas y finas al principio, a medida que avanza el siglo xII van siendo más recias, como se ve en una reja de Avila, por ejemplo. Con la manifiesta tendencia de aumentar la decoración para embellecimiento de los hierros, las sencillas volutas, aparentemente van desapareciendo. Arte popular, aquí como en Italia, por su simplicidad, en el pueblo debió conservarse su tradición, para renacer con la misma humildad en el siglo xvil, en Extremadura, Salamanca y Sevilla, aplicadas esas espiras

(1) Lecciones de Arqueologia, por el insigne maestro señor Gómez Moreno.

(2) Las espiras en iS no las hemos visto aplicadas sistemáticamente hasta siglos más tarde. en aparatos de hierro forjado (espeteras) destinados para colocar en ellos utensilios de cocina, con sus finos rizos de hierro y cresterías de pájaros y toros. (1) lgualmente fueron corrientes en el siglo xvi las rejas de barrotes cuadrados, verticales, cruzados con horizontales o decorados con espirasen "S*. Muchos trapos de lino bordados con hilos o lanas teñidas de negro, tienen como decoración de cenefas, iguales motivos de espiras, en "C"y en "S"; aunque los que tenemos vistos no seremontan más allá del siglo xvir. Esta aplicación de temas del hierro en los bordados la hemos hallado en trapos del siglo xvr, en los que por medio del bordado en colores muy vivos, se reproducen en una superficie rectangular y con el mismo orden de colocación (excepto la cerradura) todas las formas de los hierros calados de las tapas de los Vargueños. Son manifestaciones aisladas, como recuerdos de aquel arte de la grafidia en el que tanta parte debieron tomar las manos femeninas, arte que desaparece en el siglo xv, en que la amplitud y libertad de las composiciones. estaban muy lejos de la monotonía que antes tenía que ofrecer un conjunto casi uniforme de planchas caladas y recortes de cresterías. Desde el siglo xil se han conservado, por suerte, infinidad de objetos pertenecientes a las artes del hierro; objetos completos formando un conjunto, tal y como fueron en su tiempo, o elementos sueltos o fragmentados que, sin ser utilizables prácticamente, ofrecen interés para el estudio de este arte. Forman núcleo aparte por su enorme importancia, las rejas, cuyo caracter cada vez más monumental, va representando en el correr del tiempo el compendio en cada época, de variadas técnicas y composiciones decorativas, muy factibles dada la superficie a que se habian de aplicar y la amplitud del cerramiento que se hace cada vez mayor en anchura $y$ se extrema en el siglo xvI, ganando los altos con enormes cresterías y remates. Según las necesidades de la religión y de la vida oficial o particular, asi se fueron aplicando las obras de cerrajería más o menos artis-

(1) Los pájaros y toros con el mismo caracter de siluetas recortadas, se encuentran en bordados al sobrepuesto desde el siglo XI. 
tica; para el alumbrado, para guarảar joyas o materias preciadas; en objetos de devoción; en herrajes de muebles y de puertas; braseros, balanzas, relojes, etc.

Para el alumbrado litúrgico y particular se emplearon las coronas de luz o coronas luminosas, con tirantes o cadenas que permitian su suspensión; los aros eran sencillos, o dobles y concéntricos, y en sus portaluces y arandelas sufren las mismas modificaciones que los candeleros y candelabros. Eran estos de varias dimensiones, indistintamente destinados al servicio de la lglesia - de los particulares, excepto aquellos que aún no conteniendo ningún símbolo o signo religioso eran calificados como de altar, de cirio pascual y de siete luces, teniendo su peculiar destino. Hay un gran predominio en objetos al servicio de la lglesia, porque durante casi toda la Edad Media se sintió poco la representación civil, y casi todo lo ajeno al culto Cristiano tendió a desaparecer.

El elemento floral en estos últimos objetos está representado por las hojas lanciformes y el lirio. Sus fustes en el extremo inferior se resuelven en un pie triangular rematando en la parte superior, saliendo de un último nudo, con uno o más hierros lanceolados y varillas aguzadas para sostener los cirios. Avanzado el siglo xIv casi podrá determinarse como tipo el candelabro de vástago de varilla, de sección redonda o cuadrada y retorcido, en algunos ejemplares con tres o más nudos en el vástago. El fuste de tres pies generalmente, puede complicarse con el aditamento de varillas movidas en arco, o de trenzado y cordoncillo que ascienden hasta el primer nudo del vástago. Las terminaciones son variables; el pincho se cambia por un tubo apoyado en una arandela de plancha; casquete esférico montado sobre tres varillas cuyo punto de unión es el nudo superior del vástago. Las arandelas sencillas en un principio, lisas por completo en su superficie, irán recortando con almenados su linea. A la plancha recortada se le dará más vida con un ligero realce, débil iniciación del repujado; se aumentan los efectos decorativos en las cenefas, arandelas o bandejas con una o más planchas caladas; y aquí comienza la aplicación del arte de la grafidia, indicado anteriormente, representando los calados de las planchas motivos que se desarrollan en superficies circulares o rectangulares, arquerías, rosetones, etc.; elementos todos que se van tomando de los empleados por la arquitectura gótica y a la cual, aunque distanciado con el retraso por lo menos de un tercio de siglo, va siguiendo el arte del hierro en todo el curso de su desarrollo de motivos de flora y fauna, de símbolos y monstruos; escudos, torres de castillos, conchas, grifos, etc., caracterizando algunos de ellos muchas de las obras en hierro que se hicieron durante el reinado de los Reyes Católicos. En los atriles, las varillas de soporte y refuerzo y los planos superiores que sustentan, tienen parecidas modificaciones.

Las cajas para guardar joyas, arquetas o cofrecillos, con sù armazón de maderas duras, de no grandes dimensiones, con asas y anillos para su más fácil y seguro transporte, se ofrecen variadisimas de decoración, con cubiertas planas o curvas. Las hay materialmente forradas de hierros lisos al principio, y con labores caladas en los planos y festones, y varillas claveteadas o soldadas que unen las planchas y marcan las líneas de contorno. Las labures menudas, finas, de encaje, llegaron al máximun en todo el siglo xv y comienzos del xvi. En otros casos, los hierros aplicados, se limitaron a calados de amplio dibujo o solo una o dos cenefas de contorno, con cantoneras reforzadas, dejando ver a través de sus caladas paredes otro forro de la arqueta o cofre que, en los más antiguos ejemplares, serán de cueros lisos en su natural color o coloridos, o de labores punzonadas y grabadas; en el último tercio del siglo $\mathrm{xv}$ esos forros son de recios $\mathrm{y}$ ricos tejidos, terciopelos lisos o picados, de color rojo, o verde o azul. A primeros del xvi van desapareciendo las planchas de hierro labrado, por el predominio que en los forros de cajas y cofres tuvieron los tejidos, y los hierros que subsistieron, como las visagras, cantoneras y cerraduras y clavos chatones y tachuelas, se doraron a fuego. Los 
aforros en tejidos de damasco, por dentro y por fuera de las cajas, no son corrientes hasta mediados del siglo xvi.

Lo más apreciado, rico y lujoso que en todo el siglo xv se hizo en cajas y cofres, quizás no fueran las decoradas con hierros en su color natural; en niuguna relación o inventario de la época suelen nombrarse; debió ser labor corriente y casi vulgar, con caracter más que de arte, de industria, por la enorme cantidad que de ellos se produjeron. Sólo tienen en ese siglo señalada distinción las arquetas de marfil, los cofrecillos esmaltados con oro y figuras, los objetos de azofar y los estuches y las cajas doradas. Con el tiempo irán las modas, o relativas circunstancias, imponiendo otros gustos y aplicando otros materiales. La abundancia de la plata en España durante el siglo xvir hace que de este metal sean los servicios de mesa en las grandes Casas Españolas y los braseros, aldabones y herrajes del mobiliario; incluso muchos muebles serán de plata, así como los blandones, candeleros y candilones (lámparas entonces de colgar), llanos o agallonados. Igualmente harán su aparición en España en el siglo xviı los cofrecillos llamados de tortuga, guarnecidos de plata.

Cerraduras, llamadores, cerrojos y clavos son comprensivos de labores interesantísimas en las artes del hierro, principalmente desde mediados del siglo xiv hasta los comienzos del siglo xv. Las cerraduras, de doble cerrojo en el siglo xv, con mecanismos a veces de gran complicación por el número de piezas, e incluídos en cajas rectangulares, van siguiendo las variantes de técnica de planchas caladas y según predomina y se extiende el gusto gótico, así llega a verse en las cerraduras, hasta lograr producir los doseletes, pináculos, y figuras de Santos, o fantásticos animales movibles, trabajados con martillo y cincel. Los llamadores, aldabones y tiradores, siguen desarrollo parecido en cuanto a la técnica y motivos de decoración; sus figuras se forjan o cince- lan, las planchas de fondo son caladas, redondas - rectangulares; algunos rematan su encuadramiento con saliente o cornisa en plancha recortada.La traza geométrica de muchas de las planchas y anillos, es de tradición arábiga, de elementos radiados en algunas de ellas. Los cerrojos en las armellas, extremos de barretas y vástagos de cierres, reciben labores parecidas a las anteriores y con idénticas técnicas.

Los clavos, no tienen expresión artística en tanto no se amengua la necesidad de su empleo, como elemento de refuerzo y de unión de las planchas y piezas componentes de las puertas.

En el siglo xv y parte del xvi la clavazón en las puertas y su empleo en remaches de cercos de rejas, alcanza la mayor intensidad por su número y caprichosas variantes.

En la segunda mitad del siglo xIx, coleccionó en Segovia el Sr. Duque magníficos ejemplares, de que le proveyeron en abundancia las puertas de los maltrechos edificios Románicos y Góticos, de Iglesias y Castillos, principalmente de aquella provincia. Esa colección tan rica en enseñanzas como selecta, presentaba las fases del clavo durante algunos siglos. Los medioevales más antiguos, los enormes clavos de largo espigón y cabeza piramidal de base cuadrada no siguen aumentando, sino que disminuyen su longitud, transformando y reduciendo su cabeza hasta llegar a ser como un roblón; se introduce entonces el clavo por la clavera cuya caja es un nuevo tipo de cabeza de clavo. Estas cazoletas o cajas de hierro, semiesféricas, lisas al principio, van cubriendo su superficie de radios, nervaduras, dentellones y entrelazos de finas varillas del mismo metal. Los mayores ejemplares que se conservan pertenecen a la segunda mitad del siglo xv. Más tarde y hasta comienzos del siglo xviI, aunque la forma reducida del tipo anterior persistía, se van haciendo clavos bullonados, gallonados, calados, de planchas recortadas, con repujados, con varias planchas superpuestas, con representaciones florales estilizadas, trifolios, cuadrifolios. Otros clavos serán esquemas de cruces de órdenes militares, $\mathfrak{u}$ órdenes religiosas, o cifras o es- 
cudos; y asi en infinita y caprichosa variedad.

Las llaves seguirán obedientes, dentro de la limitada superficie que ofrecen, un curso de desarrollo semejante, en la técnica y riqueza decorativa, con las cerraduras a que tuvieron que aplicar sus guardas; completando el conjunto del mueble con otros detalles de tiradores, cantoneras, etc. De la sencillez ell las guardas y anillos de las más antiguas, pasan a las mayores complicaciones en las que el cincel y la linia realizaron maravillas.

Llaman poderosamente la atención unos simulacros religiosos, ejecutados en plancha recortada, a veces en parte batidos en bulto, porque ofrecen un aspecto de tosca primitividad y de rudeza, con sus cruces, figuras y símbolos de la Pasión. Parece ser un arte exclusivo de la región catalana, cuyo modelo ha podido nacer, probablemente en el siglo xIII y cuya persistencia, hierática, $\sin$ modificaciones sensibles en las representaciones y técnica, puede haberse mantenido hasta fines del siglo xviI.

\section{** *}

El espiritu corporativo gremial que empieza fundándose en la santa idea de protección y auxilio entre los que ejercian un mismo oficio y pudieran estar necesitados, va extendiéndose y a medida que se siente más poderoso va creando reglamentaciones que traban cada vez más la libertad del trabajo, para someterlo en la variedad de artes y oficios existentes en la Edad Media, dentro de conceptos rigidos e intransigentes. Tratan los Monarcas de Castilla y de Aragón de ganar su fuerza y abundan las concesiones de privilegio. Temen que el poderio llegue a ser excesivo y tasan el precio de las obras y declaran libre el trabajo. Pero en estas alternativas que se suceden desde el siglo xil, época inicial de la vida de estas Corporaciones, salen los gremios victoriosos de todas las contiendas, hasta llegar al máximun de independencia y poderio en tiempo de los Reyes Católicos, para empezar a declinar durante los reinados de los Felipes, hasta su total desaparición. Creemos que fueron útiles los gremios en cuanto cumplieron la misión de encauzar la enseñanza de las artes industriales, educando a los de cada oficio artístico con la lentitud que requería el vencimiento de las diversas técnicas. No creian en las improvisaciones; por eso nadie podía llegar a ser maestro sin haber pasado las condiciones de pruebas de aptitud, ejercicios y tiempo señalado.

En las artes del hierro, Cataluña se singulariza en España por la antigüedad de sus representaciones en los concejos y reglamentaciones gremiales. No mucho más tarde le sigue Castilla.Capmany, (1) nos dice, como Pedro 11, en 1200, habla de la corporación de eferrers: en las Constituciones Catalanas. - En 1257 figuran cuatro herreros en el Gran Concejo Municipal. En 1380 D. Pedro IV aprueba en Barcelona por privilegio Real, las Ordenanzas de los herreros, nueva cofradía, bajo la advocación de San Eloy; y así continúan aprobándose Ordenanzas para este gremio en Cataluña. En Castilla y León, Monarcas como Alfonso $\mathrm{X}$, en los "Ordenamientos de Posturas" (año 1268) y D. Pedro I en 1351 trataron en Cortes de estas materias. Aquel Monarca con motivo de poner precio a las obras con la tasa, y defendiendo este último el libre ejercicio de la fabricación.

Los Reyes Católicos también favorecieron los gremios, aunque más preferentemente ordenaron disposiciones para las artes del tejido y modo de vender esas mercaderias. Carlos 1 por Real Cédula de 22 de Abril de 1538, aprueba Ordenanzas y prohibe trabajen arcabuces, cerraduras y otros objetos de cerrajeria a quienes no estuvieran examinados por los prohombres del gremio. El cerrajero examinado y aprobado, podía trabajar en todos los ramos de la herrería. En 1529, Felipe II corta el abuso que cometían los carpinteros introduciendo herrajes extranjeros. Durante el siglo xvil se suceden sinnúmero de disposiciones relacionadas con los gremios de las artes del hierro. Las cédulas reales de tasas son continuas en los reinados de Felipe IV y Carlos 11. Por ellas sabremos de muchas labores de esa época. Llegado

(1) Obra citada. 
el siglo xvit, los gremios desaparecen; son disueltos.

La rejería del siglo $\mathrm{xv}$, influenciada por el tipo arquitectónico de su época, embellece los monumentos,-templos singularmente-con rejas coronadas de frisos, de cresterias de hojarasca y con gabletes y terminales de cardinas, lirios y azucenas; las formas lanceoladas y agudas de que están erizados los remates contienen todavía la idea de defender, de hacer impenetrable el lugar; práctica más necesaria en los pasados tiempos. En Cataluña como en Castilla muchas obras han permanecido en el anónimo; nada se sabe de sus autores.

Su factura nos acusará en la rejería catalana del siglo $\mathrm{xv}$, tan profusa como admirable, una gran influencia del arte francés que no tiene la castellana, quizás por su menor contacto de vida de relación con Francia.

Ello en nada menoscaba la gloria de los herreros, forjadores y cerrajeros catalanes, que sumados a los de las otras regiones, llámense Juan Arnau o Francisco de Salamanca, o Martín García o Juan Francés, etc., maestros fueron todos de elegancia y buen gusto, asombro del mundo y preciado timbre de honor para España.

Un periodo de evolución o de transición, en las artes del hierro comenzara a realizarse por influencias venidas de Italia, en la cual el arte gótico no tuvo profundo arraigo; y las artes se irán encaminando hacia el estilo Renacimiento cuyo predominio luce esplendoroso durante el siglo xvi. Tímidamente en el último tercio del siglo xv irán apareciendo en las rejerias $y$ otras obras de conjunto y sentido ojival, algunos elementos de decoración, ya definida como propia del llamado estilo del Renacimiento; irán manifestándose en medallones, decoraciones de barrotes y pilastras, hasta que francamente predomine ese nuevo estilo, con sus grandes concepciones, tan bellas como decorativas. La técnica se transforma por necesidad; las filigranas de los calados, de las labores de forja, lima y cincelado se perderían inaprecia- das en gran parte, si las hubiesen aplicado en las partes más altas de los grandiosos conjuntos que ofrece el Renacimiento.

Esa gran habilidad de ejecución de los artifices plateros, cuando se llevó al hierro, a la piedra o a la madera, creó el concepto del estilo plateresco en España, con propia personalidad, en Castilla principalmente. Escultores, orfebres, plateros y ferreros, se dieron en muchos casos en un mismo artista. Fueron del tipo de aquellos «hombres de ingenio» que produjo la ltalia del Renacimiento, que lo mismo dirigian la construcción de un gran templo, que esculpian o pintaban o proyectaban en el arte militar la defensa o ataque de una plaza fuerte.

Se empleó en el siglo xvi la técnica del repujado en menuda labor, y en masas grandes en medallones, figuras quiméricas y alegóricas y figuras en grupos de composicion, aplicadas y sobrepuestas en los diversos cuerpos de las rejas hasta los grandes coronamientos, mantenidas por medio de redoblones, remaches o prisionerosque asi se llamaron-y más tarde por tornillos.

El conjunto ofrecido a la vista, de grandes rejas con muchas superficies de planchas repujadas, presentadas con un tono uniforme y monótono, se enriqueció con la policromía-hasta entonces no aplicada en el arte del hierro-y con el dorado y plateado a fuego. Con igual riqueza de detalles y en conjuntos, se labraron púlpitos, candelabros, lámparas, facistoles, etc. Queda impuesto el gusto plateresco en las incomparables rejas de España hasta que en el último tercio del siglo xvi, en pleno reinado de Felipe II, por reacción-caso frecuente en la historia de las artes-se inicia la decadencia de tanta fastuosidad. "El ocaso del Renacimiento, dice el Sr. Orduña y Viguera, (1) lo motivó el deseo de buscar en las producciones un solo orden grandioso y severo de líneas (el Greco Romano) cultivado por Herrera en el edifício del Escorial....."

Muchos de los nombres de los autores de tantas maravillas han llegado hasta nosotros. Arqui-

(1) Rejeros españoles (Ensayo artístico y arqueológico) Madrid 1915. 
tectos, escultores y plateros, fueron la mayor parte de los maestros rejeros que acudían de todas las regiones de España, en honrosa competencia, para hacer postura y presentar proyectos, allí donde los Cabildos tenian necesidad de su ingenio. Aprendices instruidos en la técnica les ayudaban y nos sorprende ahora el saber que las rejas más grandiosas de Barcelona, Sevilla, Guadalupe, Toledo o Granada, se labraron en un lapso no mayor de cuatro o cinco años.

Tal hicieron, por ejemplo, en la Catedral Prima; da, Villalpando y el maestro Domingo, y en la Capilla Real de Granada el maestro Bartolomé; y en otros lugares el famosísimo cuanto insuperable Fr. Francisco de Salamanca, digno de ser comentado, pues en su larga vida realizó obras del estilo Gótico, Renacimiento y Neo-clásico, con igual maestría. De este fraile y ferrero, de andariego vivir, dice el Sr. Gómez Moreno (1) que fué «...primero cartujo hacia 1490, cuando hizo grandes rejas góticas en el Paular y Miraflores, según el estilo del maestro Juan Francés; dominico más adelante, y con residencia en Avila, como ya sabemos, trabajando asociado en lo sucesivo con un Fr. Juan de Avila; ya suena en Guadalupe hacia 1510; ya haciendo el reloj de la Catedral de León; ya en Palencia; ya empeñado en grandes ohras para la Catedral de Sevilla - siguiendo allí el gusto Romano, conforme a la moda del dia. Al fin se desgarró también de los dominicos y acabó por desaparecer, segun el Padre Sigüenza. Sus últimas noticias alcanzan hasta 1547».

Hubo en el siglo Xvi entre los maestros rejeros, defensores e impugnadores del empleo del metal al propio tiempo que el hierro en las rejas, púlpitos, etc.; decían unos, (como Andino) que la obra que se hacía en bronce era de más perfección y más durable que no en hierro; y otros, (como Domingo de Céspedes) que el bronce era vidrioso y no se podía hacer en él cosas tan sutiles como del hierro. Lo cierto es que el bronce empezó a aplicarse con el hierro, y en la región Aragonesa

(1) La Capilla de la Universidad de Salamanca - Madrid 1914 (Folleto) desde la segunda mitad del siglo $\mathrm{xvI}$, se hicieron rejas y púlpitos muy importantes solamente de bronce; gusto que se extendió por muchas partes de España. Baste recordar las obras en bronce del Aragonés Juan Bautista Celma, que además de varias rejas, labró púlpitos en Burgos y en Santiago de Galicia.

El siglo xvil es mortal para todas las artes industriales en España. En las del hierro, solo por excepción, se producen algunas rejas que por su trabajo son recuerdo no más del anterior esplendor; también pueden mencionarse algunos grandes balcones, verjas para sepulcros, y púlpitos como el de Cortegana (Huelva), de consumada habilidad de técnica en su ejecución y que aún siendo lo mejor de su tiempo, acusa la decadencia y muestra la influencia barroca que ha de predominar.

A nuestro entender, solo el arte popular, alguna vez llevado al mueble, permanece libre, repugnando dentro de su sencillez todo influjo extraño; por eso el siglo xvil, es el periodo en que más variados objetos para uso doméstico se hicieron en España, no solo en hierro, pues el cobre y el azofar se usaron en igual profusión, para algunos menesteres de las casas, servicios de chimeneas, cocinas, etc.

Coadyuva fatalmente al decaimiento de nuestras artes industriales, el que en el siglo xvil, las energías nacionales despues de tantas luchas interiores y empresas de descubrimientos, guerras y conquistas, estaban agotadas, el país empobrecido y los campos faltos de brazos para su cultivo. Paralizada la vida en los talleres, la habilidad técnica se iba olvidando, porque anémicos los gremios ya no había exigencias de rigor en los aprendizajes. Las pragmáticas contra el lujo, reiteradas y novadas con buena fé por todos los Monarcas Españoles durante el siglo xvil, eran puras ficciones. La nobleza y poderosos mercaderes, acaparadores de los metales preciosos que venian de América, no las cumplian; los menesterosos, no tenian con qué desacatarlas. Mal podian las artes del hierro vivir y medrar como en los pasados tiempos, en este misérrimo ambiente. 
E1 barroquismo, absoluto dominador ve las artes en el siglo xviti, comenzaba a hincar en ellas sus garras y lo ampuloso y exagerado de las decoraciones, compañeros inseparables de las decadencias artísticas, se inicia en las labores al comenzar la segunda mitad del siglo xvil.

Se transforma la técnica, porque el arte del repujado casi desaparece, sin que lleguen a reemplazar sus bellezas los trabajos ejecutados al agua fuerte sobre el metal; procedimiento entonces muy extendido.

Los plateros, escultores y cinceladores, de raro en raro manifiestan su talento en obras de rejería. Es la época en que, aparte las lámparas, atriles, marcos, frontales y barandillas de plata para las iglesias, se hacen para el servicio y capricho de los ricos infinidad de objetos de plata; las vajillas, los espejos, lámparas, candelabros y candilones, enormes braseros, y aún los herrajes de muchos muebles, de plata son. Se estiman esos objetos más que por el arte que contengan, por la cantidad o mayor peso del metal en ellos empleado. La mayoría de las obras en hierro se ocultan y cubren con plateados, dorados y pavones.

La más modesta clavazón, los clavos vallones, los chaflones y los de ojo de buey para taburetes y sillas, son dorados. Los pavonados negros de aderezos de espadas y dagas son corrientes; así como el de los hierros de los bufetes, dejando los extremos dorados. Las cerraduras maestras, de dentellones, las llamadas de pelambor, las de pestillo, picaportes, etc., se exornan con planchas recortadas, de escudos, de veneras, de conchas; muchos pasadores toman la forma de las dagas con guardamano. Los clavos más corrientes son los de estrella de chapa con sus calamones; las llaves de Anillo de Rey, de anillo abierto a línea, de anillo aovado, etc., etc. Estas y otras menudencias de variantes, cuya enumeración sería interminable, pertenecen al siglo xvis y continúan durante buena parte del xviı.

Nuestra escasa producción en las artes del metal, no podia cubrir las necesidades nacionales y como natural consecuencia, es en el siglo xvII, en su último tercio, cuando se acentúa más la importación en nuestra Pátria de los productos extraños; pacífica invasión que mantenía una continua corriente de salida de nuestro numerario para el extranjero. Cerraremos estas notas con un testimonio, que por ser de la época juzgamos de interés. Es un folleto de autor anónimo que dió la imprenta de Madrid a fines del siglo xvir. Se intitula "Advertencias para la prohibición de las mercaderías extranjeras, dando las causas por qué no se deben prohibir generalmente y los daños que causarán la absoluta prohibición de entrada de mercaderías extranjeras". Hablando de los metales dice: "he de advertir que del metal que más y mejor tenemos, que es el hierro, es imposible hoy vedar la entrada a muchas cosas que son precisas y no nos podemos de repente prevaler de ellas, como es la clavazón menuda, desde la tachuela de carda hasta el clavo gemal, el hilo de hierro, la cuchillería... que teniendo tanto de obra y tan poco de metal, el extranjero lo labra muy barato... Desayúdanos también nuestro descuido de hasta aqui, porque el alemán ingenioso, no solo enseña y ocupa la juventud desde cuatro años, en lo que sus fuerzas alcanzan, sino que usa de artificios con que se ayuda a disponer la materia, como quiere a sus obras. La clavazón se hace con arte, casi sin golpe. El hierro para obras menudas se calienta y corta con artificio y hace como si fuera masa, y deste ingenio vino aquí Juan Cursio, y hizo asiento para introducirlo en Vizcaya y tiene en Madrid los operarios esperando el despacho del privilegio... Del cobre: dicen que lo hay en España muy aventajado... se podría inquirir... interín no es posible vedar su entrada, pues aunque en España se hallase el metal y se sacase la plancha dél, nos habriamos de enseñar a la labor que hace el extranjero que, de un verguejon como dos dedos, lo labra con agua y bate como papel y es imposible sin nuevo gobierno hacerse estos "efetos". Dice el autor luego, que se deben despachar pronto los privilegios a cuantos deseen implantar enseñanzas de estas artes en España, porque de esa suerte siempre habría muchos maestros españoles. " $Y$ este es el verda- 
dero medio de excluir lo extranjero, haciendo obras que excluyan las suyas».

Lástima es, el que no sepamos, para honrarle, el nombre del autor de tal folleto. Buhonero, mercader o arbitrista, su doctrina es sábia, su voz es profética; pero es aún más doloroso el considerar, cuanto ignoraron de estas materias, o el desdén y desatención con que las miraron los Gobernan- tes. Han de pasar todavía algunos años; han de venir los reinados de Fernando VI y Carlos III, para que se produzca en España el insólito caso de ejercer sus funciones unos Ministros, tan instruídos como deseosos de defender y acrecentar el bienestar de la Nación.

Luis PÉrez Bueno

Conservador del Museo Nacional de Artes Industriales 
INDICE DE LAS LAMINAS 



\section{INDICE DE LAS LÁMINAS}

\begin{tabular}{|c|c|c|}
\hline Lámina & Figura & \\
\hline 1 & 1 & $\begin{array}{l}\text { Reja de la fachada principal de Ntra. Sra. del Mercado, en León, Siglo xll; arte ro- } \\
\text { mánico. Decoración por volutas o espiras. (Fot. Roig). }\end{array}$ \\
\hline I & 2 & $\begin{array}{l}\text { Fragmento de la reja de la capilla del Sagrario, en la catedral de Palencia. Siglos } \\
\text { xll al xil1; arte románico. Decoración por volutas o espiras. (Fot. Roig). }\end{array}$ \\
\hline II & 3 & $\begin{array}{l}\text { Reja de tragaluz en San Cipriano, Zamora. Primera mitad del siglo xil. Los dos ba- } \\
\text { rrotes transversales, superpuestos, son de época muy posterior. (Fot. Gómez } \\
\text { Moreno). }\end{array}$ \\
\hline 11 & 4 & $\begin{array}{l}\text { Puerta de la iglesia de Ezcaray, provincia de Logroño. Herrajes de los siglos xII } \\
\text { al xuI. (Fot. Gómez Moreno) }\end{array}$ \\
\hline 111 & 5 & $\begin{array}{l}\text { Fragmento de una puerta del castillo de Perelada, provincia de Gerona. Siglos xitr } \\
\text { al xiv. Decoración y refuerzos por fajas y volutas. (Fot. Mas). }\end{array}$ \\
\hline $11 \mathrm{I}$ & 6 & $\begin{array}{l}\text { Detalle de una reja en los claustros de la catedral de Barcelona. Siglo xv; arte po- } \\
\text { pular; labor de ruda sencillez. (Fot. Serra). }\end{array}$ \\
\hline IV & 7 & Puerta de la catedral de Tarragona. Siglo xv (Fot. Mas). \\
\hline V & 8 & Reja en los claustros de la catedral de Barcelona. Siglo xv (Fot. Serra). \\
\hline V & 9 & Reja en los claustros de la catedral de Barcelona. Siglo xv. (Fot. Serra). \\
\hline VI & 10 & Reja en los claustros de la catedral de Barcelona. Siglo xv. (Fot. Roig). \\
\hline VII & 11 & Detalle de la reja fig. 9. Plancha calada. (Fot. Serra). \\
\hline V1I & 12 & $\begin{array}{l}\text { Detalle de una reja en los claustros de la catedral de Barcelona. Siglo xv. Plancha } \\
\text { calada. (Fot. Serra). }\end{array}$ \\
\hline VIII & 13 & $\begin{array}{l}\text { Reja de la capilla real en la catedral de Granada. Obra del maestro Bartolomé; } \\
\text { primer tercio del siglo xvı. Una de las más notables rejas que existen en Es- } \\
\text { paña. (Fot. Roig). }\end{array}$ \\
\hline $\mathrm{IX}$ & 14 & $\begin{array}{l}\text { Detalle de la reja fig. 13. Cresteria o remate con diez escenas de la Pasión; las fi- } \\
\text { guras, recortadas: los bajorrelieves, etc., con policromía. }\end{array}$ \\
\hline $\mathrm{X}$ & 15 & Detalle de la reja fig. 13. Escudo central; con policromía. \\
\hline $\mathrm{X} 1$ & 16 & $\begin{array}{l}\text { Detalle de la reja de la capilla del Cardenal, en la catedral de Avila. Obra de Juan } \\
\text { Francés; fines del siglo xv a principios del xvi (Rep. Ic. de Esp.-fot. Lladó). }\end{array}$ \\
\hline XII & 17 & $\begin{array}{l}\text { Reja del lado de la Epistola, en el presbiterio de la catedral de Sevilla. Obra del } \\
\text { maestro Sancho Muñoz, de Cuenca; se terminó en 1520. (Fot. Roig). }\end{array}$ \\
\hline XIII & 18 y 19 & Detalles de la reja fig. 17 . \\
\hline $\mathrm{XIV}$ & 20 & $\begin{array}{l}\text { Reja del coro en la catedral de Sevilla. Obra de Fray Francisco de Salamanca y } \\
\text { Fray Juan de Avila: año 1523. (Fot. Roig). }\end{array}$ \\
\hline
\end{tabular}


XV 21 Detalle de la reja de la capilla de los Albornoz en la catedral de Cuenca. Primer tercio del siglo xvi; obra de Limosín (?) (Rep.Ic. de Esp.-fot. Gómez Moreno).

XV 22 Detalle de la reja de debajo del coro, en la capilla real de la catedral de Granada. Primer tercio del siglo xvi; obra del maestro Daniel, de la escuela de Bartolomé (?) (Rep. Ic. de Esp.-fot. Martinez Victoria).

XVI 23 Reja del frente del Presbiterio de la catedral de Sevilla. Año 1529; obra de Fray Francisco de Salamanca. (Fot. Roig).

XVII 24 y 25 Detalles de la reja fig. 23.

XVIII 26 Reja de una ventana de la casa llamada de las conchas, en Salamanca. Autor desconocido; principios del siglo xvi (Fot. Roig).

XV1II 27 Reja de una ventana de la casa llamada de las conchas, en Salamanca. Autor desconocido; principios del siglo xvI (Fot. Roig).

XIX 28 Reja lateral de la capilla mayor de la catedral de Palencia. Obra de Cristóbal Andino; labor policromada y dorada. En el centro del remate, en un medallón de labor repujada, el patrón Sn. Antolín. (Fot. Roig).

XX 29

Reja construida por el maestro Juan López, en 1554, para la capilla del Smo. Sacramento de la catedral de Toledo. Es dorada y con dos órdenes de balaustres.

$\mathrm{XX} \quad 30$

Reja de la ventana en la capilla de los Apóstoles, de la catedral de Cuenca. Primera mitad del siglo xvi (Rep. Ic. de Esp.-fot. Gómez Moreno).

XXI 31 Reja de una ventana de la casa llamada de Pilatos, en Sevilla. Tipo del maestro rejero Pedro Delgado: por el año 1550. (Fot. Roig).

XXII 32 Reja del interior de la iglesia de la Cartuja, en Jerez de la Frontera. Tipo barroco: segunda mitad del siglo xvir (Fot. Roig).

XXIII 33

Reja del coro de la catedral de Plasencia. Obra del maestro aragonés Juan Bautista Celma. Año 1604. (Fot. Roig).

XXIV 34

Reja de bronce repujado de la capilla de Zaporta, en la iglesia de la Seo. Zaragoza. Siglo xvi1. (Fot. Roig.)

XXV 35 Reja del coro de la catedral nueva de Salamanca. Año 1767; obra del maestro Pedro José Duperier. (Rep. Ic. de Esp.-fot. Gómez Moreno).

XXVI $\quad 36$ Reja lateral de la capilla mayor de la catedral de Cuenca. Segunda mitad del siglo xvin (Rep. Ic. de Esp).

XXVII 37 Puerta del palacio del Marqués de Dos Aguas, en Valencia. Siglo xviII (Rep. Ic. de Esp.-fot. Mas).

XXVIIl 38 Reja de una ventana del palacio del Marqués de Dos Aguas, en Valencia. Siglo xvil. (Rep. Ic. de Esp.-fot. Mas)

XXIX 39 Reja de entrada, Catedral de Sigüenza. Siglo xviI (Rep. Ic. Esp.-fot. Gómez Moreno)

XXX 40 Reja de altar en la iglesia de San Martín Pinario, Siglo xviI, en Santiago de Compostela. (Fot. Mas).

XXXI 41 Barandilla del presbiterio de la iglesia de Olius, provincia de Lérida. Labor tipo de la primera mitad del siglo xilt. (Fot. Mas).

XXXII 42 Detalle de la escalera de la puerta alta de la catedral de Burgos. Primer tercio del siglo xvl; obra del maestro Hilario.

XXXIII 43 Barandilla de tribuna de una capilla al N. E. de la girola de la catedral de Cuenca. Hacia el año 1550. (Rep. Ic. de Esp.-fot. Gómez Moreno). 
XXXIII 44 Balcón de una casa de Reus. Siglo xvir. (Rep. Ic. de Esp.-fot. Mas).

XXXIV 45 Balcón de una casa de Reus. Siglo xvi. (Rep. Ic. de Esp.-fot. Mas).

XXXIV 46 Barandilla de la escalera de una casa particular, en Barcelona. Siglo xvin. (F.otografia Mas).

XXXV 47 Balcón de una casa en Santa Coloma de Queralt. Siglo xvin. (Rep. Ic. de Esp.-fot. Ribera).

XXXV 48 Balcón de una casa de Pineda. Siglo xviII (Rep. Ic. de Esp.-fot. Mas).

XXXVI 49

Balcón de una casa de Lérida. Año 1767. La composición es a base de elementos tradicionales españoles o italianos. (Fot. Mas).

XXXVII 50

Balcón de comienzos del siglo xvin. Influencia francesa de la misma época (?) Actualmente en el Museo de la Ciudadela de Barcelona. (Fot. Serra).

XXXVII 51 Barandilla de la antigua iglesia de la Ciudadela de Barcelona. Siglo xviI; estilo Felipe V; arte neoclásico. (Rep. Ic. de Esp.)

XXXVII 52 Barandilla procedente de la antigua iglesia de la Ciudadela de Barcelona. Siglo xvII estilo Felipe V; arte neoclásico. (Rep. Ic. de Esp.)

XXXVIII 53 Balcón del Seminario Conciliar de Avila. Segunda mitad del siglo xvill. (Rep. Ic. de Esp.-fot. Gómez Moreno).

XXXVIII 54

XXXIX 55

XXXIX 56

$\mathrm{XL} \quad 57$

$\mathrm{XL} \quad 58$

XL $\quad 59$

XLI $\quad 60$

XLI 61

XLII 62

XLII 63

XLIII 64

XLIII 65

XLIV 66

Balcón de la casa del Gremio de Zapateros de Barcelona. Siglo xvin. (Fot. Mas). Balcón de una casa particular de Barcelona. Siglo xviı. (Fot. Más).

Balcón de la casa llamada de la Virreina, en Barcelona. Ultimo tercio del siglo xvin (Fot. Mas).

Aldabón de la puerta del jardin, en el castillo de Perelada. Siglo xv; arte popular. (Fot. Mas).

Aldabón del siglo xv; arte popular. Actualmente en la colección Plandiura, BarceTona. (Fot. Serra).

Aldabón de la puerta de la iglesia del castillo de Perelada. Siglo xv; arte popular. (Fot. Mas).

Llamador gótico, de plancha calada. Ejemplar del último tercio del s. xv. (Fot. Roig)

Aldabón procedente del palacio del Arcediano, de Barcelona; actualmente en la colección Rusiñol, "Cau Ferrat», Sitges. Fines del Siglo xv; labor de tipo Toscano. (Fot. Mas).

Llamador de anillo sobre plancha festoneada y calada. Finales del siglo xv o primer tercio del xvi. Actualmente en la colección Rusiñol, "Cau Ferrat", Sitges. (Fot. Mas).

Llamador de la puerta deI Archivo de la Corona de Aragón, en Barcelona. Comienzos del siglo xvı. (Fot. Serra).

Aldabón y clavos de una casa particular, en Barcelona. Siglo xvı, muy avanzado; arte popular. (Fot. Serra).

65 Llamador sobre cuadro rectangular, dosel doble, de coronas en plancha recortada y realzada la exterior; el llamador con sus animales quiméricos, la concha, etc., y clavos ornamentados. Conjunto muy bello, de composición acertadisima Del primer tercio del siglo xvi. Actualmente en la colección Lázaro, Madrid (Fot. Roig).

66 Tirador de una puerta de los claustros de la catedral de Barcelona. Siglo xvI al xviı. (Fot. Serra). 
XLIV 67 Llamador de forja y plancha recortada; arte popular. Tipo del siglo xvil. Colección Rusiñol, "Cau Ferrat", Sitges. (Fot. Mas).

XLIV 68 Anillo de la puerta llamada La Piedad, en la catedral de Barcelona. Tipo de arte popular de los siglos xvi a comienzos del xvir. (Fot. Serra).

XLV 69 Aldabón de casa señorial de Sta. Cruz, Rivadulla, provincia de La Coruña. Fines del siglo xvil a comienzos del xvir (Rep. Ic. de Esp., fot. Mas).

XLV 70 Aldabón de una casa de Alcover, provincia de Tarragona. Arte popular del siglo xvili. (Rep. Ic. Esp., fot. Mas).

XLV 71 Aldabón de ura casa de Mascalvó, provincia de Tarragona. Siglo xvin (Rep. Ic. Esp., fot. Mas).

XLVI 72 a 78 Llaves de fines del siglo xvir y comienzos del xviI. Colección Vallin, Barcelona. (Fot. Mas).

XLVII 79 a 83 Llaves tipos del siglo xvit. Algunos de esos modelos tuvieron los anillos en bronce. Museo de la Ciudadela de Barcelona. (Fot. Serra).

XLVII 84 a 87 Llaves con los anillos de traza morisca, tradición mudéjar; los vástagos, torneados y cincelados. Siglos xvi y xvir. Museo de la Ciudadela de Barcelona. (Fot. Serra).

XLVl11 88 Cerraja gótica de hierro; plancha calada y repujada. Siglo xv. Colección Lázaro, Madrid. (Fot. Roig).

XLVIII 89 Cerradura gótica; plancha calada, pináculos laterales macizos; arte de influencia francesa. Ultimo tercio del siglo xv. Colección Rusiñol. "Cau Ferrat", Sitges. (Fot. Mas).

XLIX 90 y 91 Cerraduras góticas; plancha calada y realzada; en dos órdenes de planchas. Ultimo tercio del siglo xv. Colección Rusiñol, "Cau Ferrat", Sitges. (Fot. Mas).

XLIX 92 Cerradura en caja realzada, plancha calada y recortada; decoración de elementos góticos en el vástago de cierre. Segunda mitad del siglo xv, obra de arte popular. Colección Lázaro, Madrid. (Fot. Roig).

L 93 Cerradura gótica. Círculos en plancha calada; decoración floral estilizada. Primer tercio del siglo xvi. Colección Rusiñol, "Cau Ferrat». Sitges. (Fot. Mas).

L $94 \quad$ Cerradura de fines del siglo xv a comienzos del xvi. (Fot. Roig).

LI 95 Cerraja de bronce dorado; predominio del arte francés de la época. Siglo xvi. Colección Lázaro, Mađrid. (Fot. Roig).

LII $\quad 96$

Cerradura con decoración del tipo arquitectónico. Renacimiento español de la segunda mitad del siglo xvı. Procedente del Monasterio Escorial. (Fot. Roig).

LiI 97 Cerradura múltiple de decoración con planchas recortadas y grabadas. Segundo tercio del siglo xvi. Procedente del Monasterio del Escorial. (Fot. Roig).

LII 98 Cerradura del primer tercio del siglo xvir. Museo de la Ciudadela de Barcelona. (Fot. Serra).

LII 99 Cerradura en plancha recortada y calada. Siglo xviI. Castillo de Perelada. (Fot. Mas).

LIII 100 Cerrradura de la puerta de la iglesia de las Magdalenas, en Alcalá de Henares. Año 1672, obra de Juan Gómez, de Madrid. (Rep. Ic. Esp., fot. Moreno).

LI11 101 Cerradura de la puerta de la Iglesia Magistral de Alcalá de Henares. Siglo xvit. (Rep. Ic. Esp., fot. Moreno). 
Lảmina Figura

LIII 102 Falleba en la cancela de la iglesia de San Justo, en Segovia. Siglo xvil. (Rep. Ic. Esp.)

LIV 103 Cofrecillo de planchas de hierro, reforzadas en el juego de la cubierta o tapa y en las cantoneras. Fines del siglo xv o comienzos del xvi.

LIV 104 Arquilla con forro de cuero labrado, con refuerzos en hierro, varillas y remates de discos. Segunda mitad del siglo xv. Colección Lázaro, Madrid.

LV 105 Cofrecillo con candado de bola. Trabajo de planchas caladas con menuda decoración gótica y pináculos de refuerzo en los ángulos. Las proporciones y distribución de los variados elementos que la decoran, dan alto interés a este bellísimo ejemplar. Tipo gótico del últímo tercio del siglo xv. Colección Lázaro, Madrid. (Fot. Roig).

106 Tedero; San Feliu de Guixols. Siglo xv. (Fot. Mas).

LVI 107 Tedero; labor en forja y plancha calada. Segunda mitad del siglo xv. Colección Rusiñol, "Cau Ferrat", Sitges. (Fot. Mas).

LVII 108 Candelabro; vástago de cordón con nudos, arandelas festoneadas y caladas. Tipo del siglo xiv al xv. Museo Episcopal de Vich.

LVIl 109 y 110 Candelabros. Segunda mitad deI siglo xv. Museo Episcopal de Vich.

LVIII 111 Parte superior de un candelabro de corona ie luz. Trabajo de forja y plancha recortada. Cuatro candeleros en pincho sobre la corona, sostenidos por grifos; el vástago remata en un candelero en tubo. Ultimo tercio del siglo xv. Colección Rusiñol, "Cau Ferrat", Sitges. (Fot. Mas).

I.IX 112 Candelabro de la iglesia del castillo de Perelada. Tipo bellísimo del primer tercio deI siglo xvı. (Fot. Mas).

LIX 113 Magnífico ejemplar de candelabro ( $2 \mathrm{~m}$. de altura). Labores en planchas repujadas; decorado con bustos y otros motivos de! Renacimiento; basamento triangular, vástago circular. Primera mitad del siglo xvı. Catedral de Burgos.

LX 114 y 115 Cruz de linde, con el Cristo, figuras y atributos. Siglo xıv. Cruz de linde flordelisada, con la Virgen y el Niño. Fines del siglo xiv. Colección Rusiñol, "Cau Ferrat, Sitges. (Fot. Roig).

LX 116 Cruz de linde flordelisada, con la Virgen, figuras y atributos. Fines del siglo xIV a comienzos del xv. (Fot. Roig).

LX 117 Cruz, unidos sus extremos por medio de varillas retorcidas; en los brazos, figuras y atributos; el pie y las terminales de la cruz, de plancha recortada. Tipo: tradición tal vez del siglo xul. Técnica: fines del xv o comienzos del xvi. Colección Rusiñol, "Cau Ferrat", Sitges. (Fot. Roig).

LXI 118 Cruz de hierro con decoración en volutas al pie; doble estrella en plancha recortada, algo repujada. Siglo xvi, arte popular. (Fot. Mas).

LXII 119 Púlpito de hierro repujado de la catedral de Avila.Primer ter. del siglo xvi. (Fot.Roig).

LXII 120 Púlpito de hierro en la iglesia del Salvador en Cortegana, provincia de Huelva. Es uno de los más característicos ejemplares que dentro del siglo xvı, en la época decadente son todavía en España un modelo de labor excepcional.

121 Palomilla. Siglo xvil. Colección Marycel. (Fot. Serra).

LXIII 122 Palomilla procedente de una casa derribada con motivo de la Reforma de Barcelona. Siglo xv; arte popular. (Fot. Mas). 


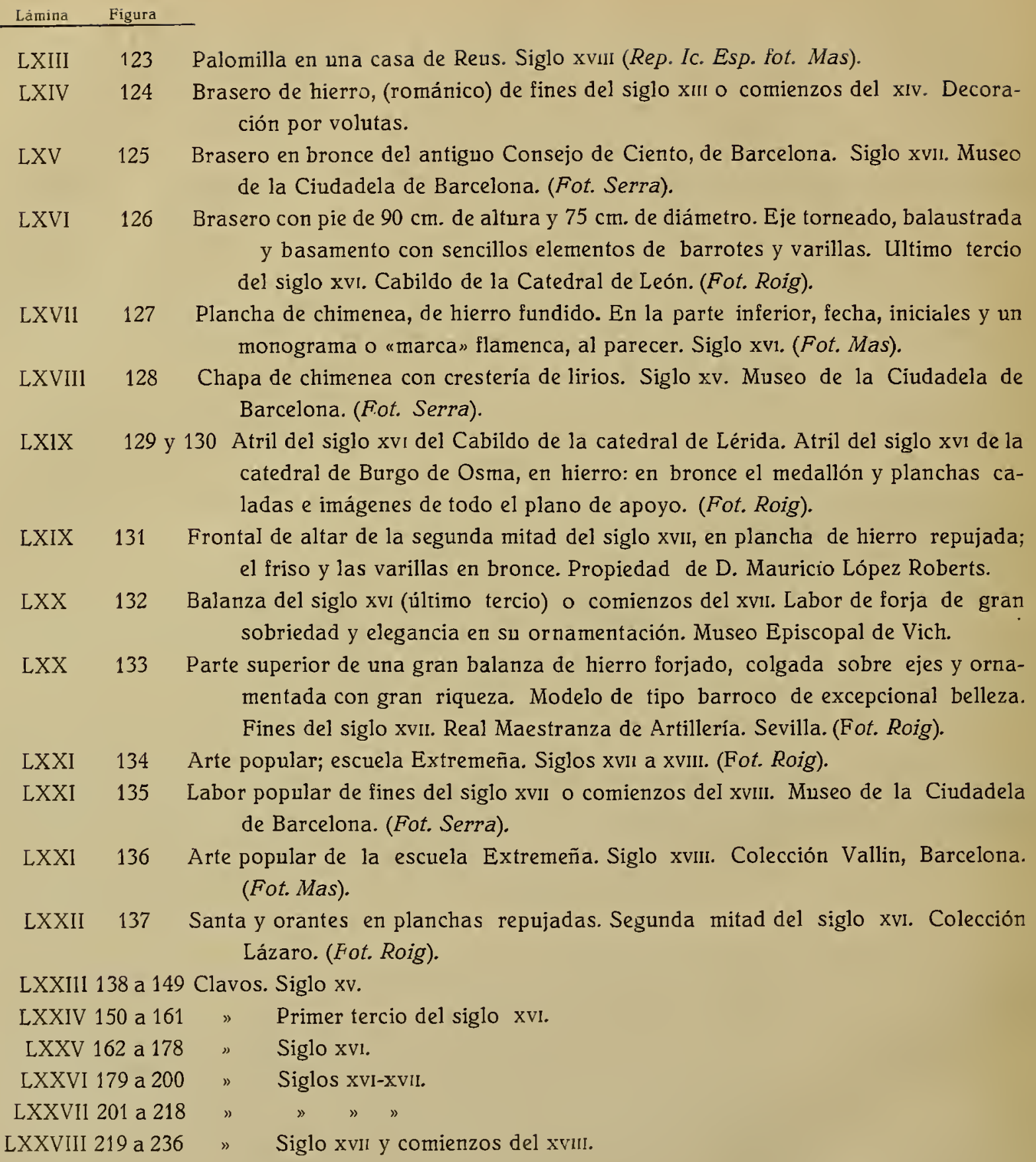




\section{L Á M I N A S}





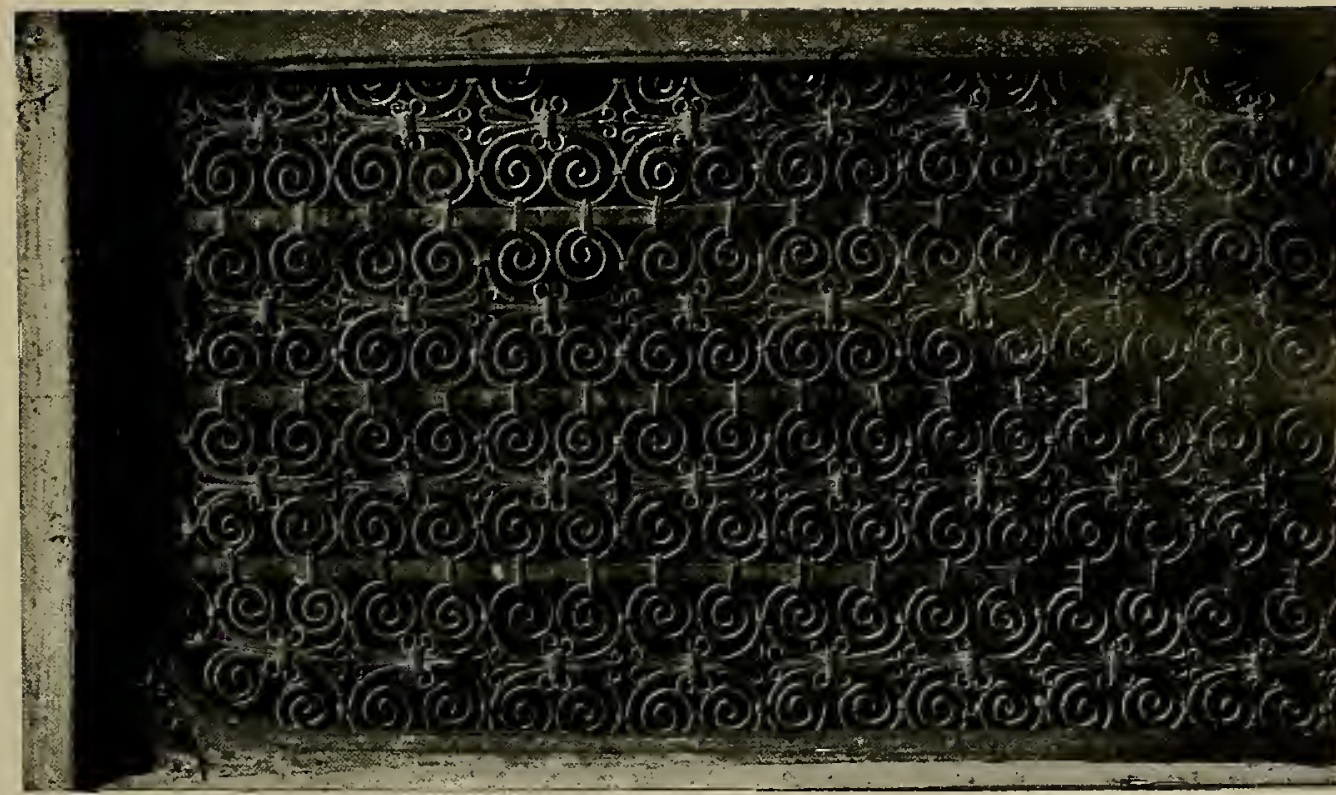

$\sim$

$\dot{0}$

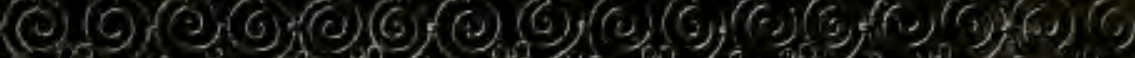

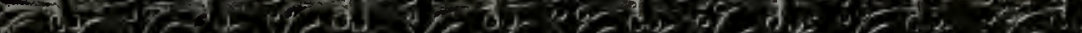
2) (2)

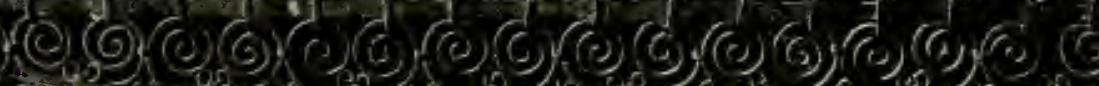
-

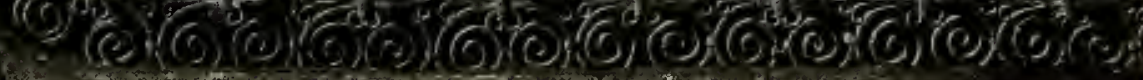

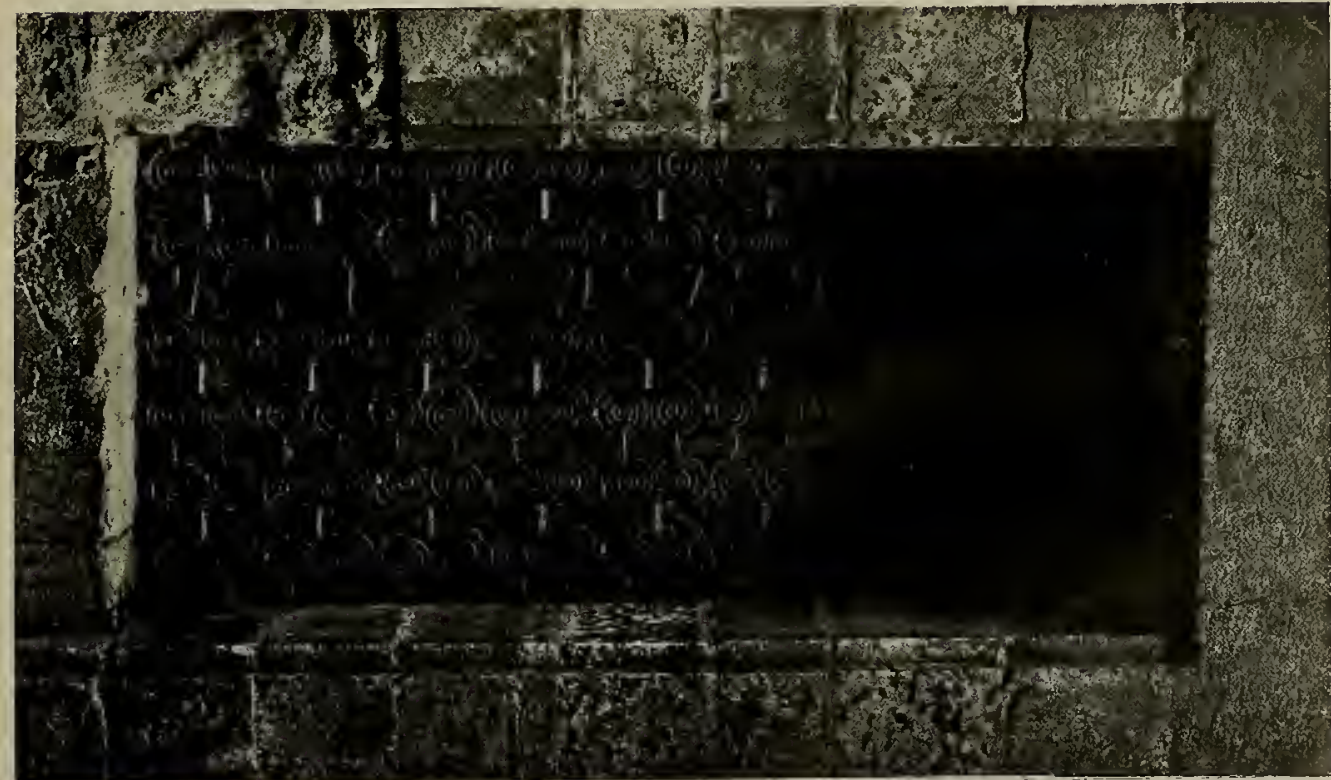





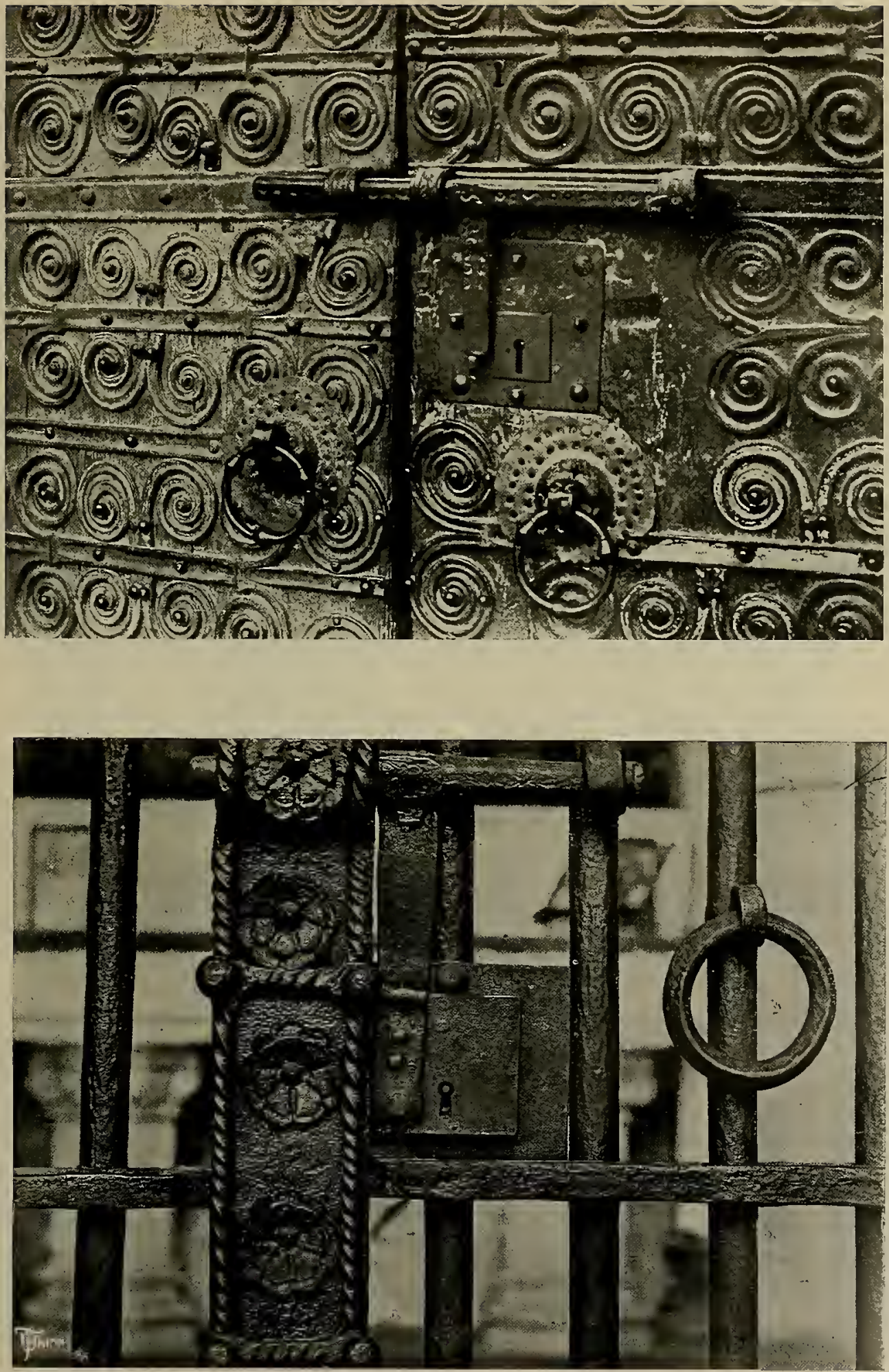

Figs. 5-6 


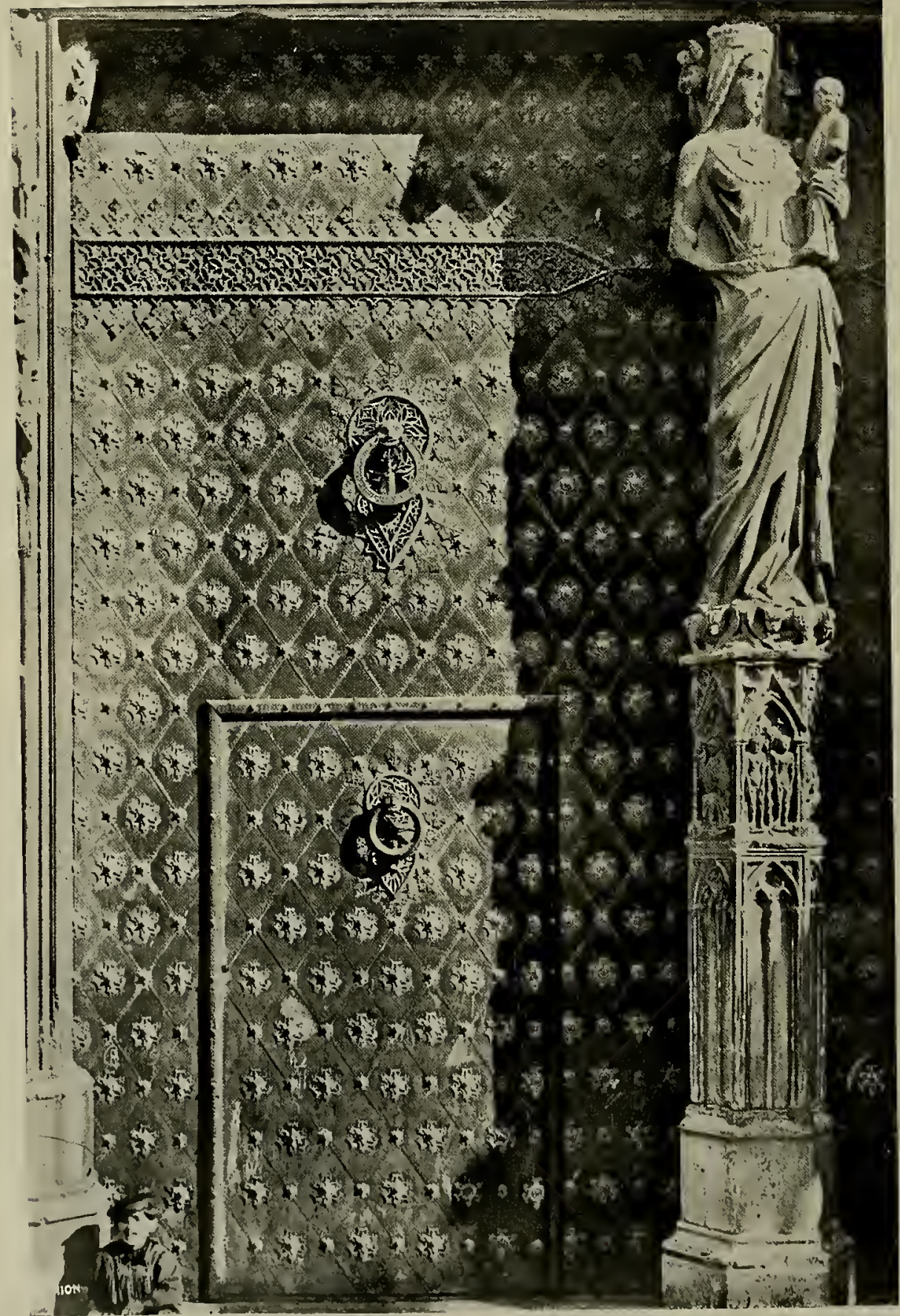

Fig. 7 


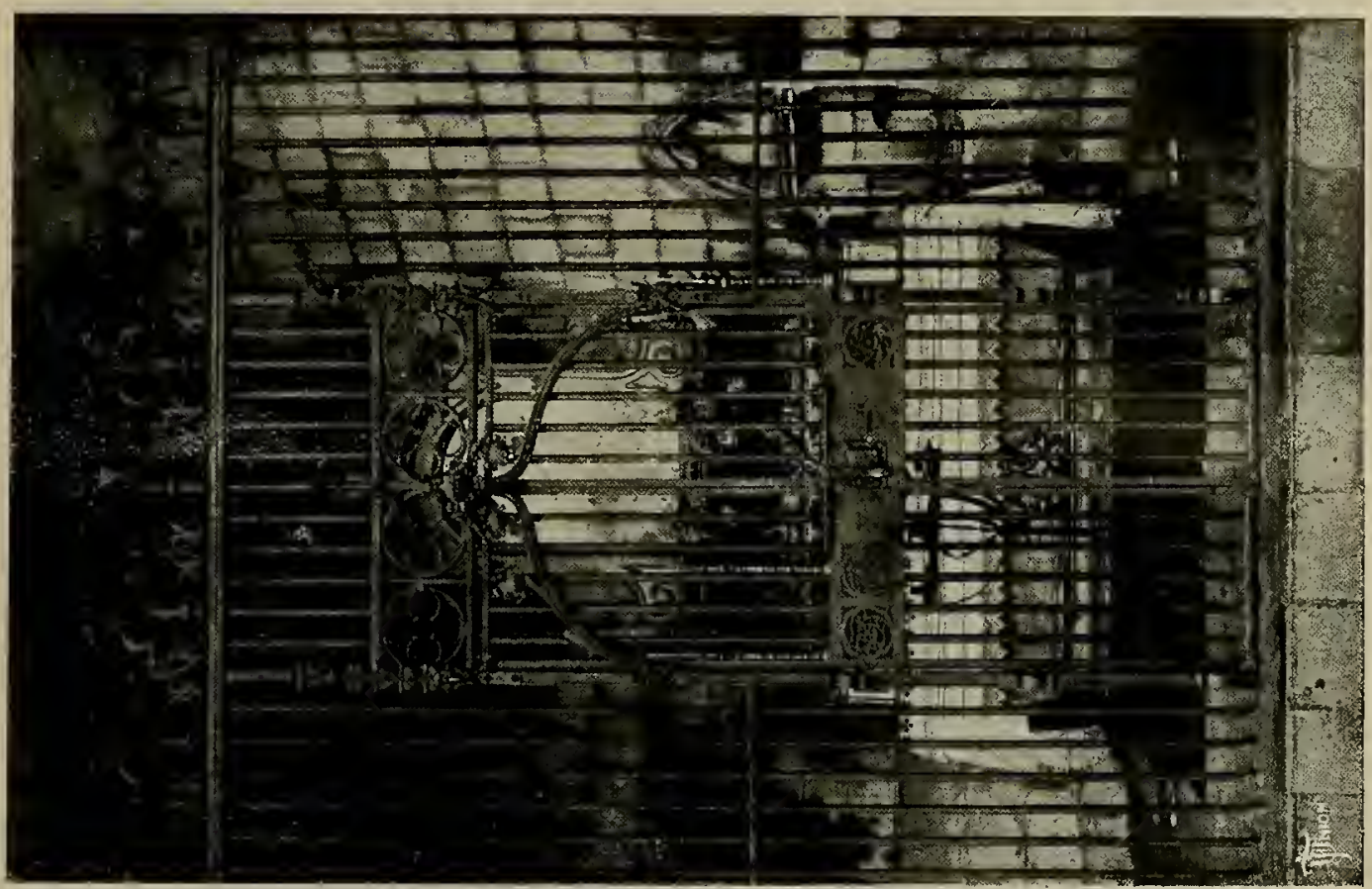

a

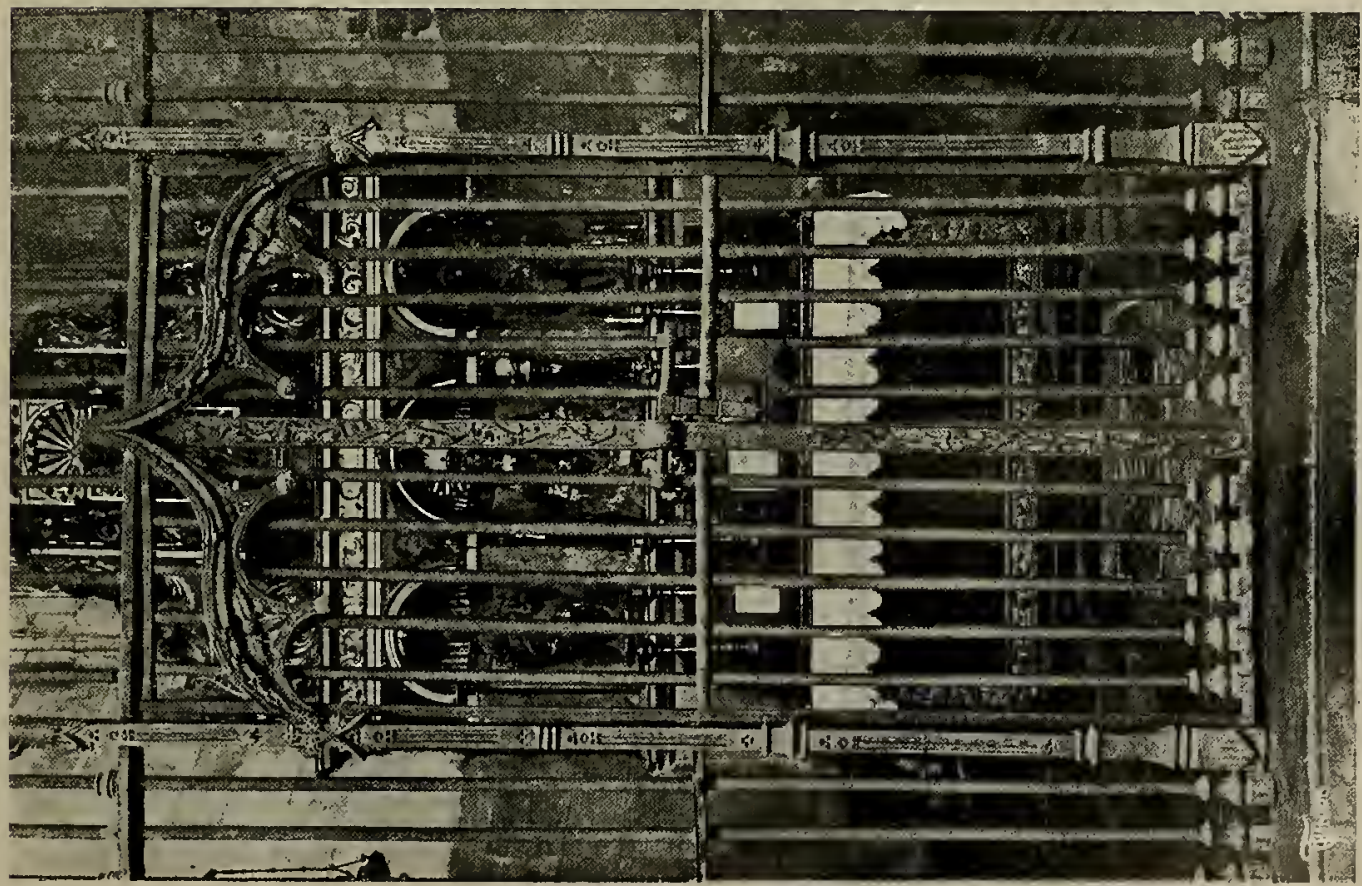




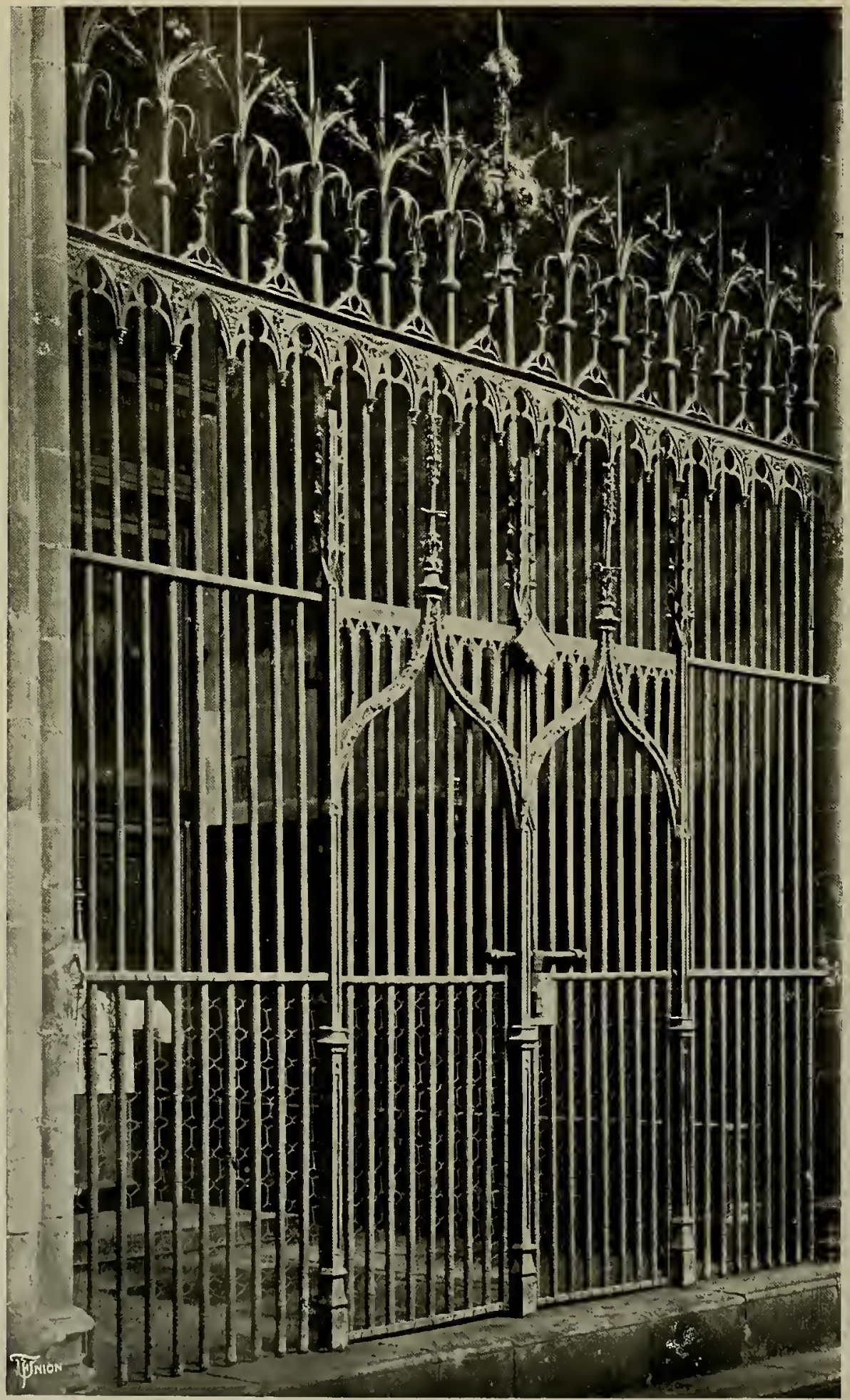

Fig. 10 

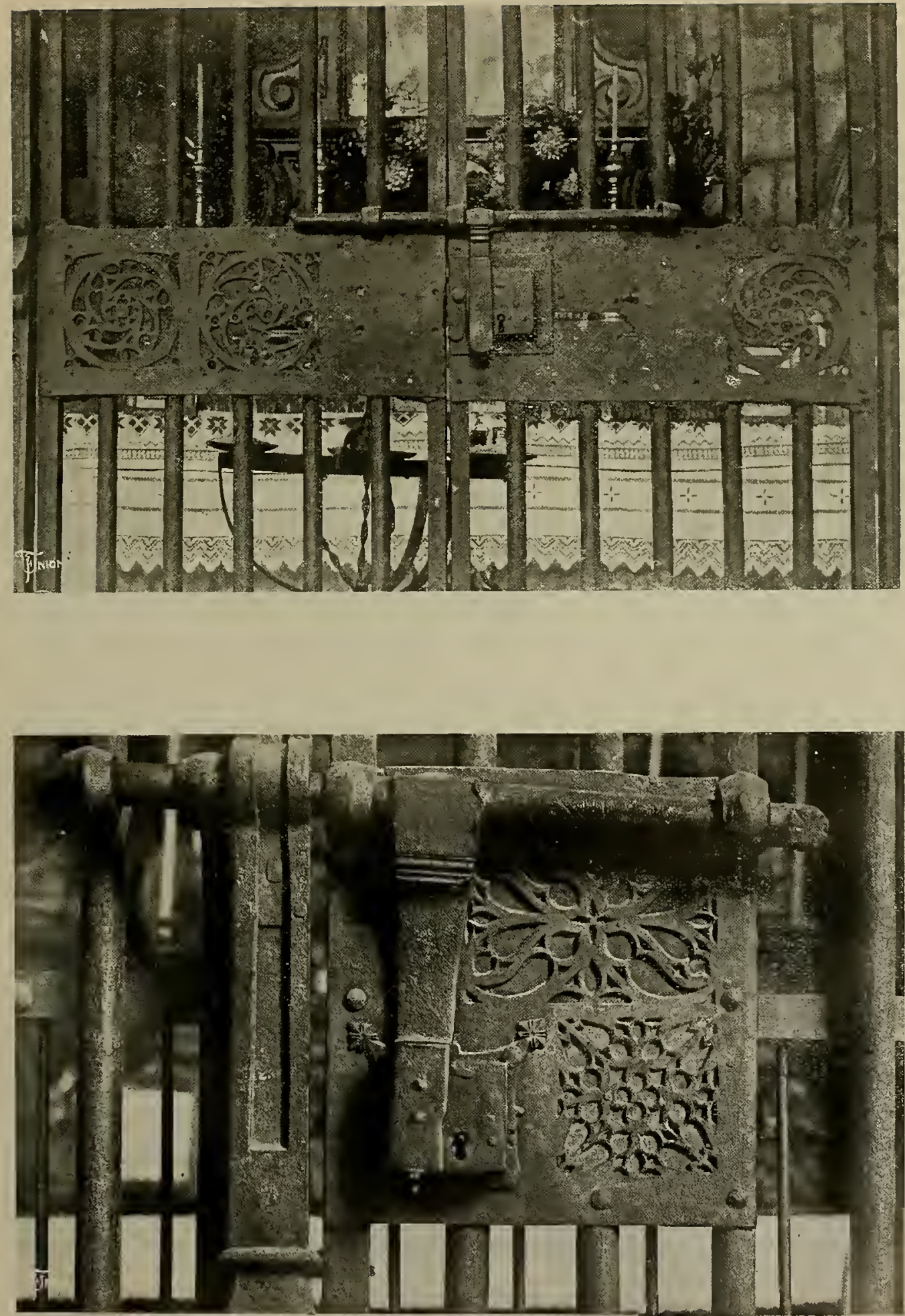

Figs. 11-12 


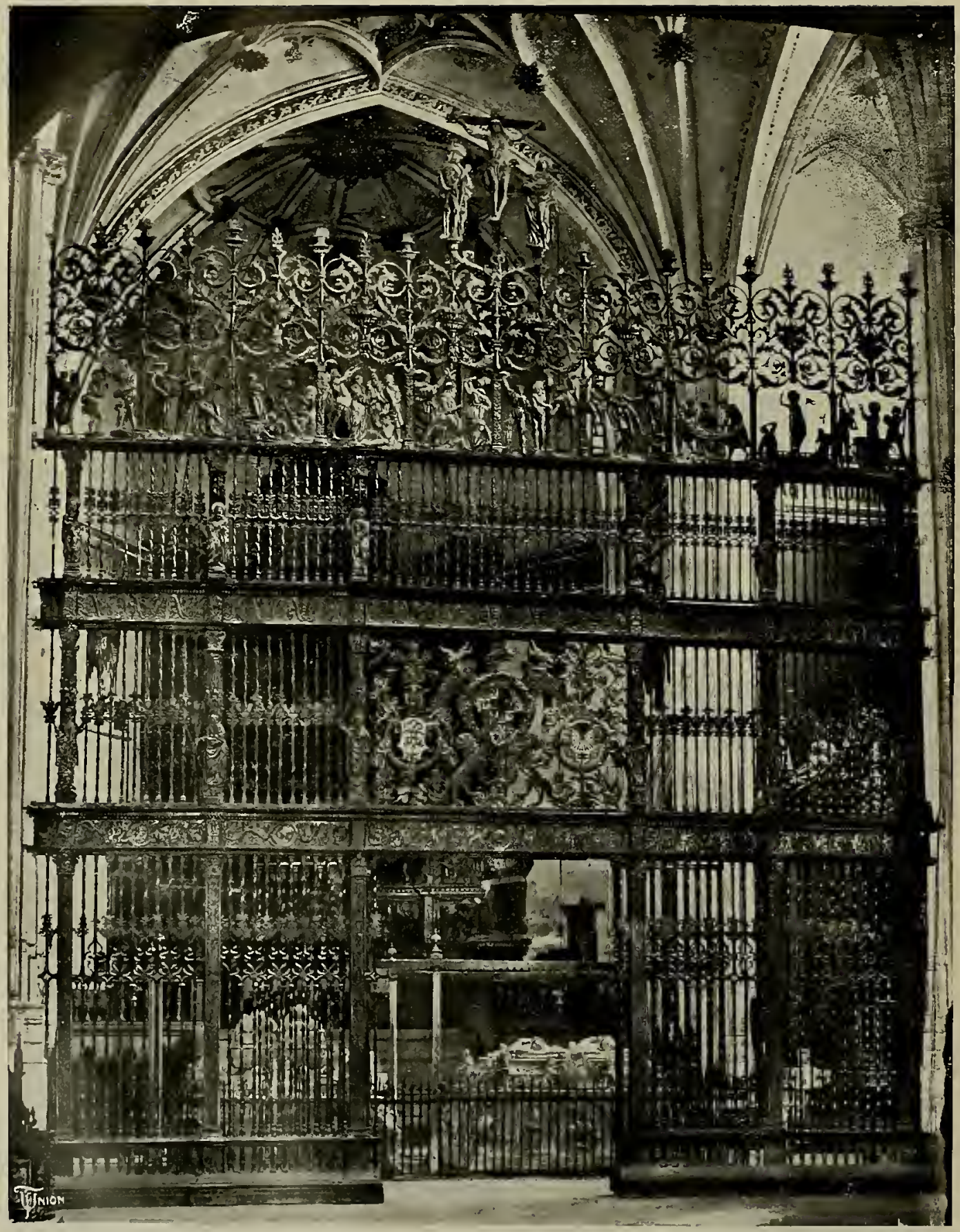

Fig. 13 


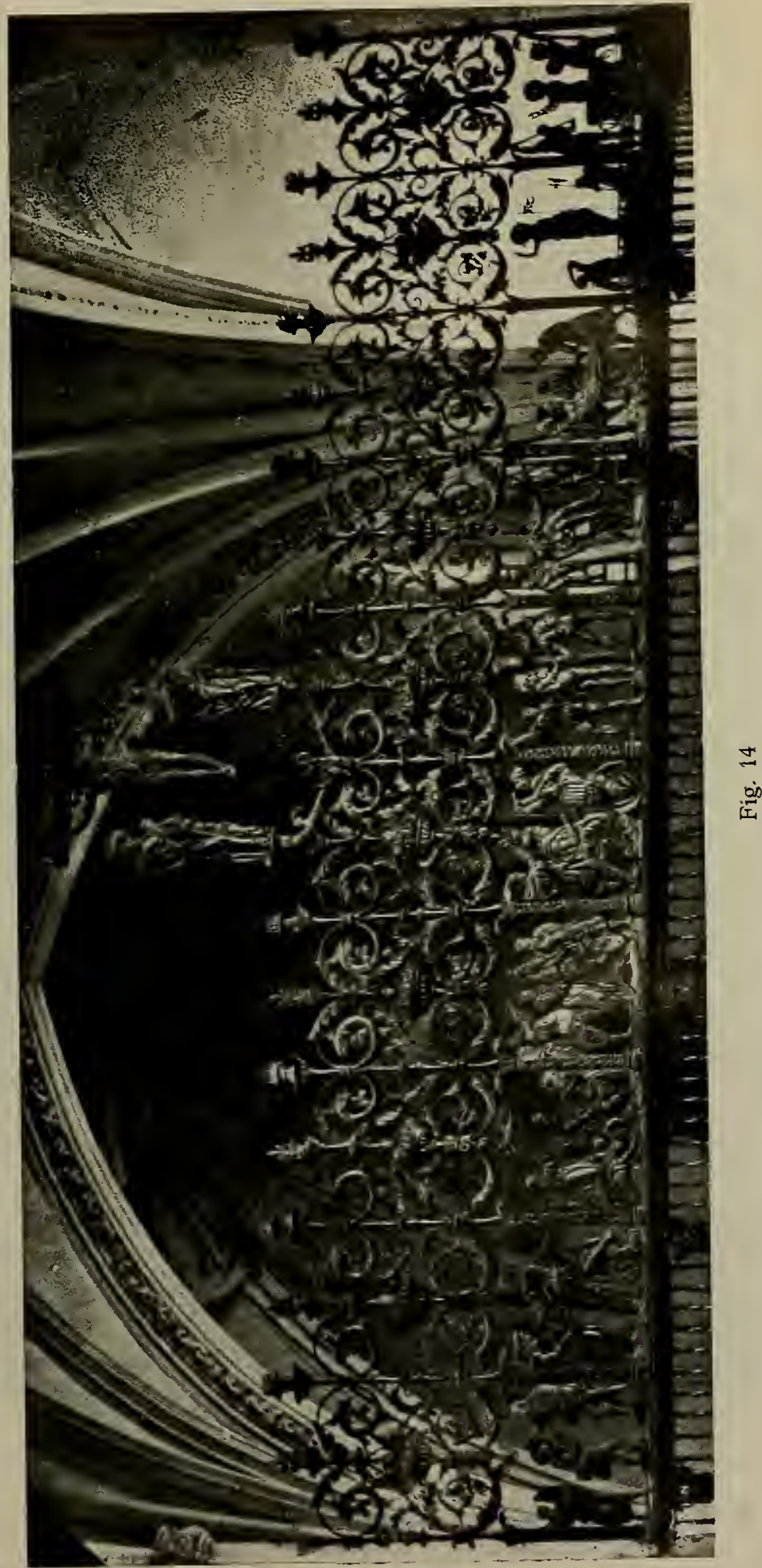






in 


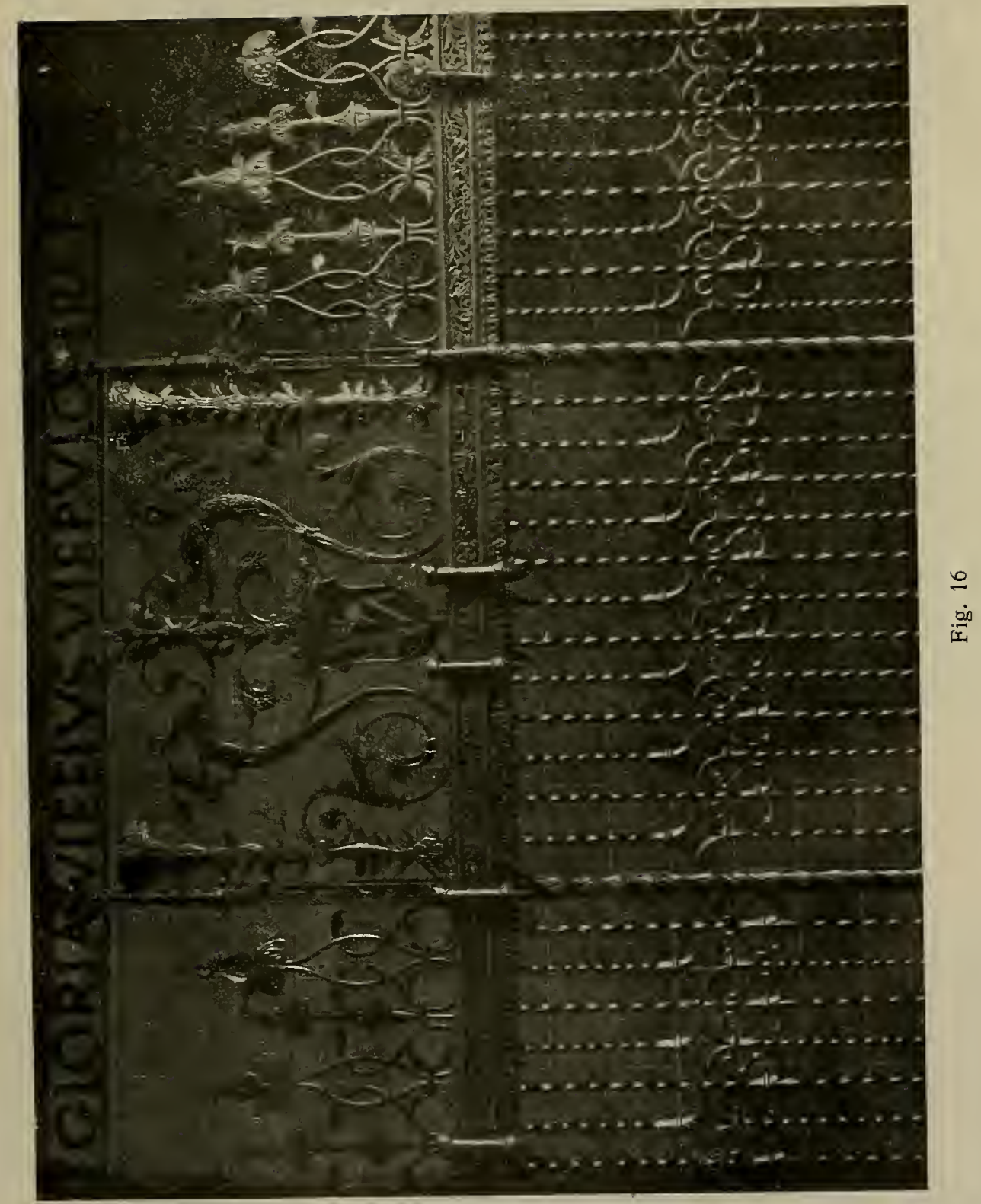




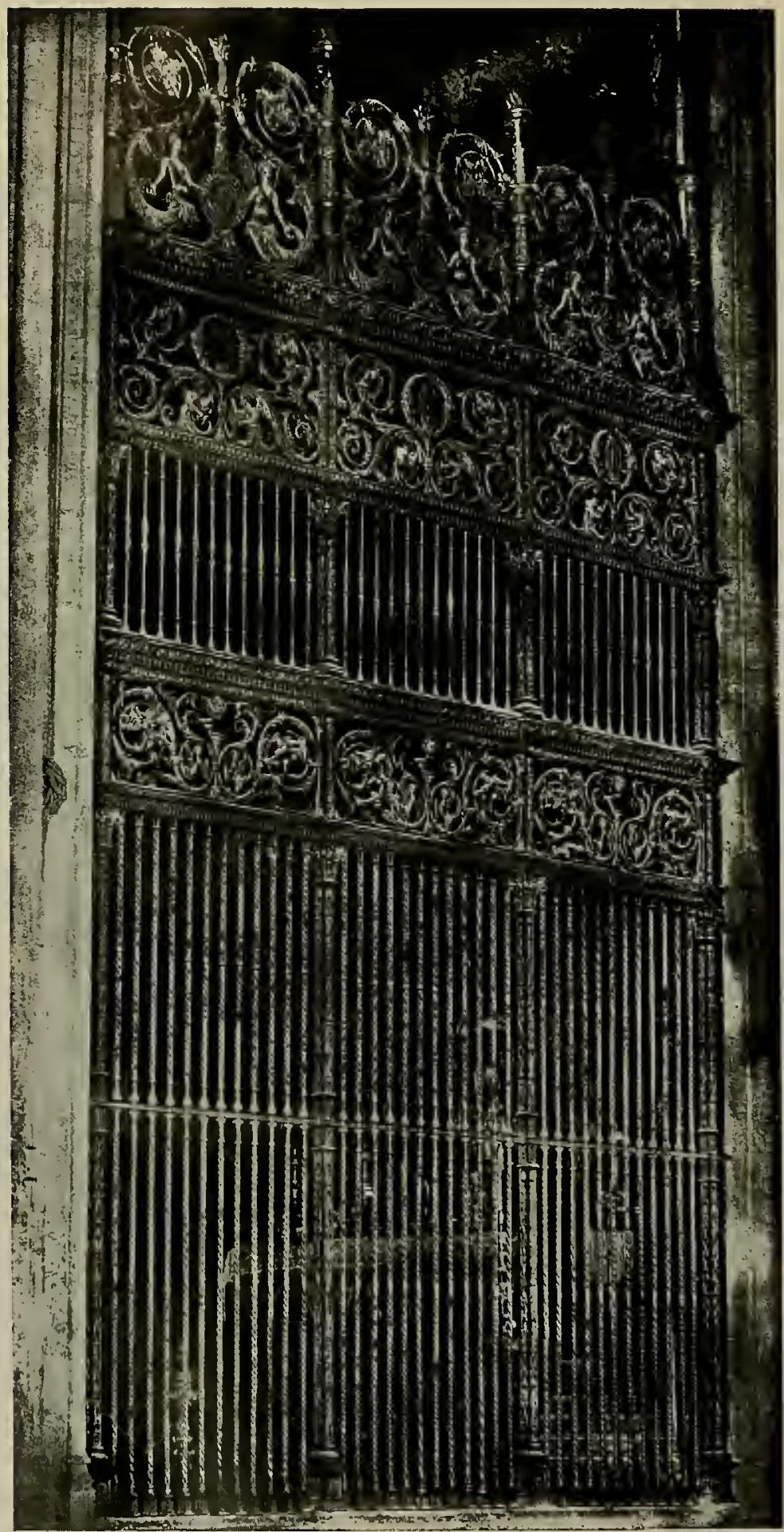

Fig. 17 

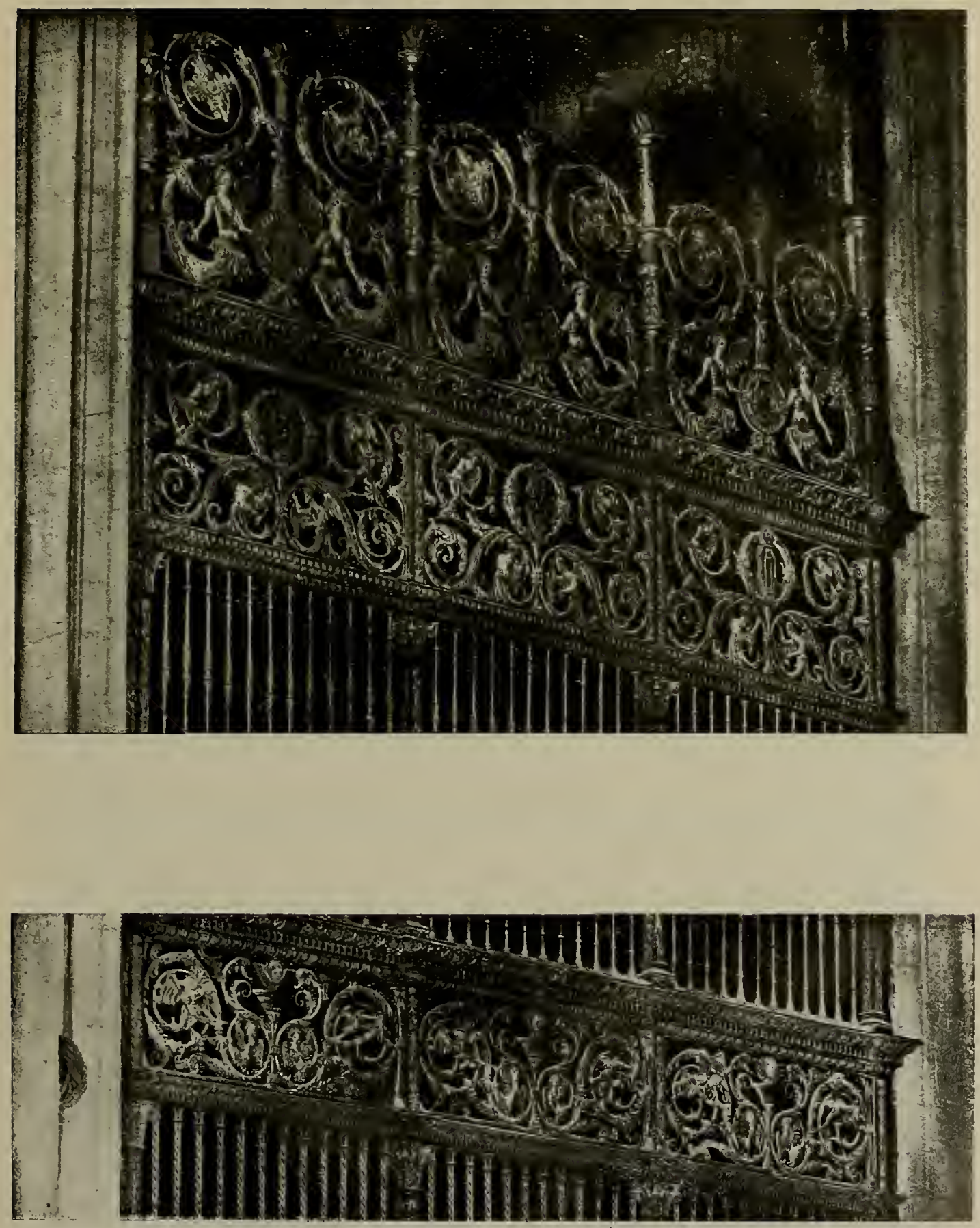

Figs. 18-19 


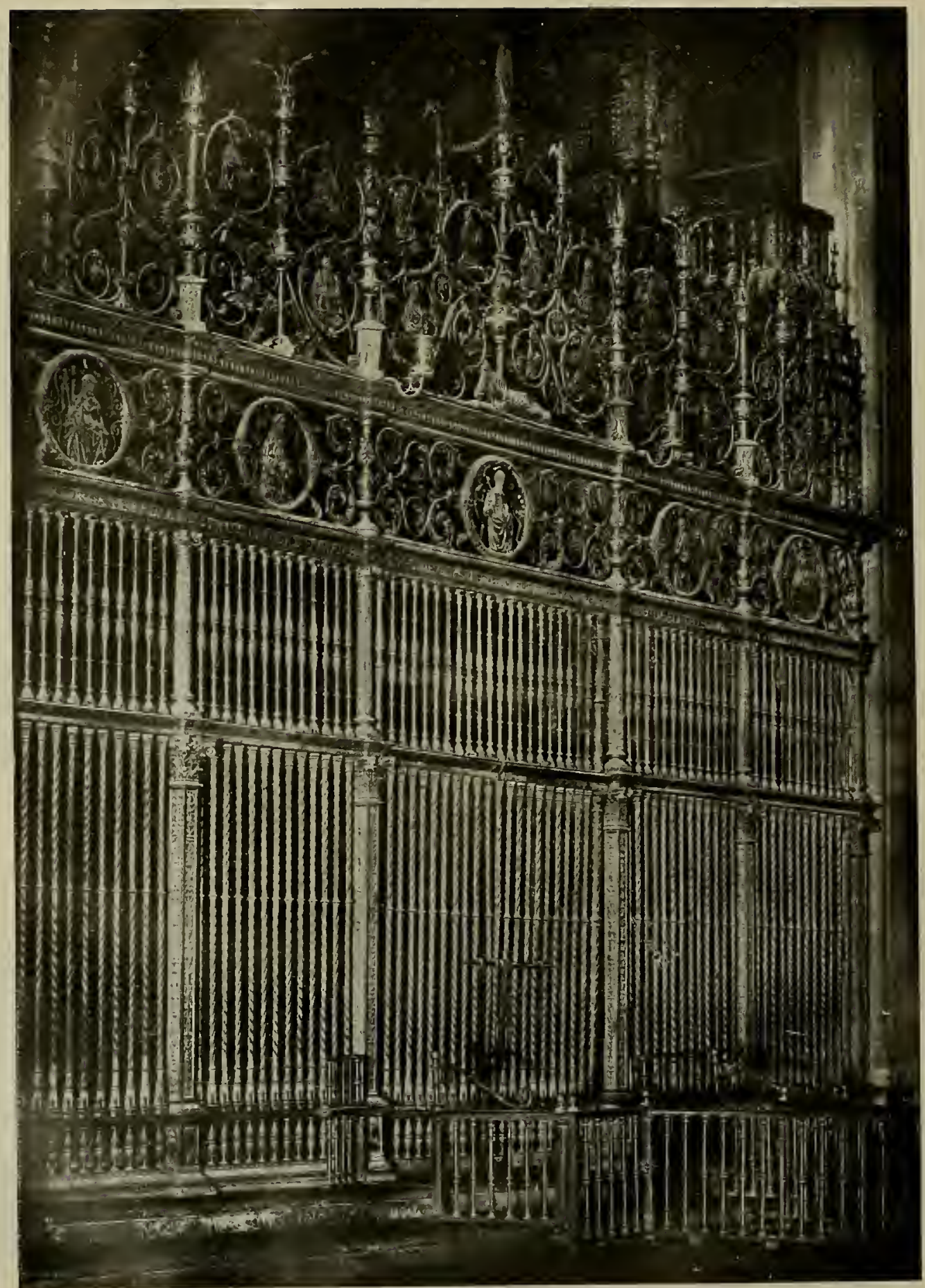

Fig. 20 

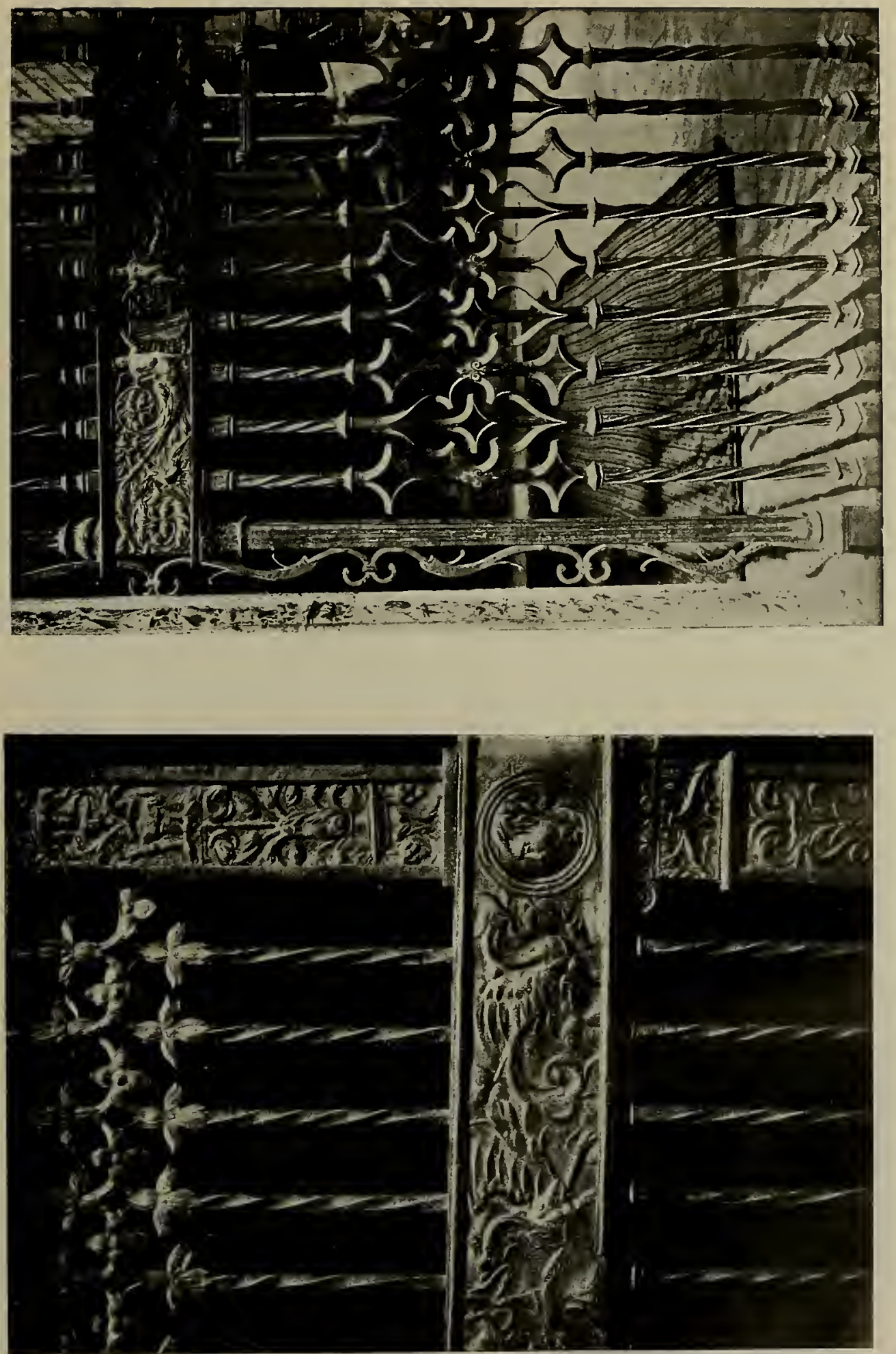

$\vec{\sim}$ 


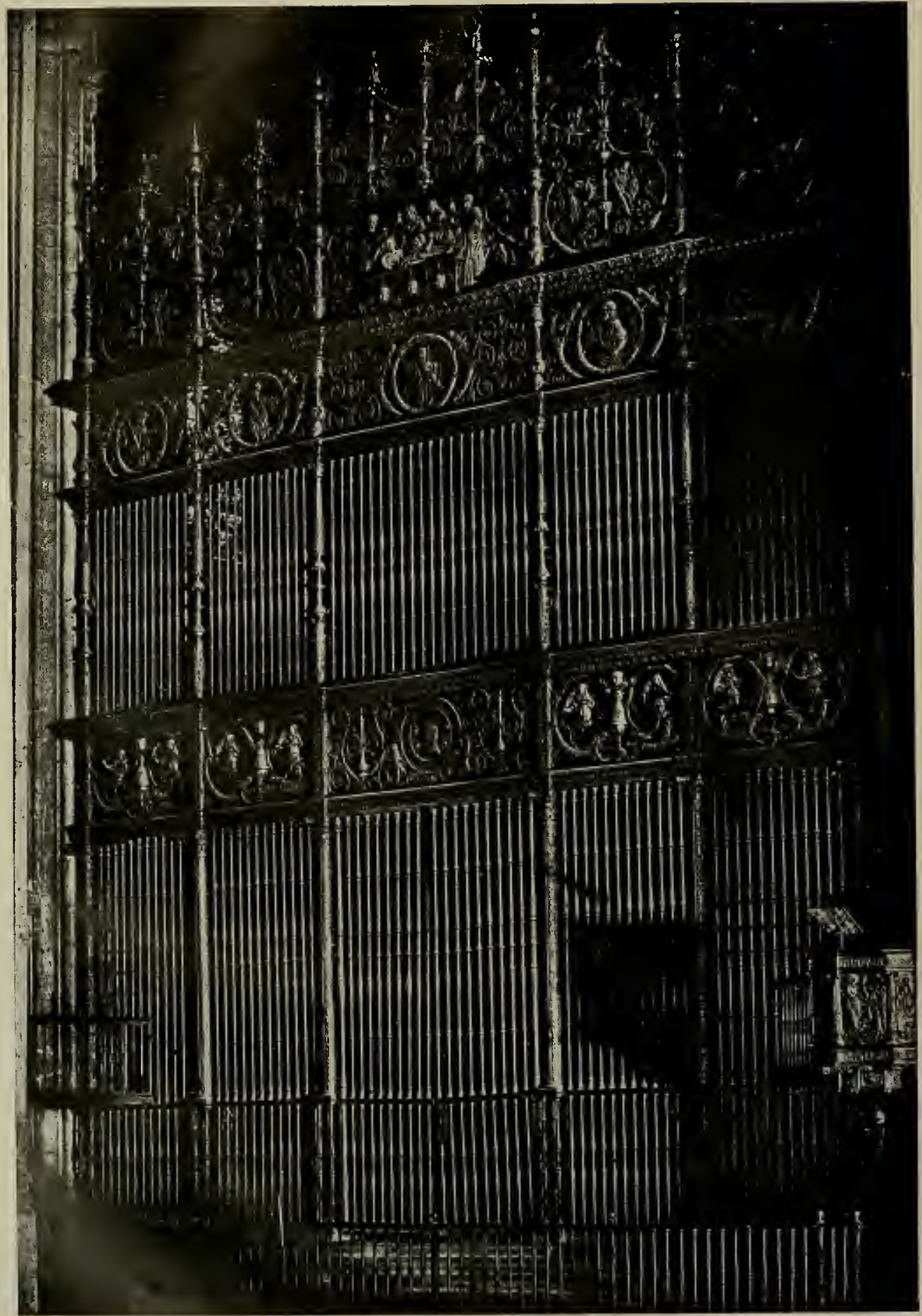

Fig. 23 

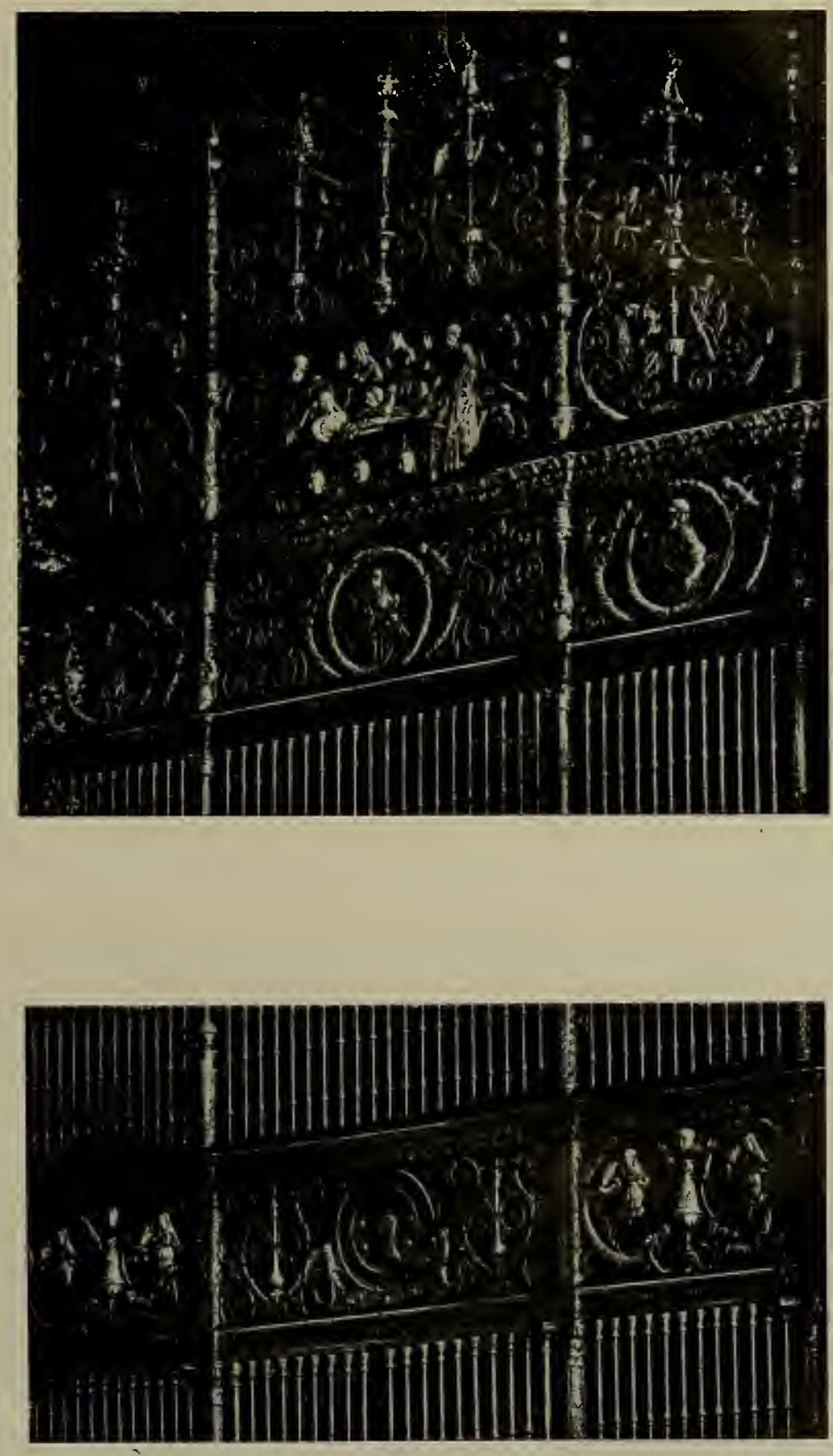

Figs. 24-25 

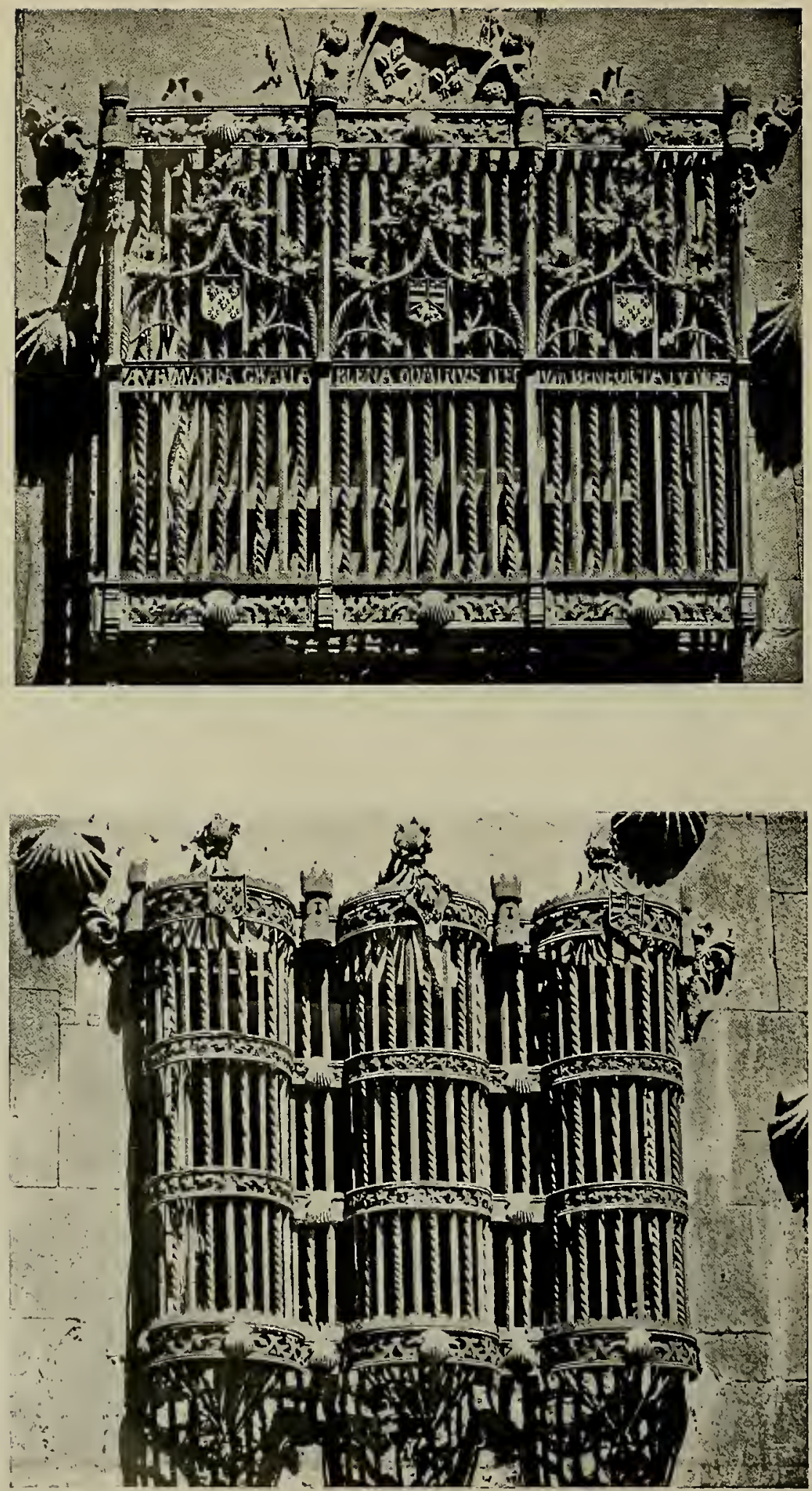

Figs. 26-27 


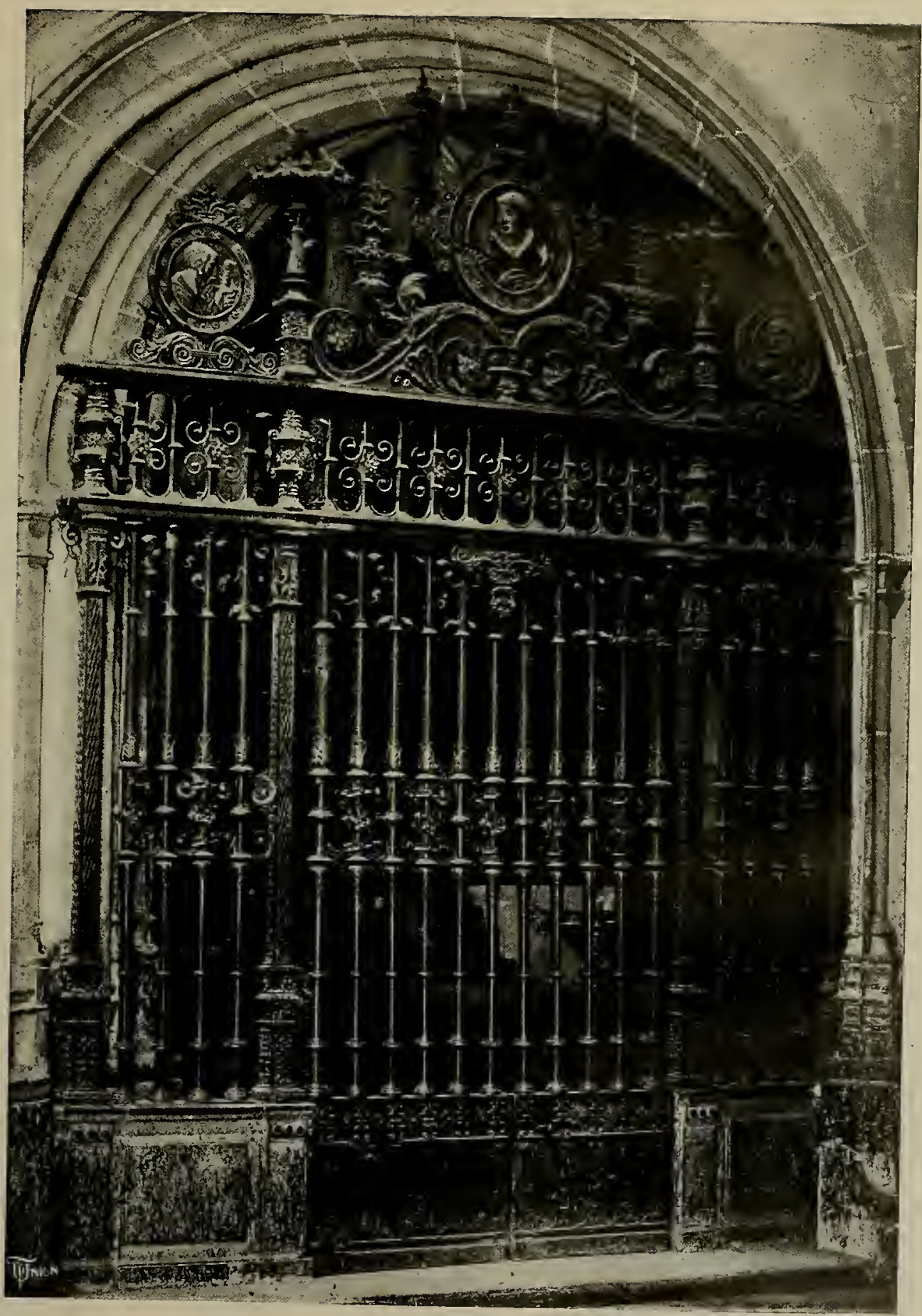

Fig. 28 


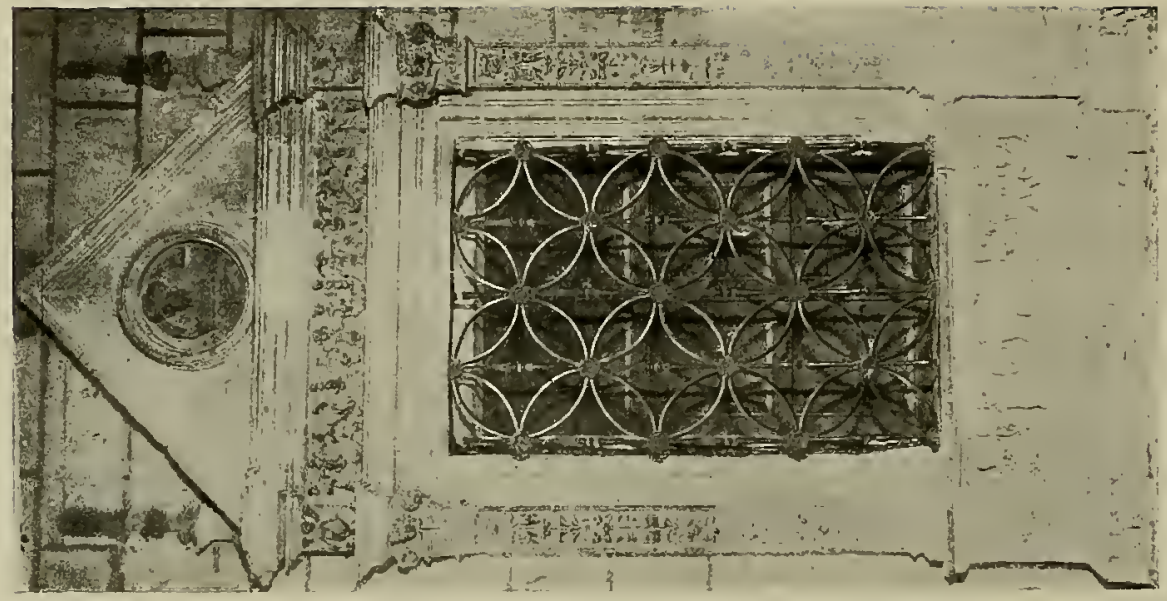

요

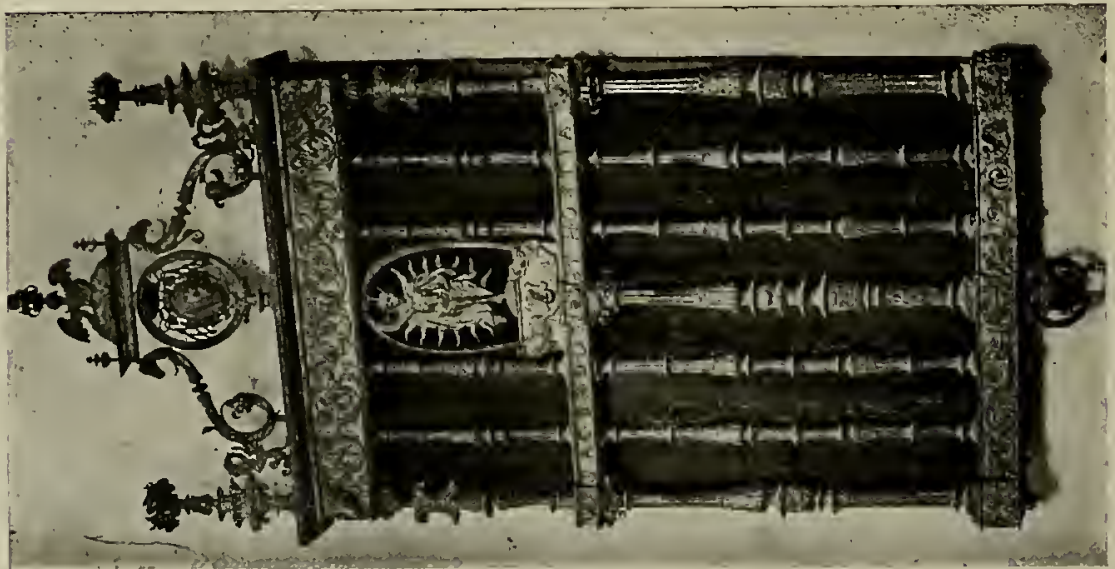

요

拄 


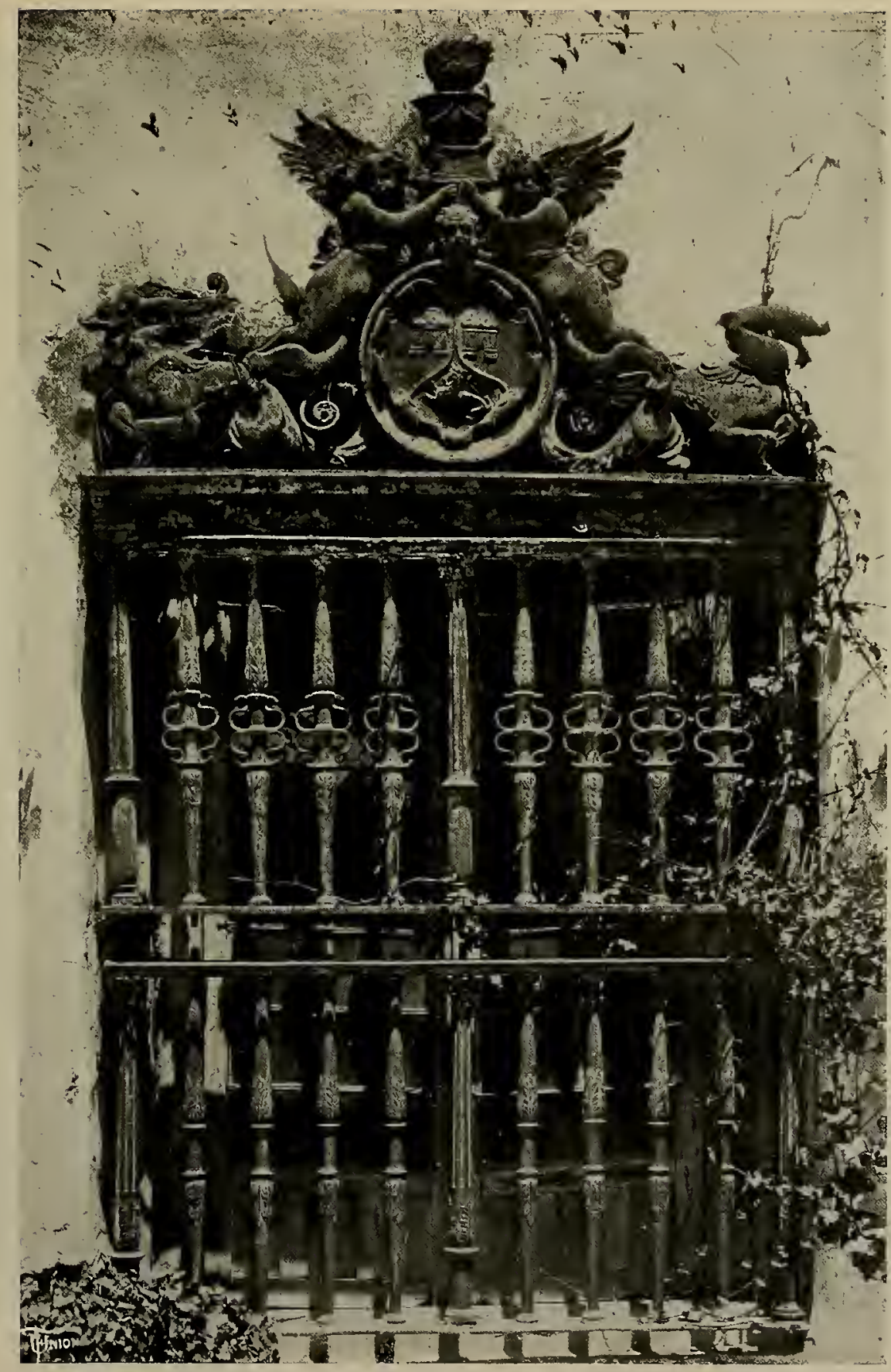

Fig. 31 


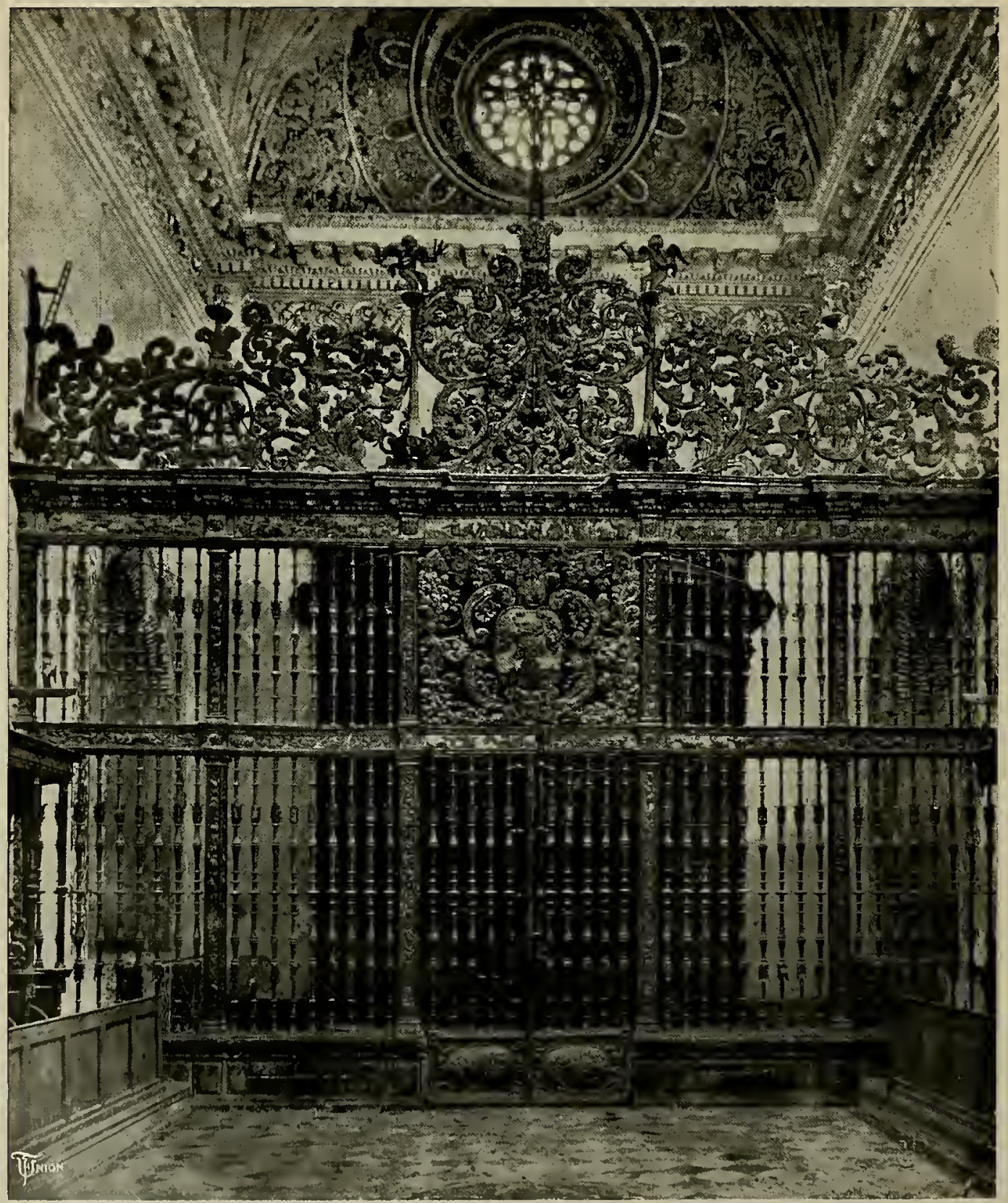

Fig. 32 


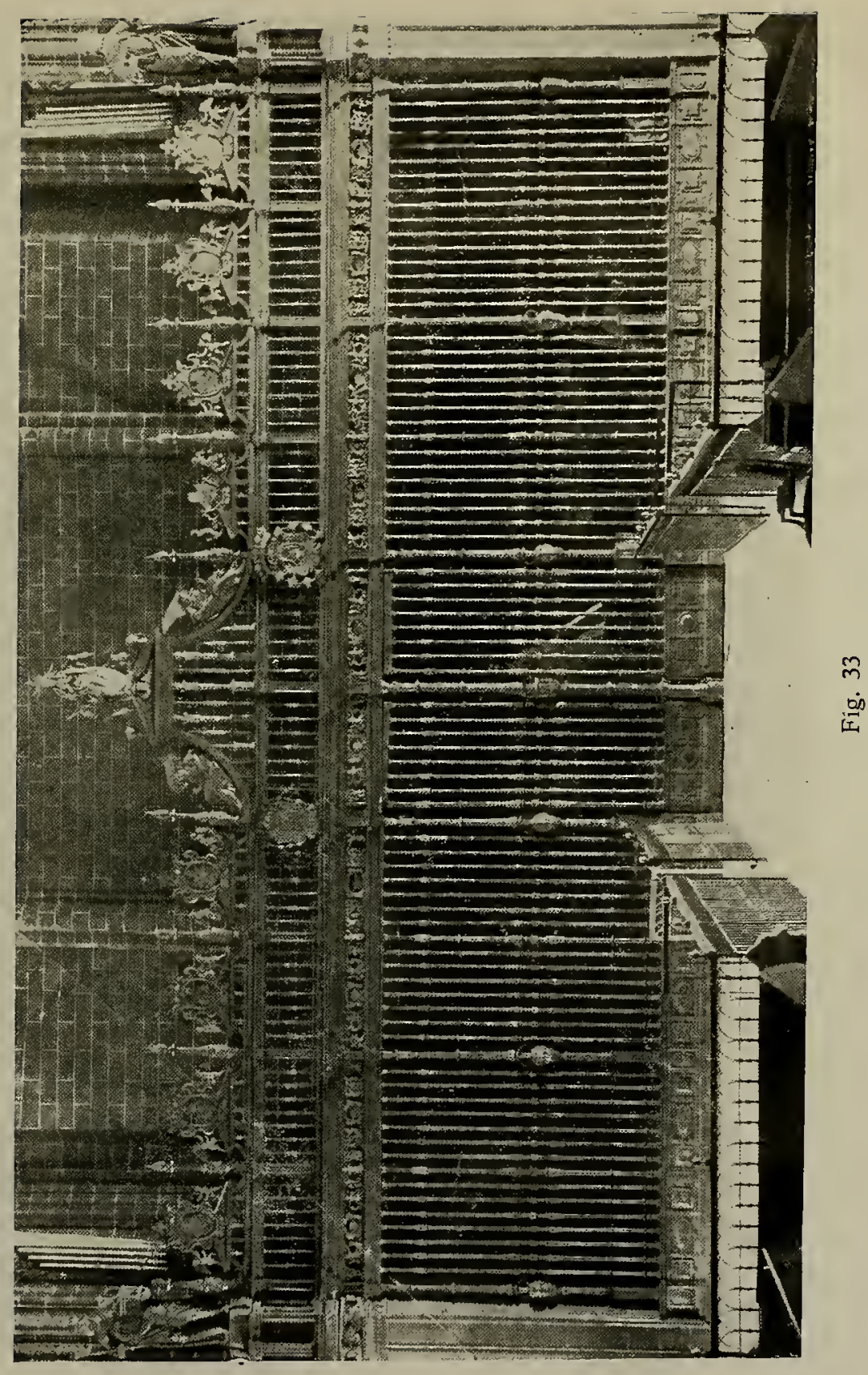




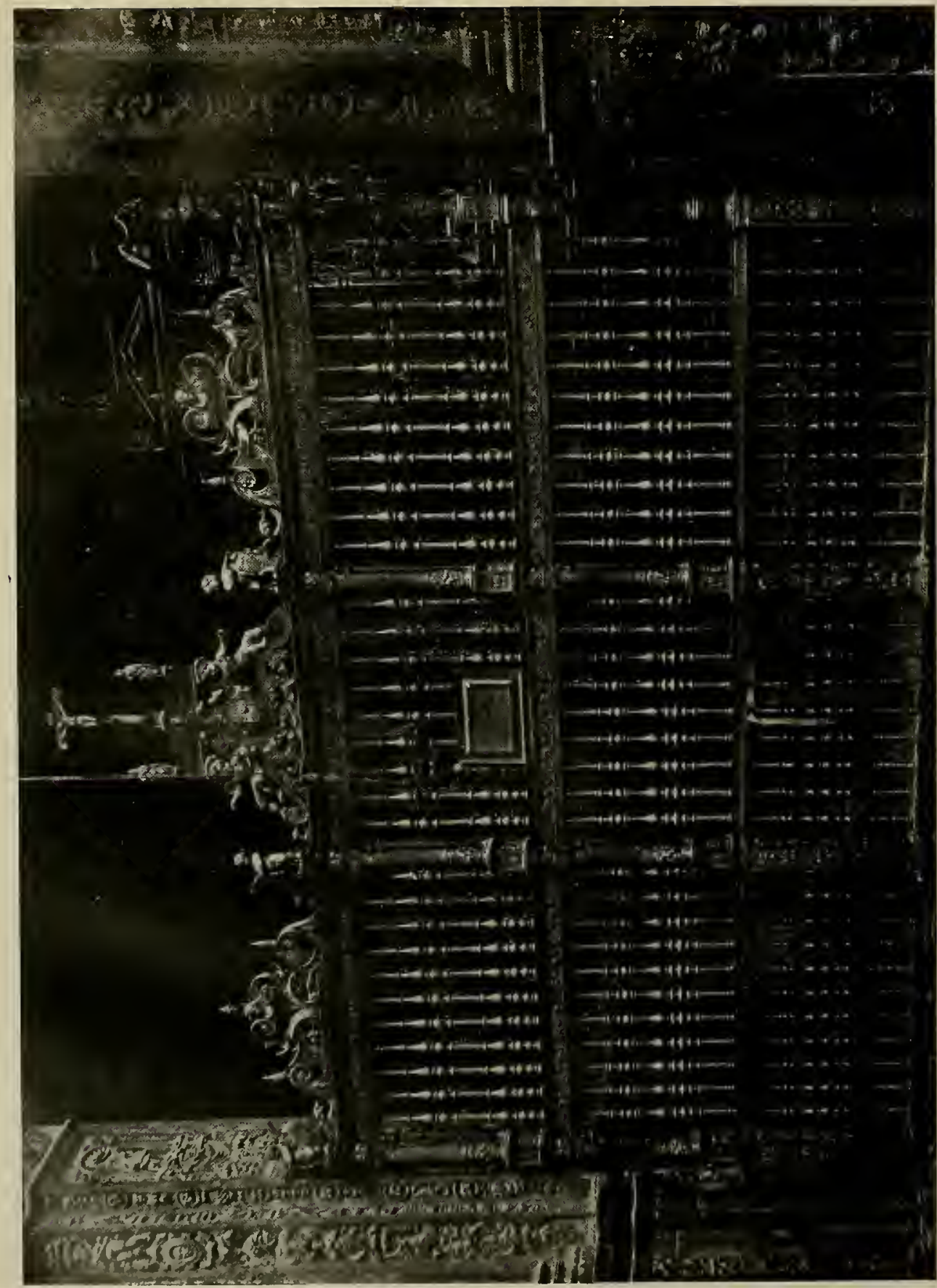

m

离 







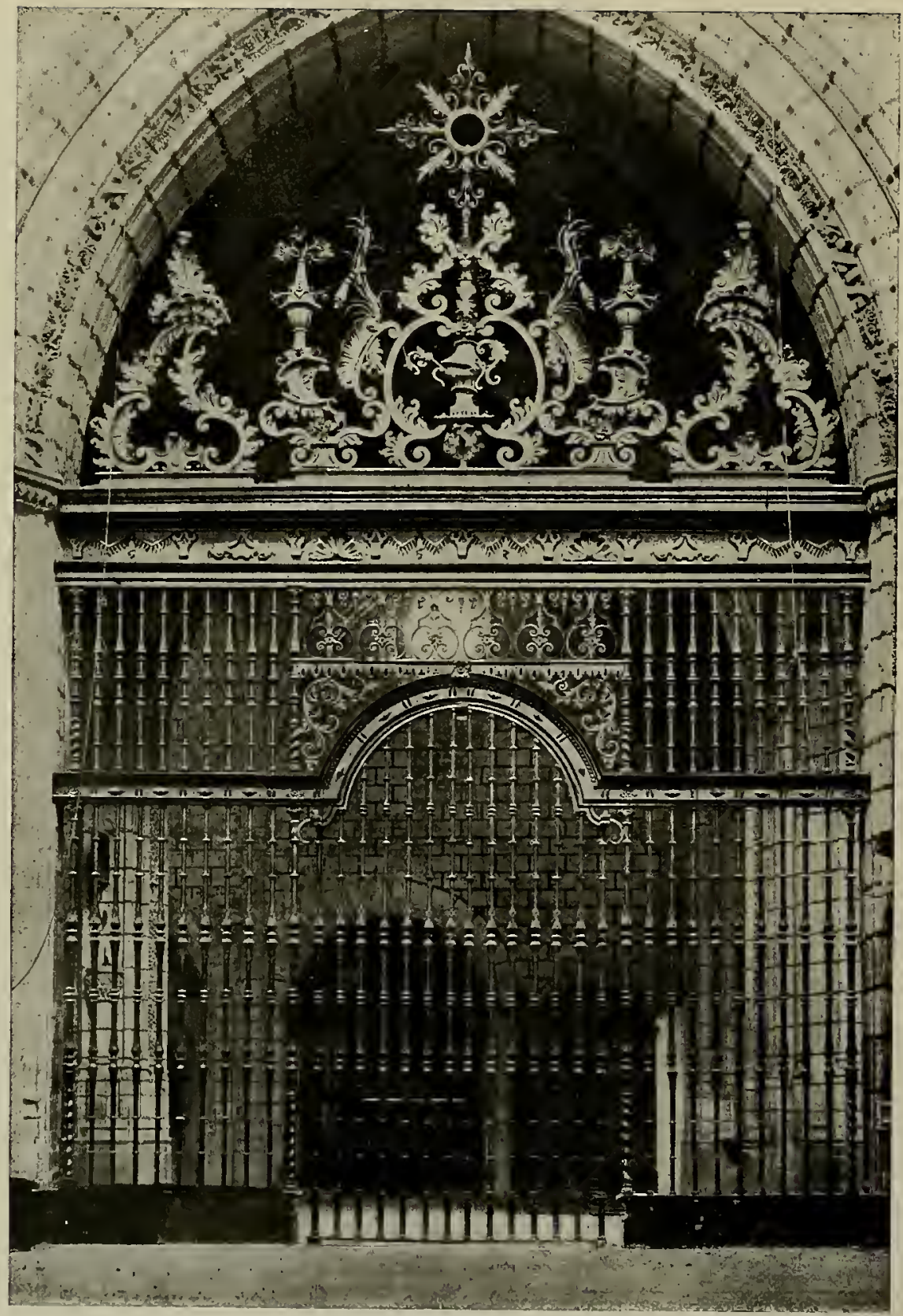

Fig. 36 


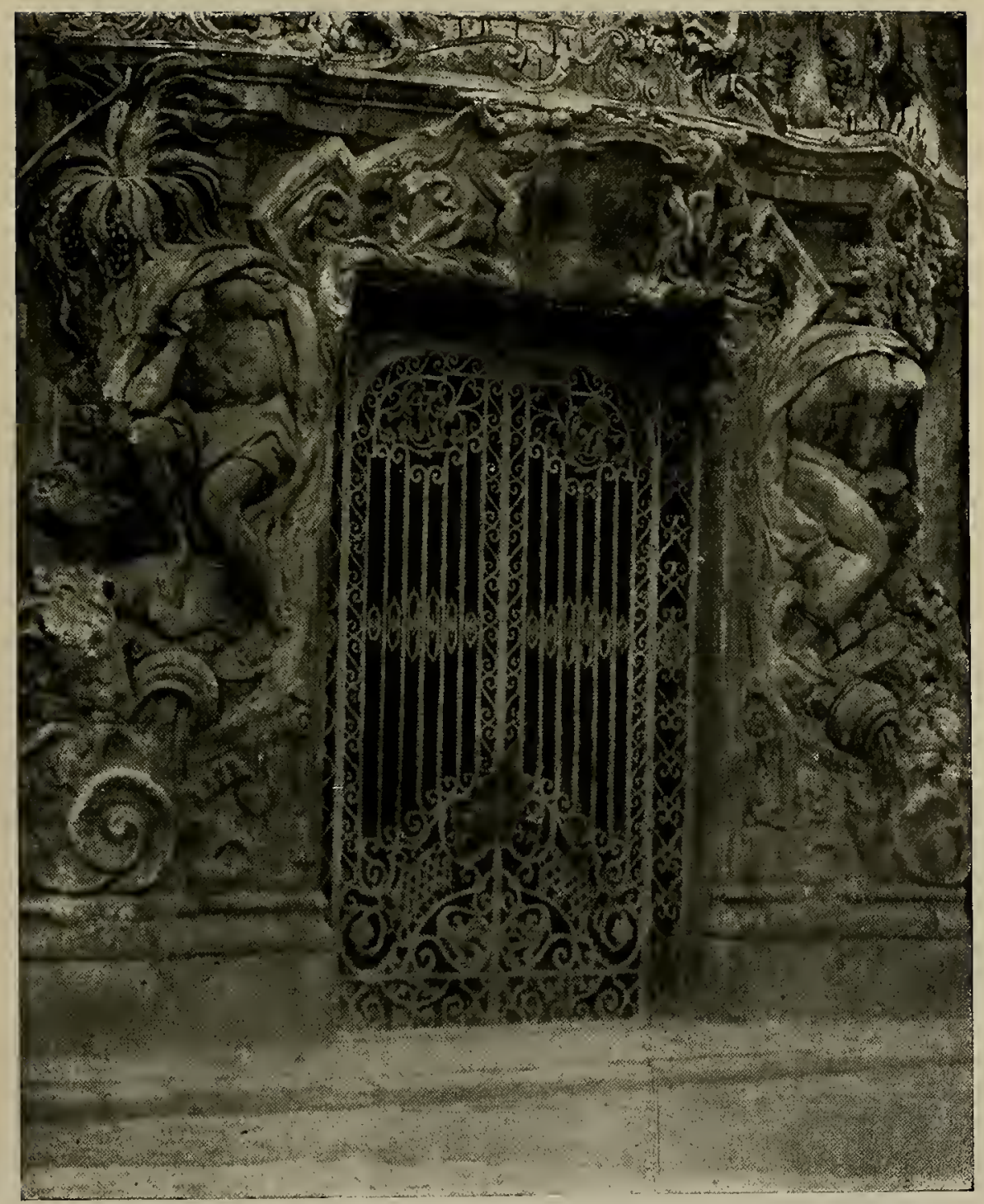

Fig. 37 




Fig. 38 


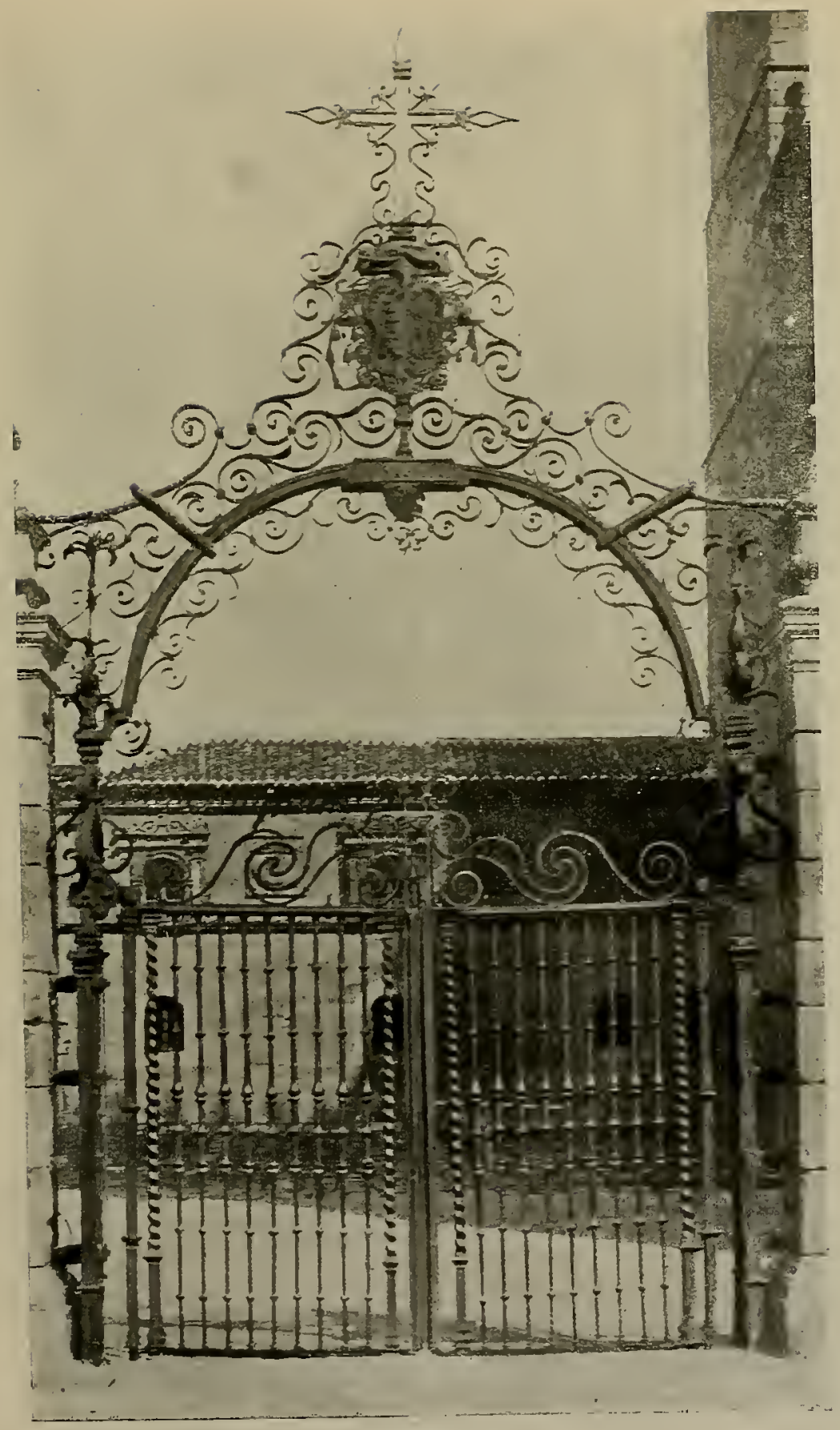

Fig. 39 


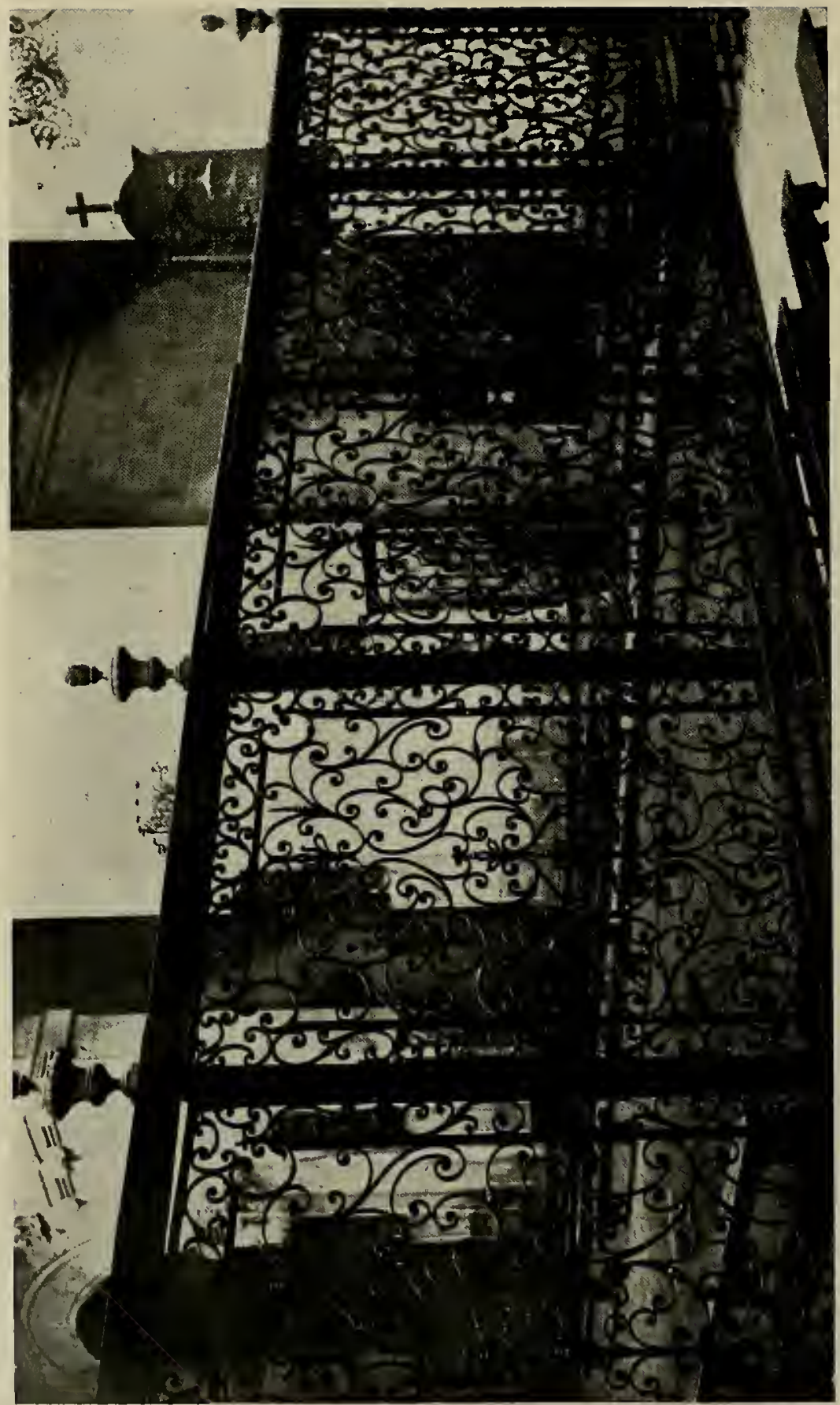






Fig. 41 


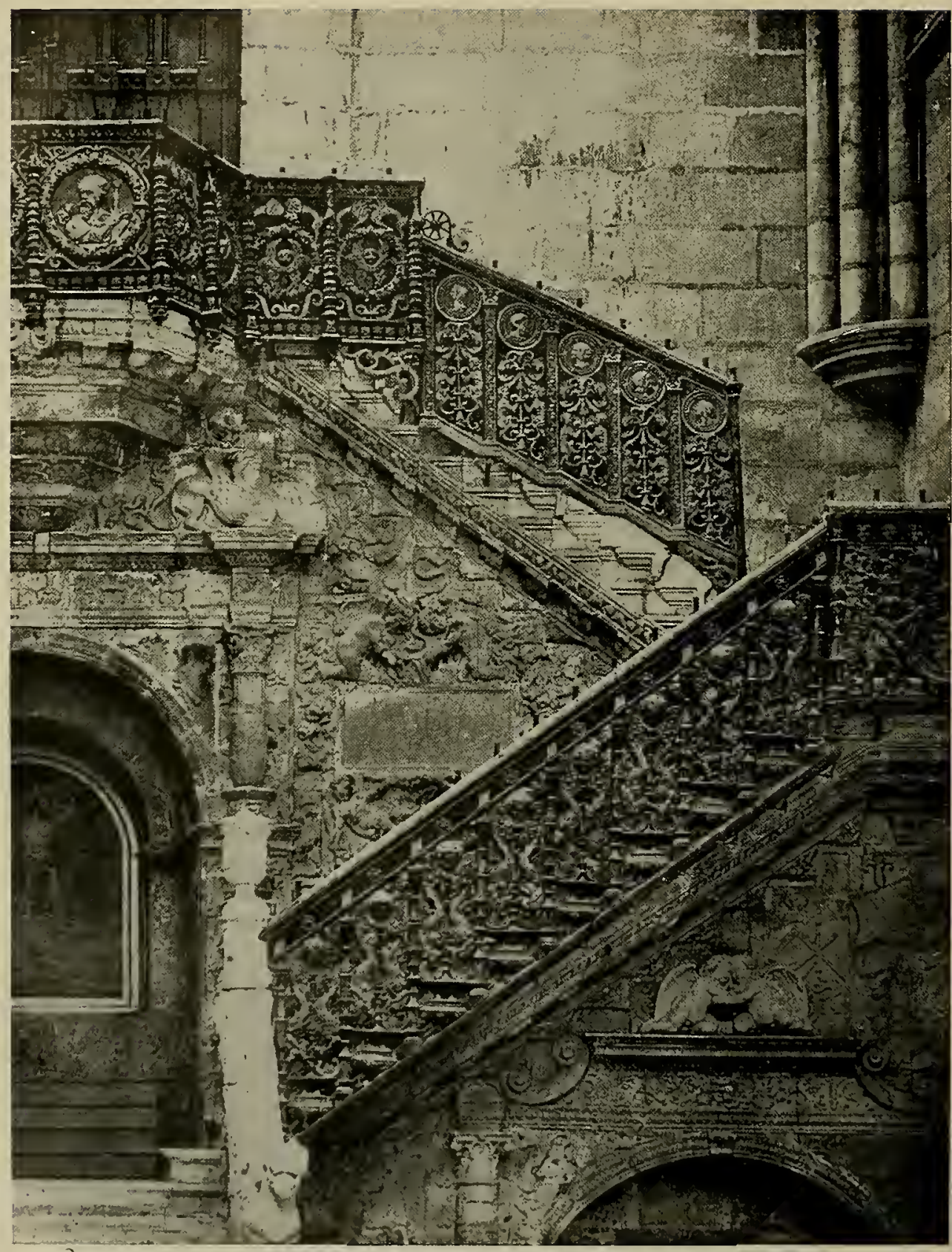

Fig. 42 

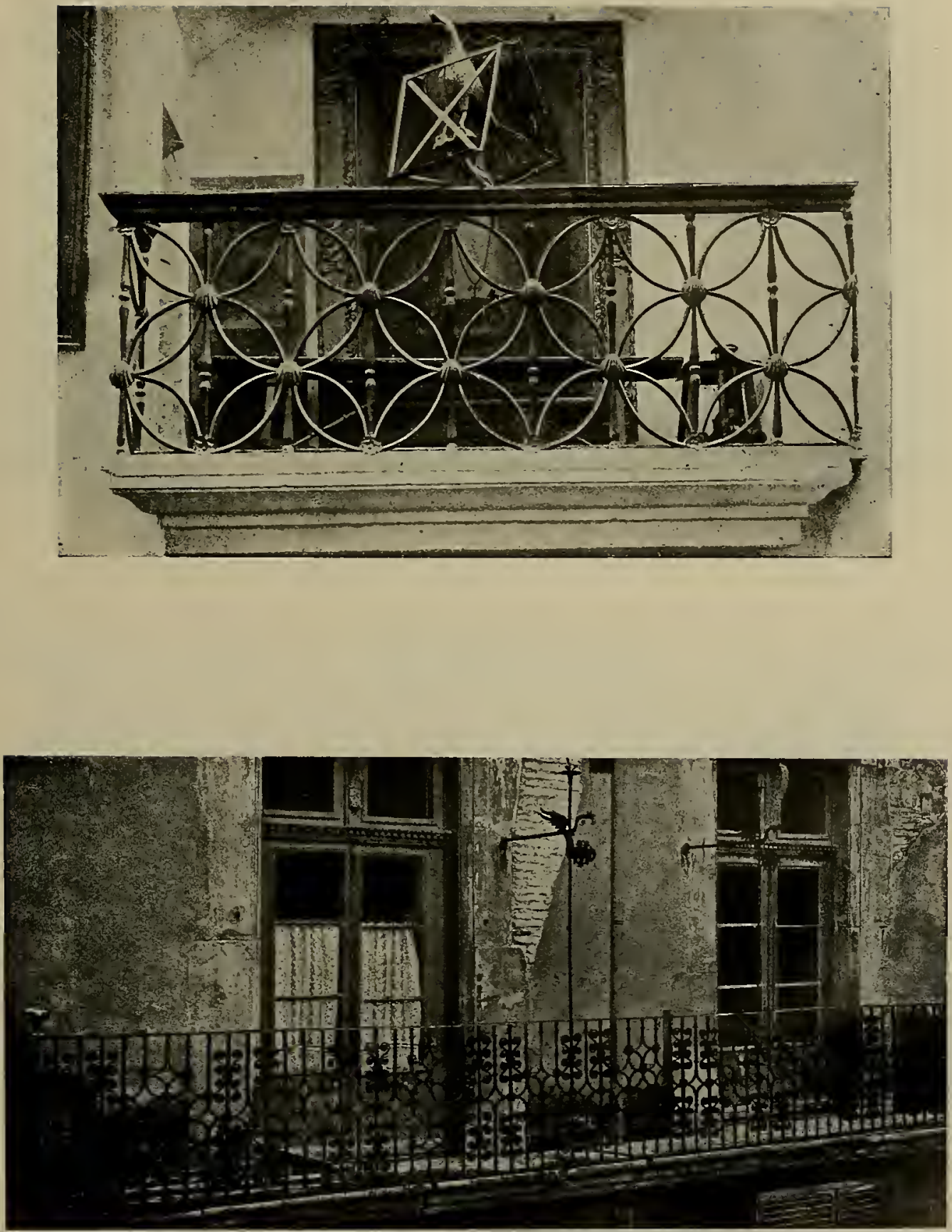

Figs. 43-44 

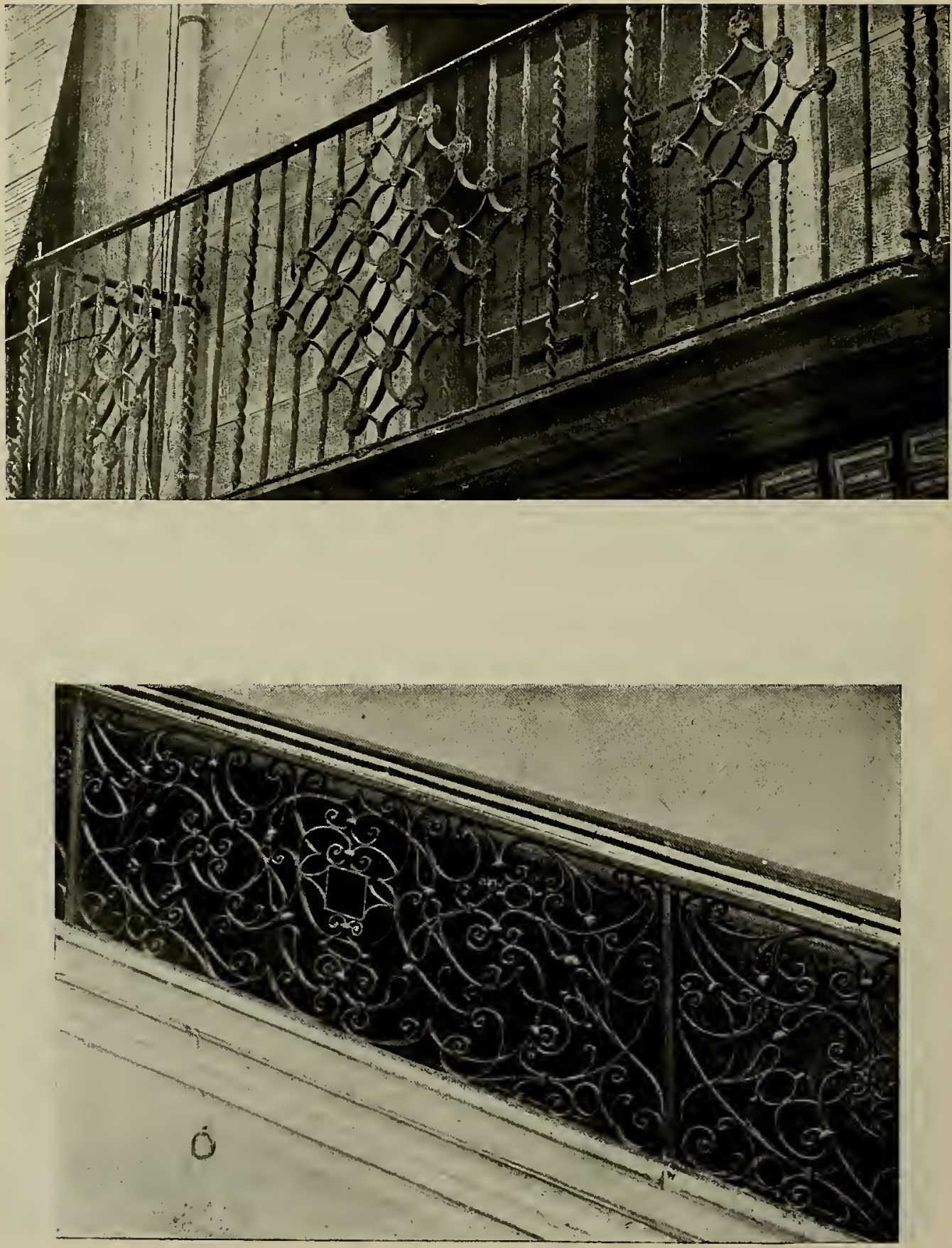

Figs. 45-46 



Figs. 47-48 






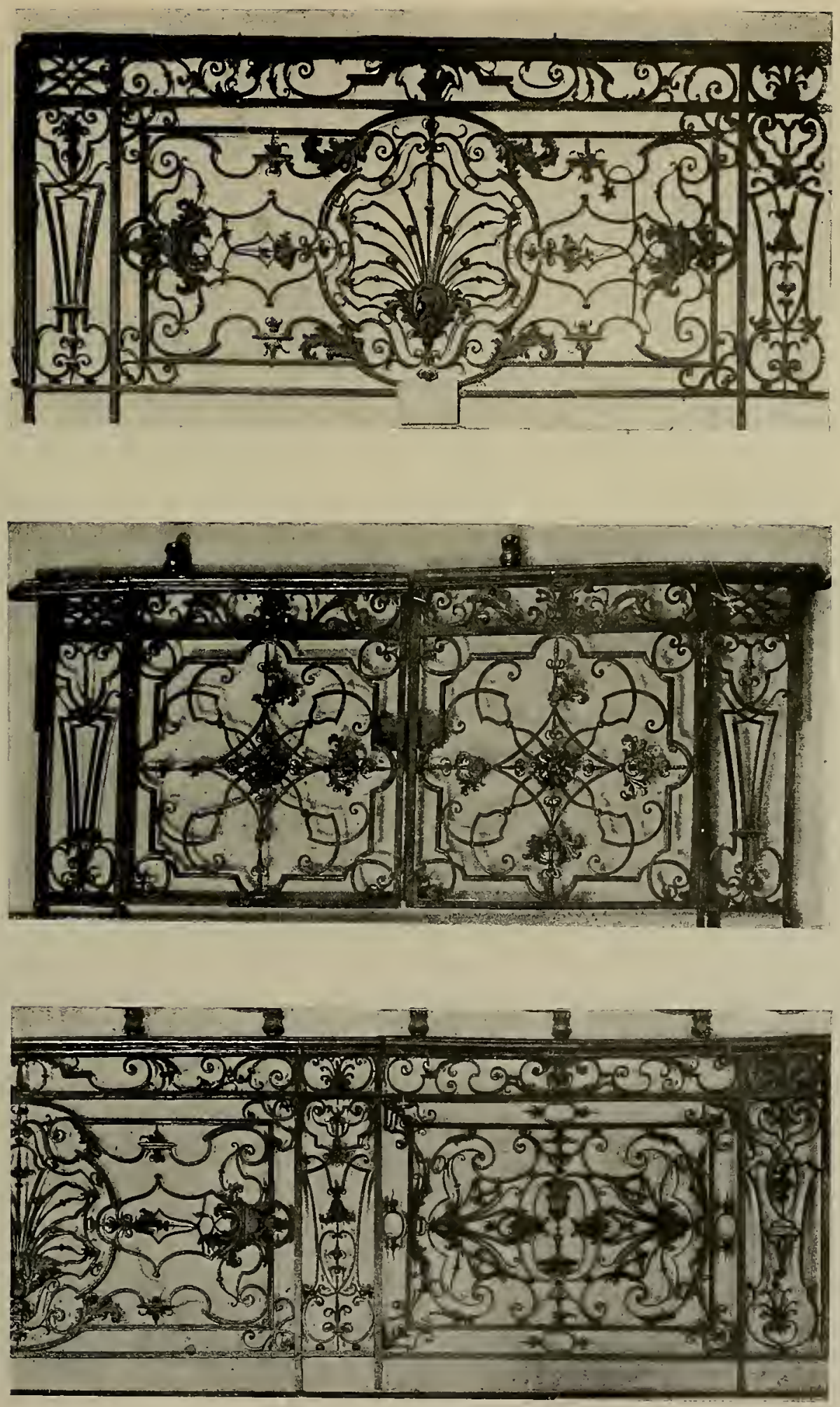

Figs. 50-51-52 

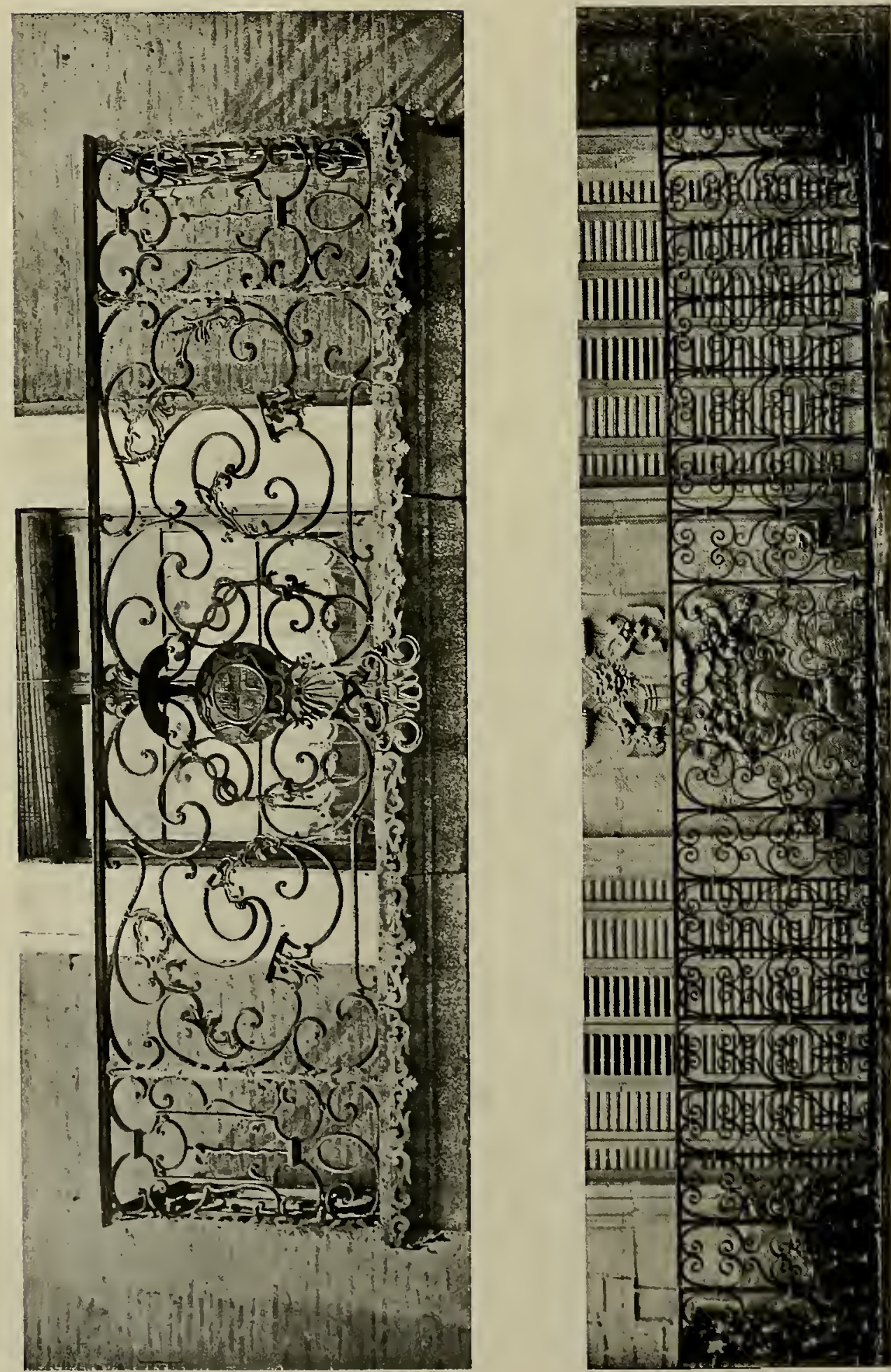

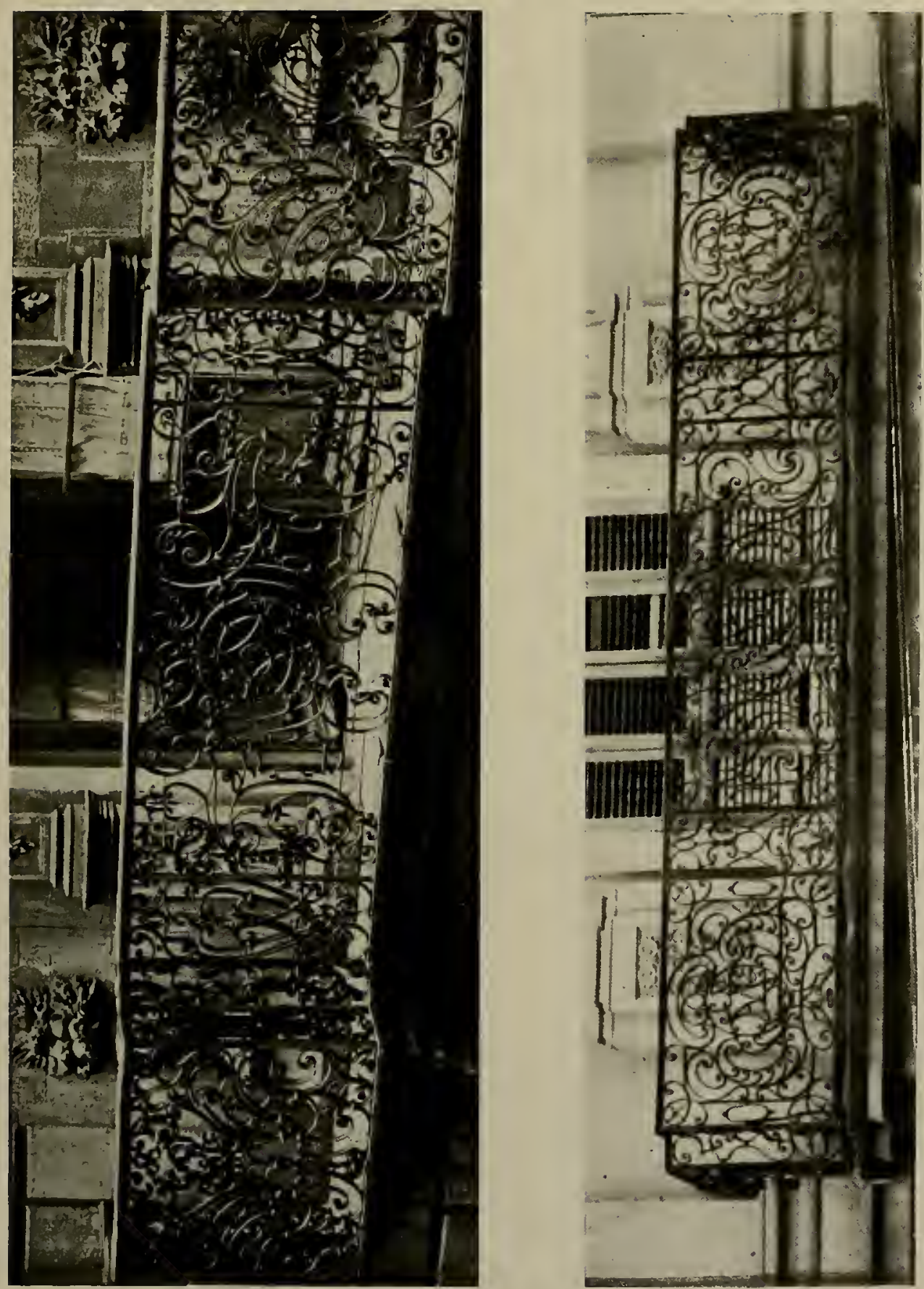

贻 


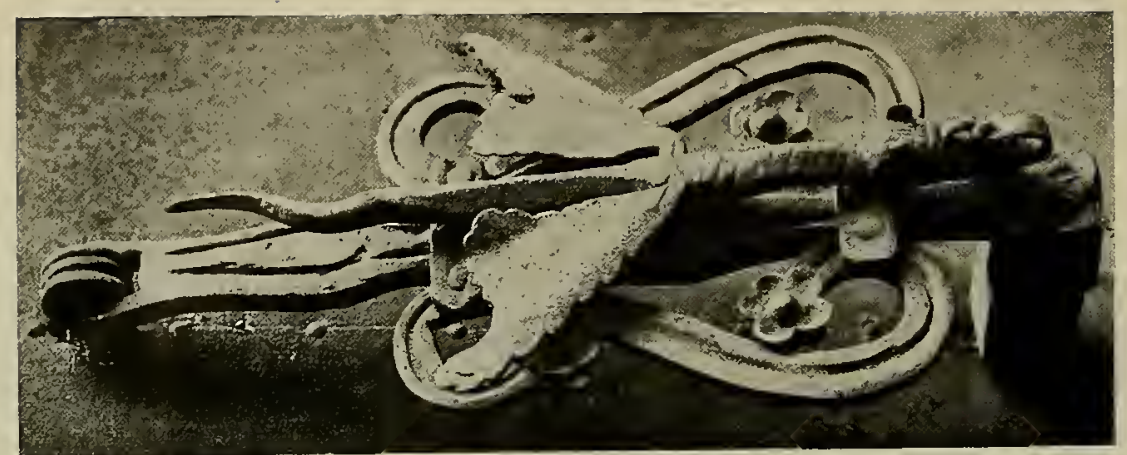

in
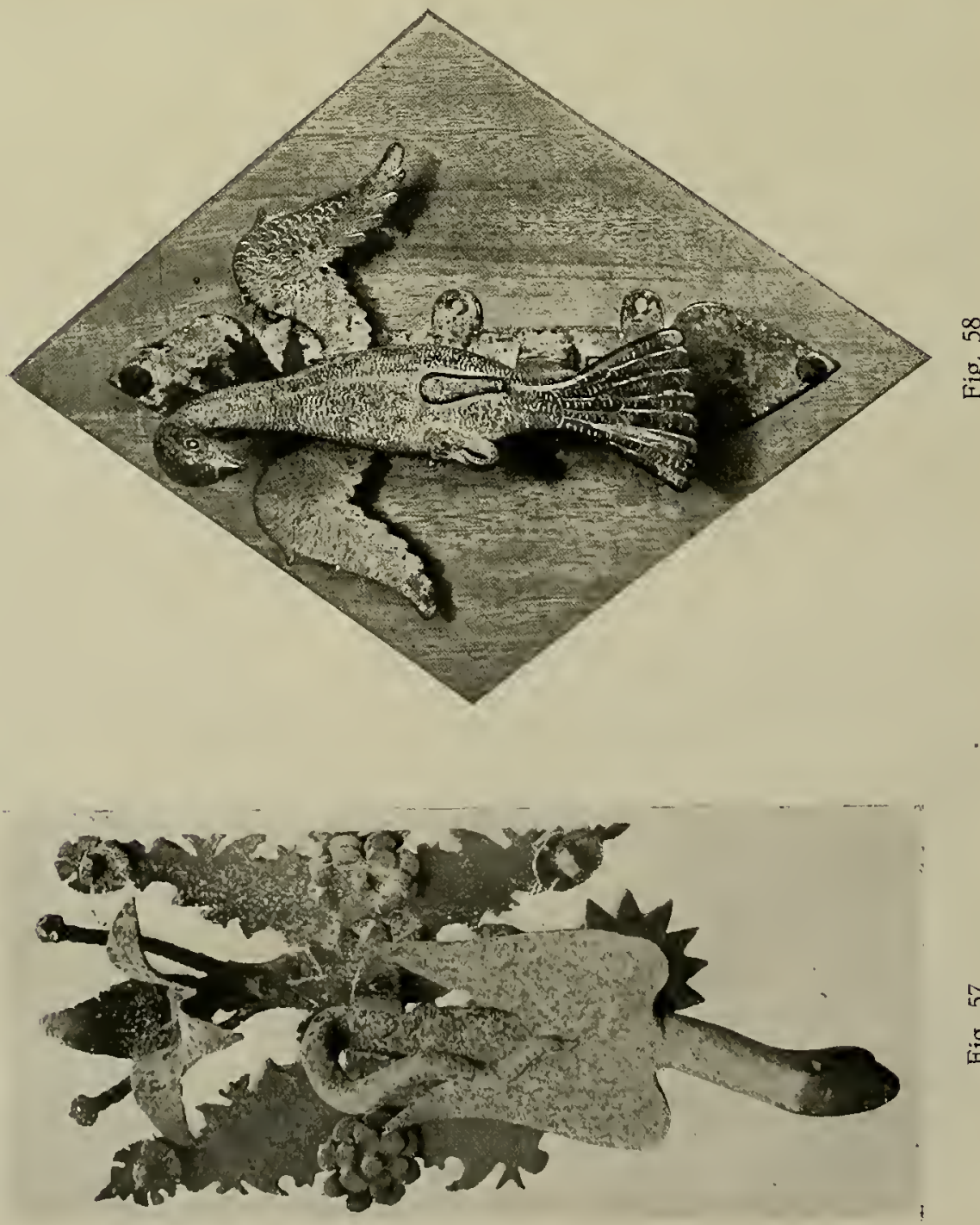

in

离 


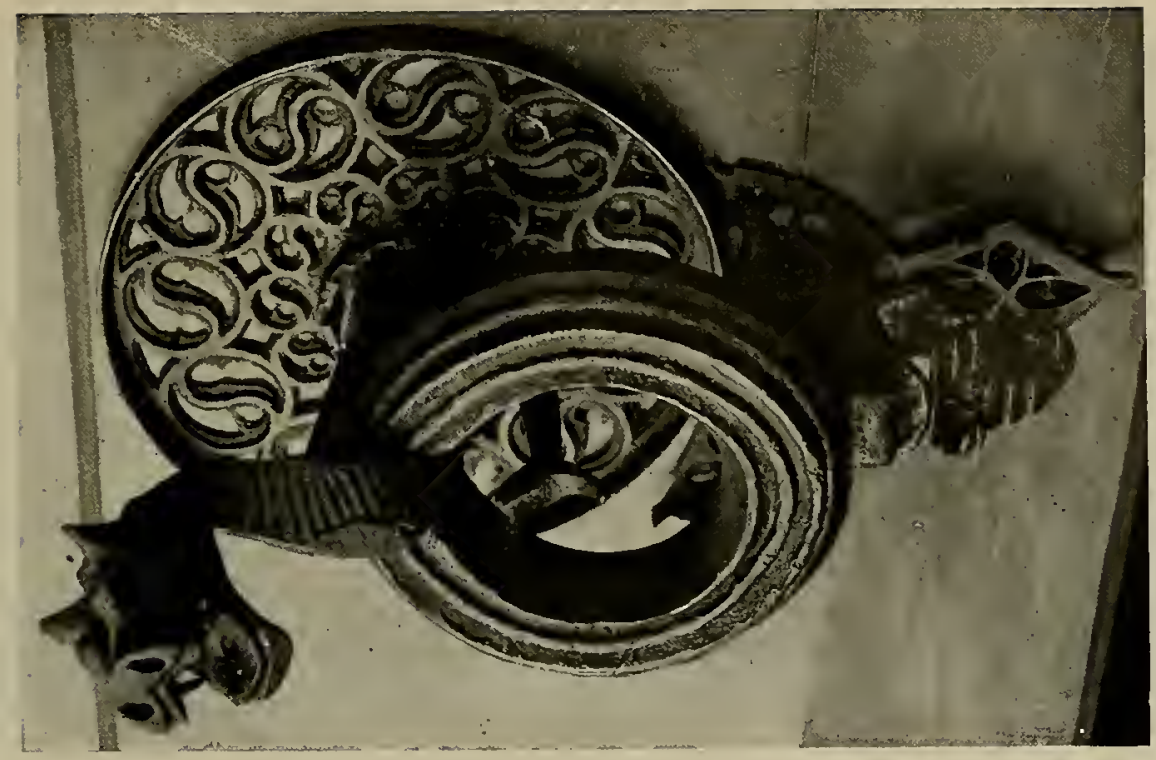

$\overline{6}$

诖

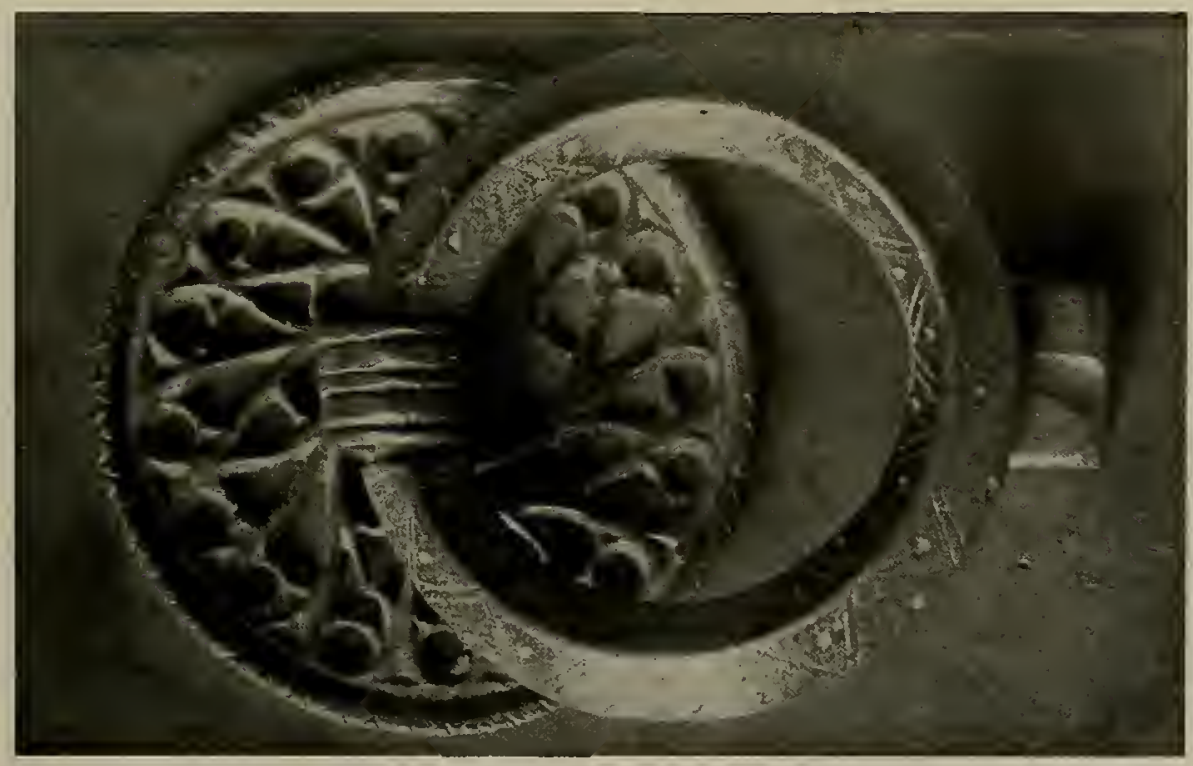

8 



6 

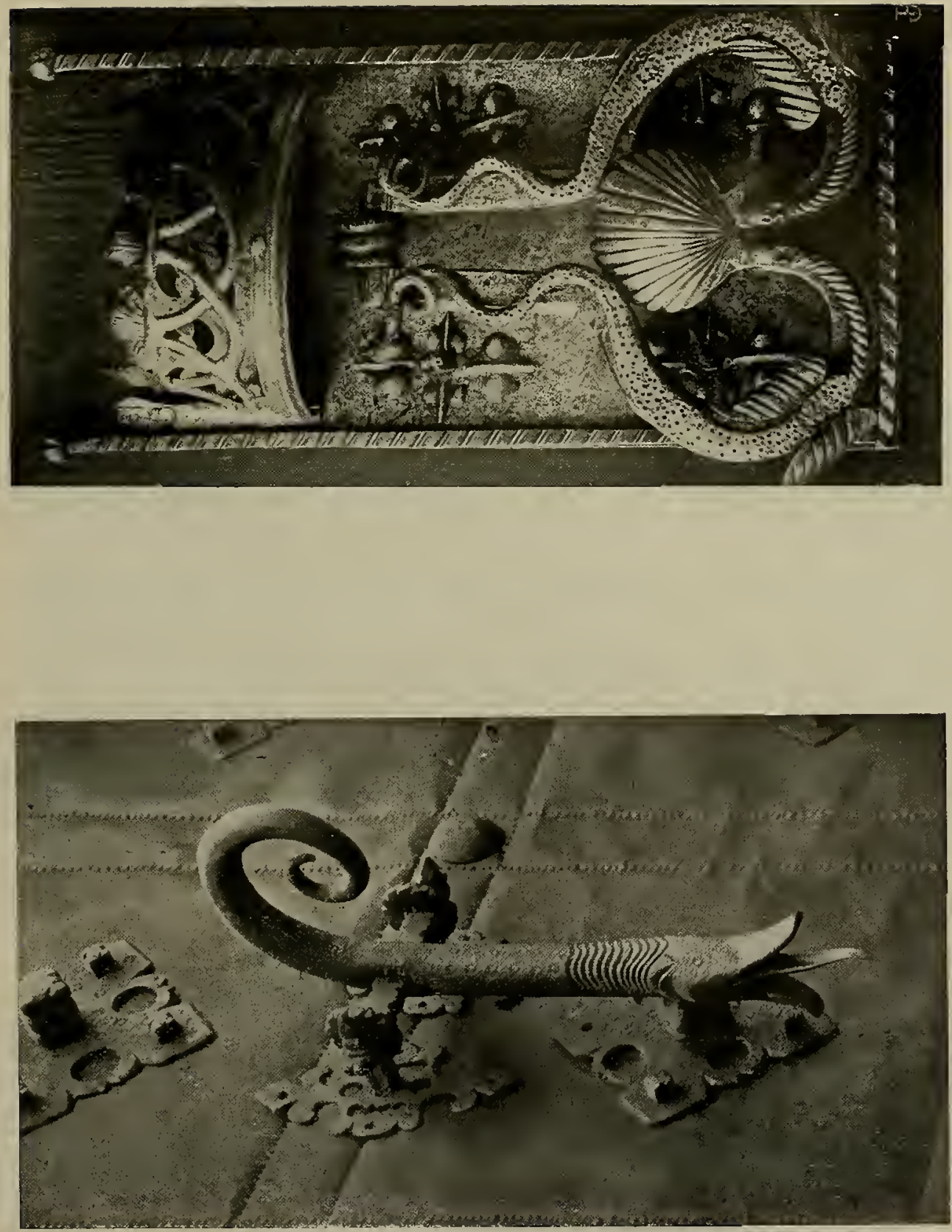

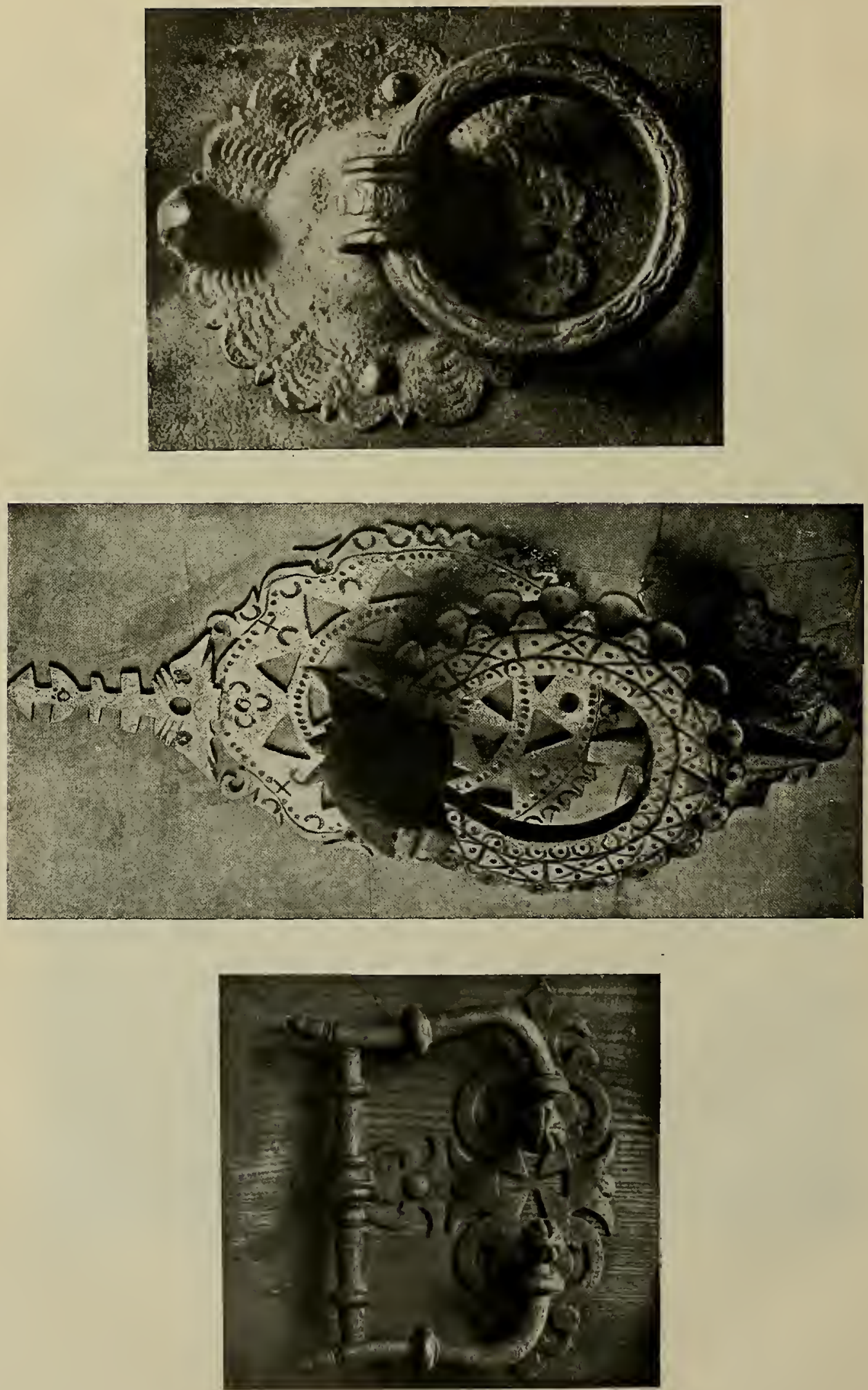

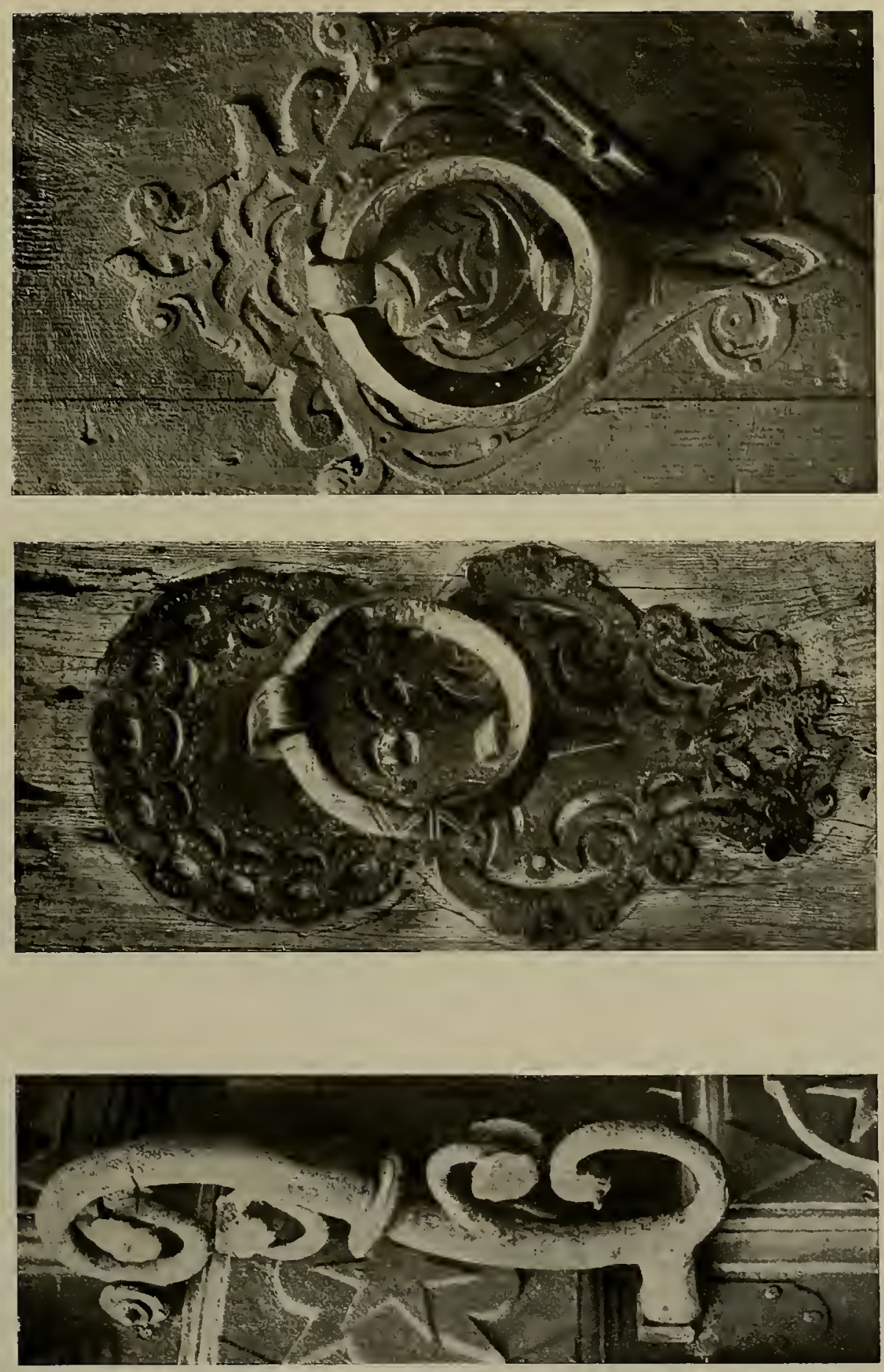

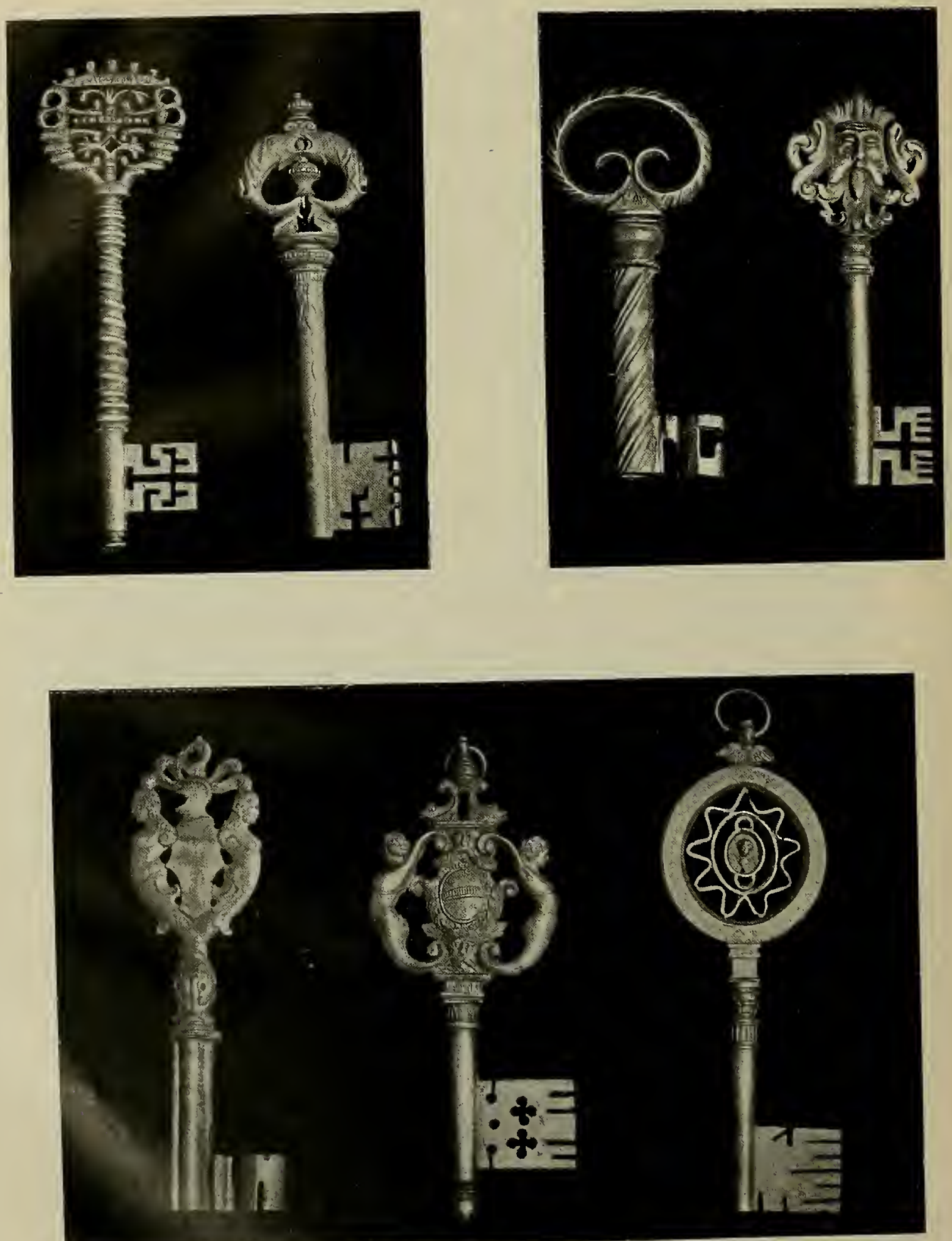

Figs. 72 a 78 

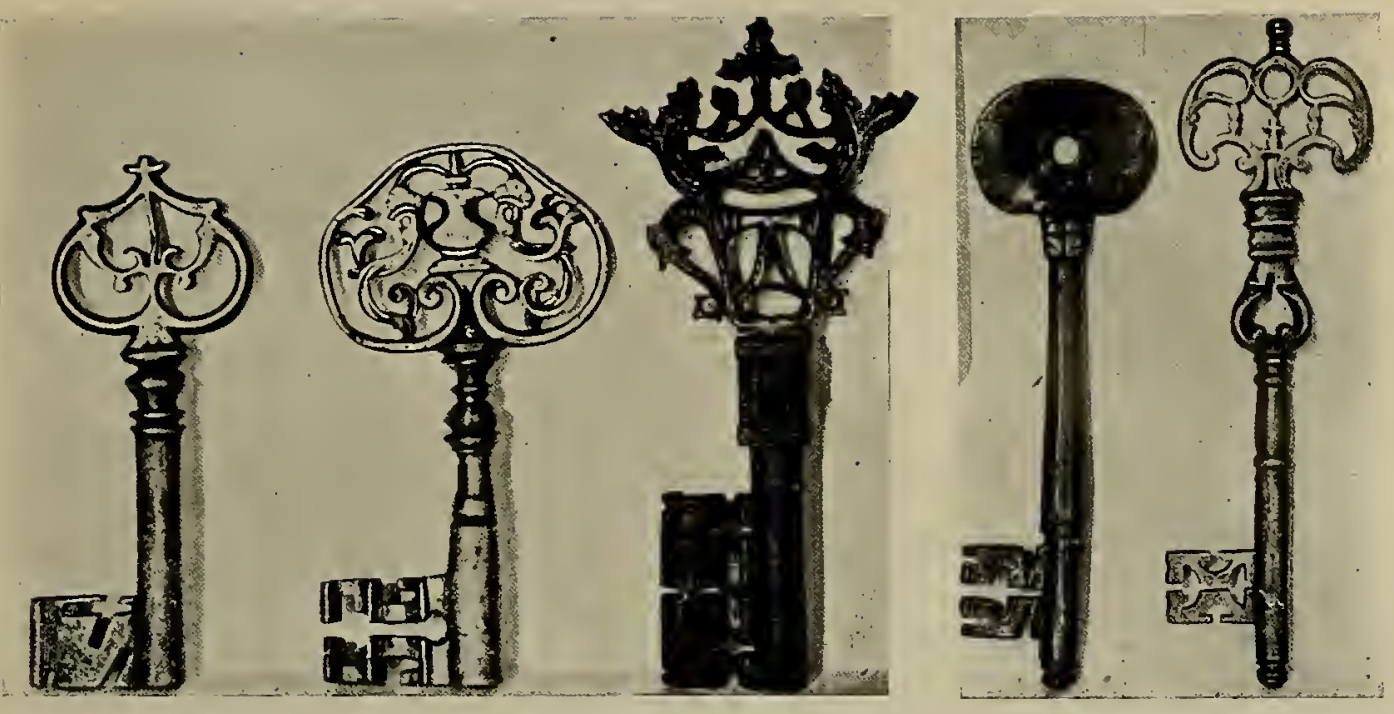

Figs. 79 a 83
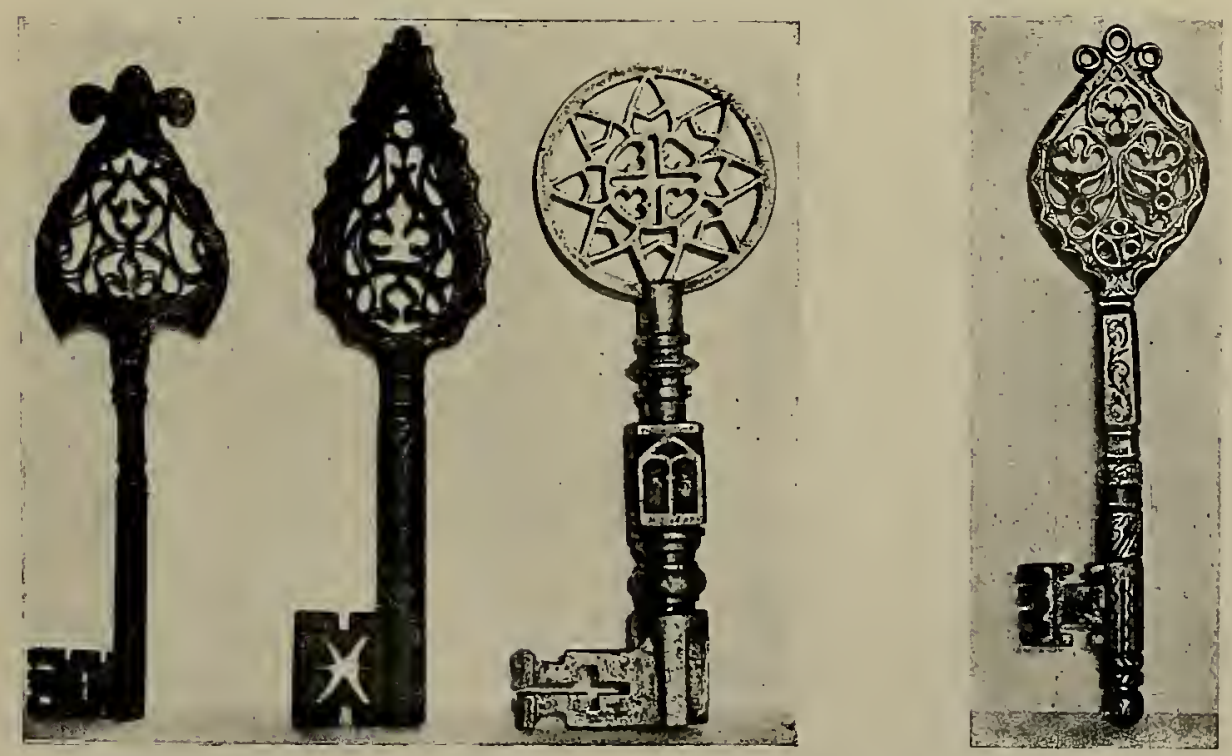

Figs. 84 a 87 

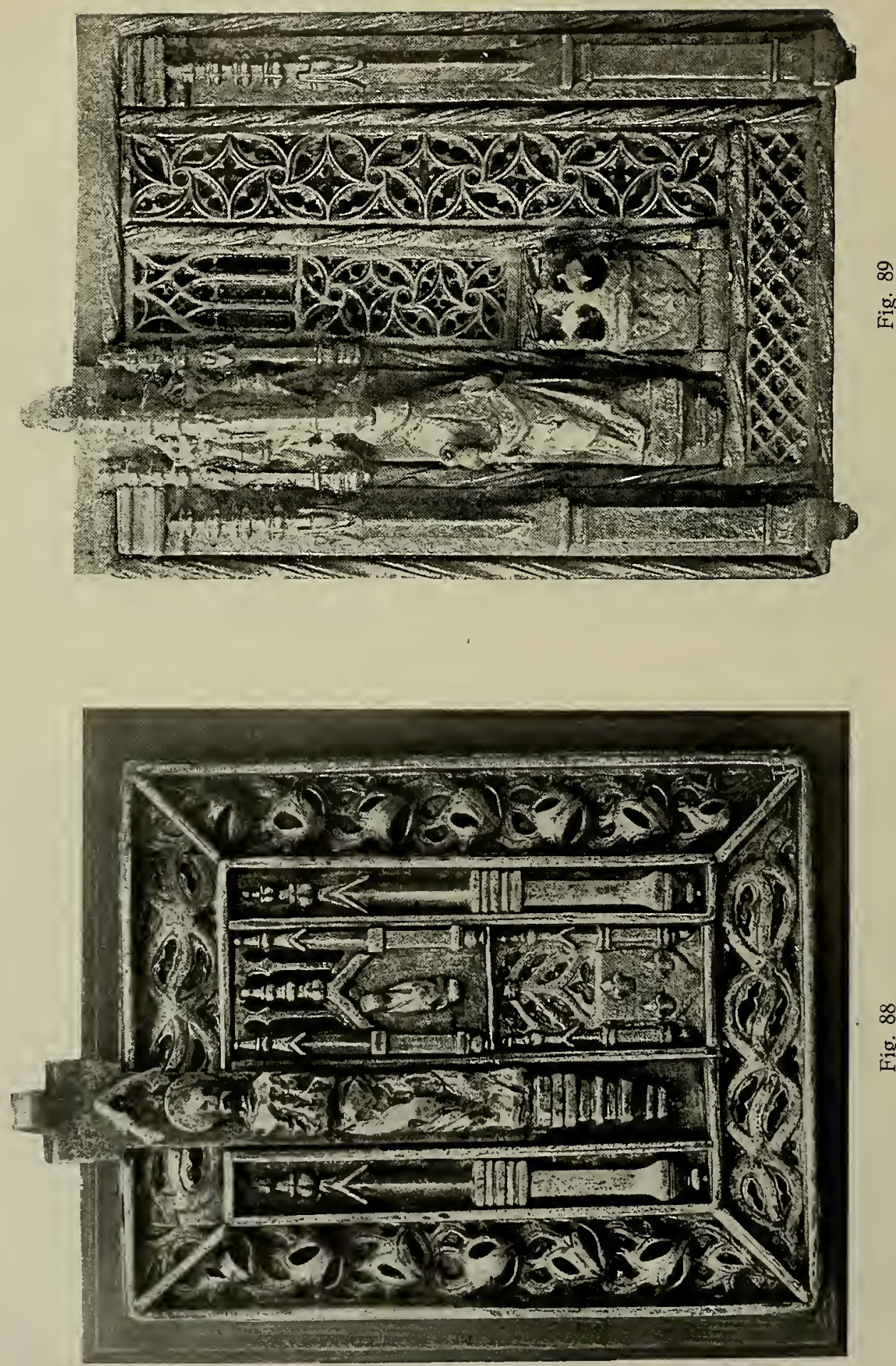

$\infty$

识 

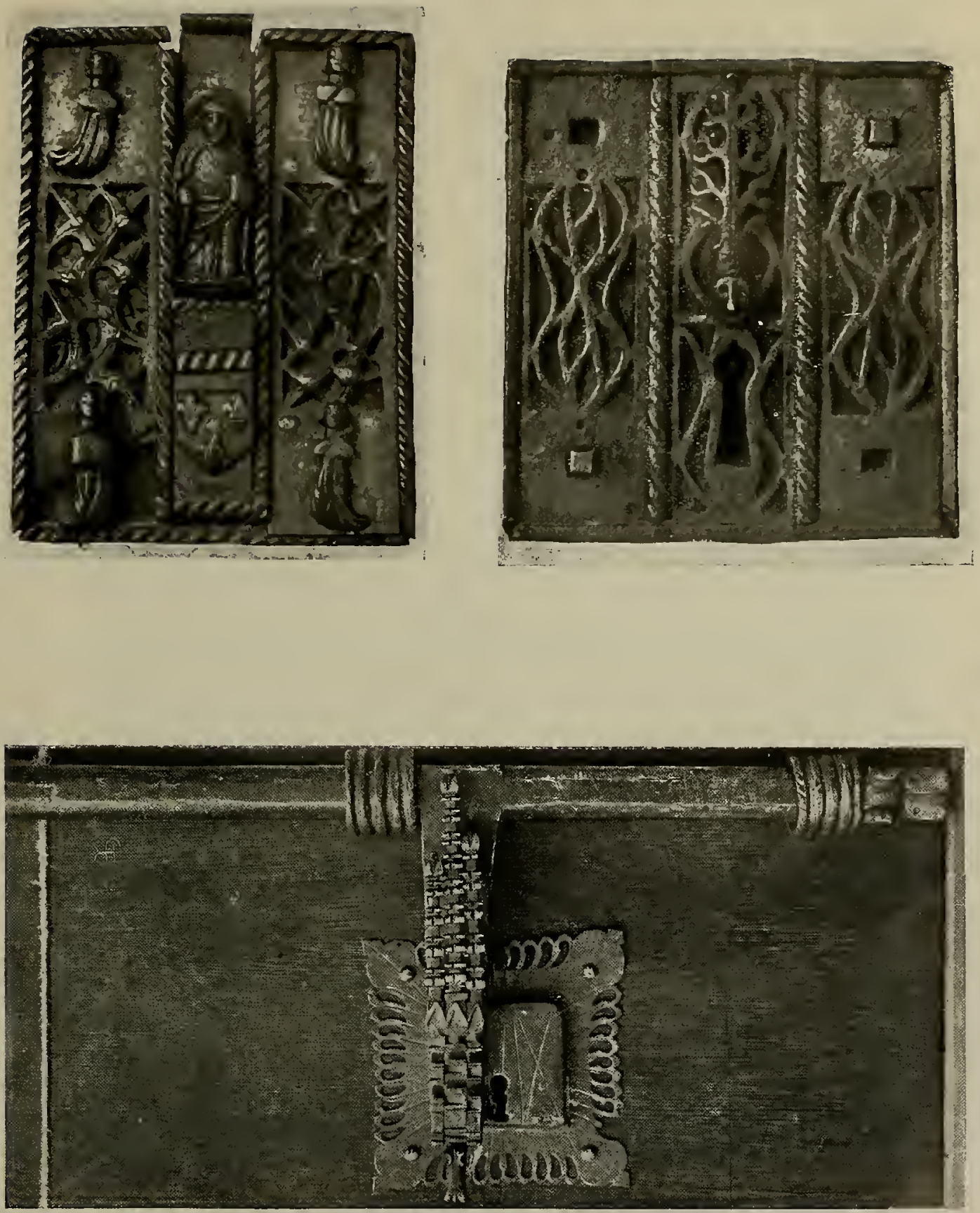

Figs. 90-91-92 


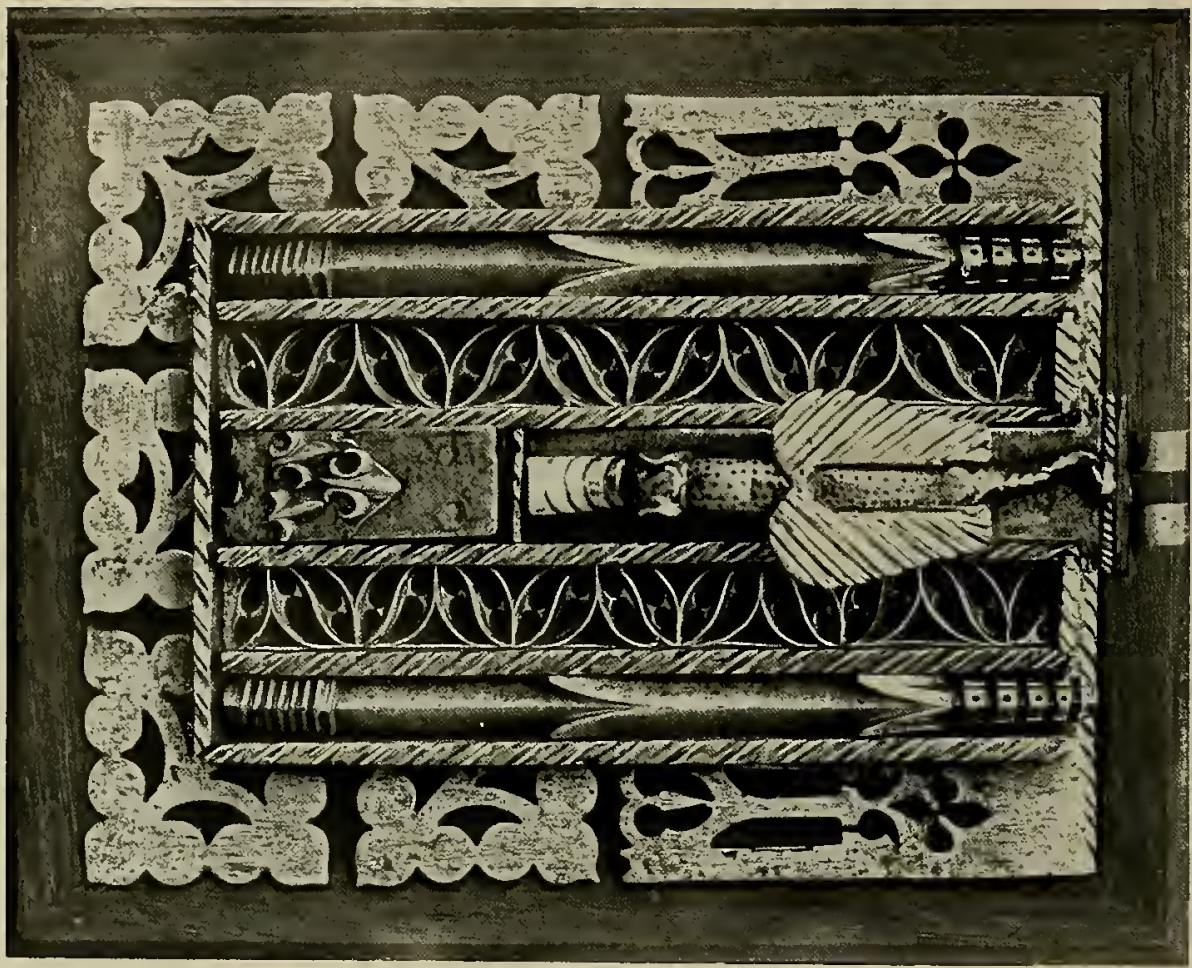

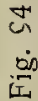

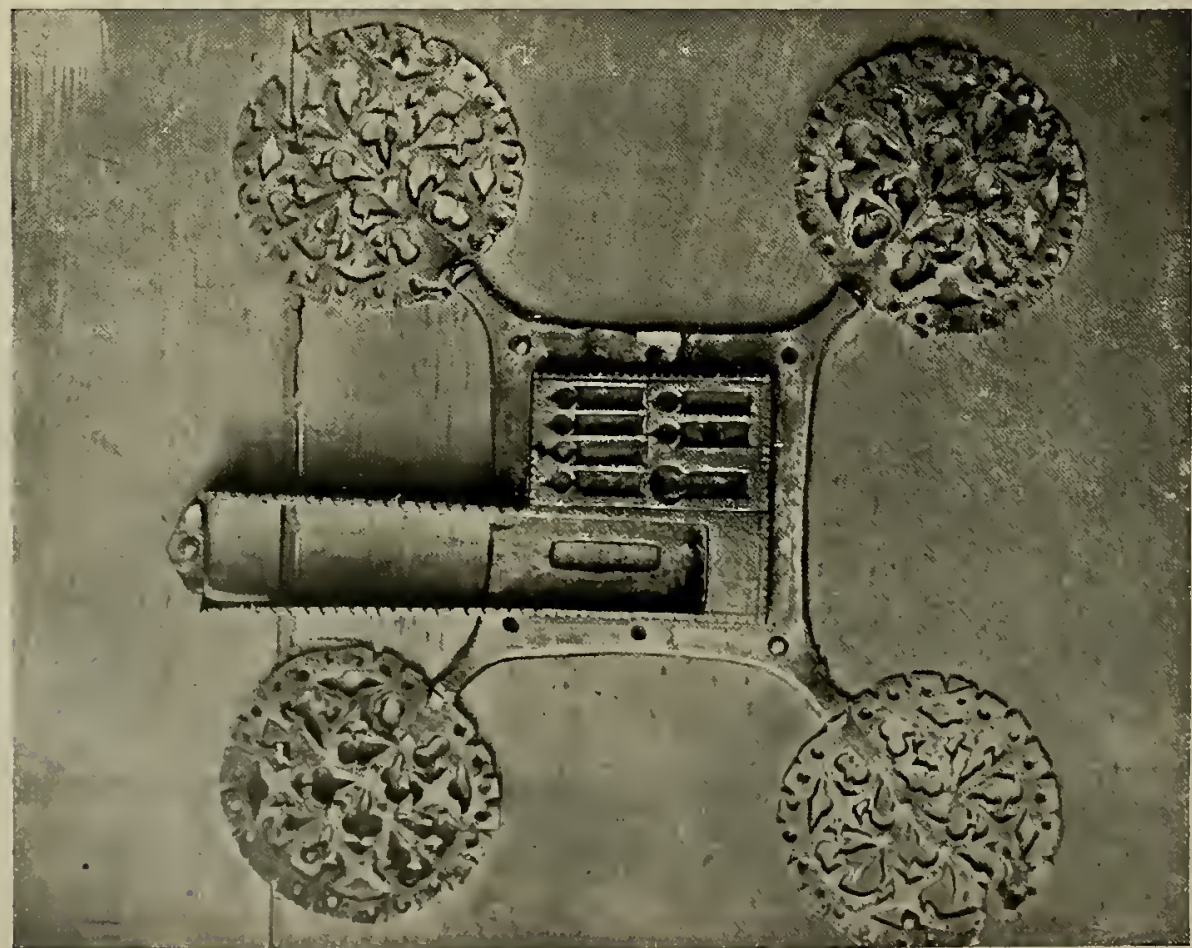






Fig. 95 

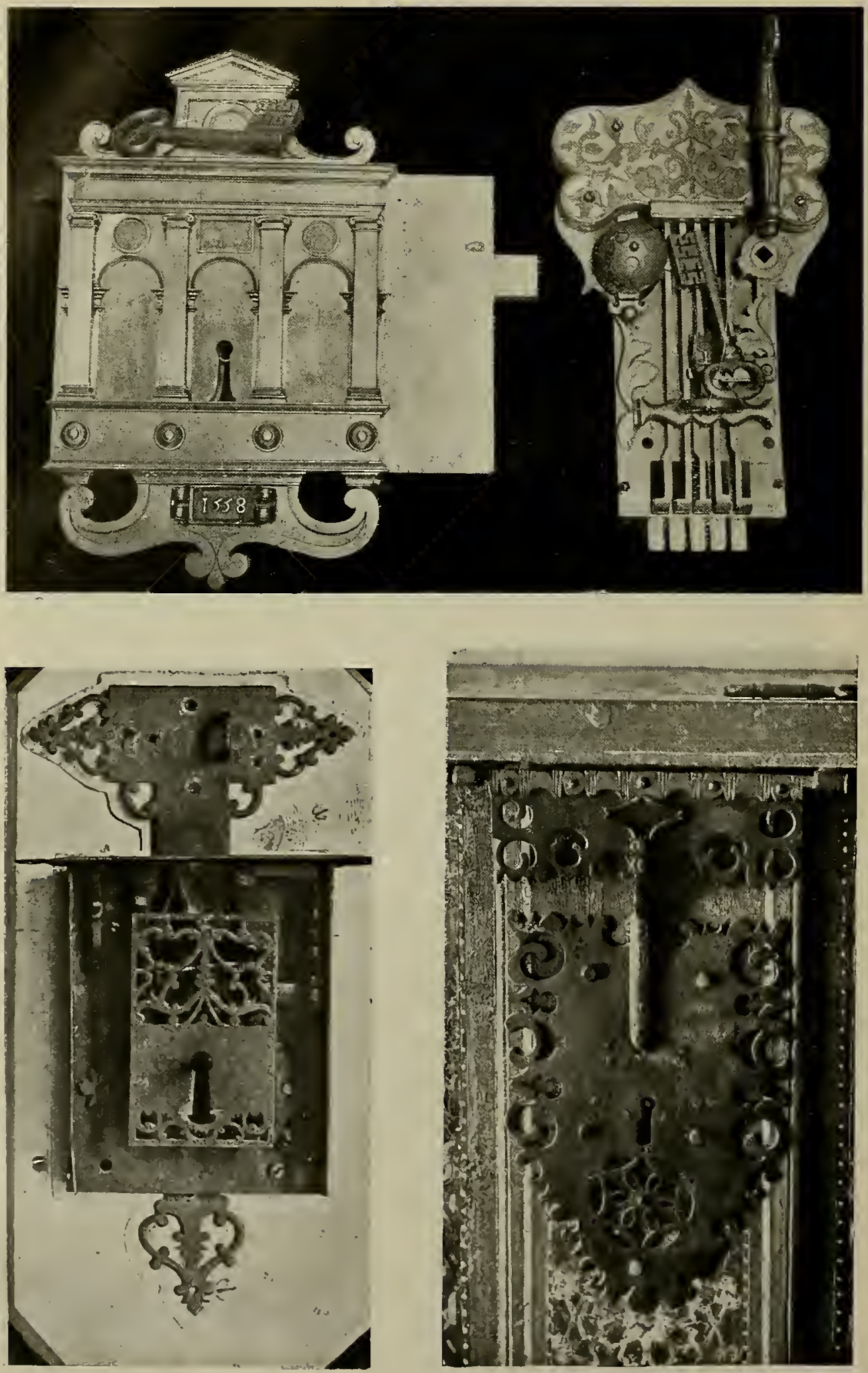

Figs. 96 a 99 



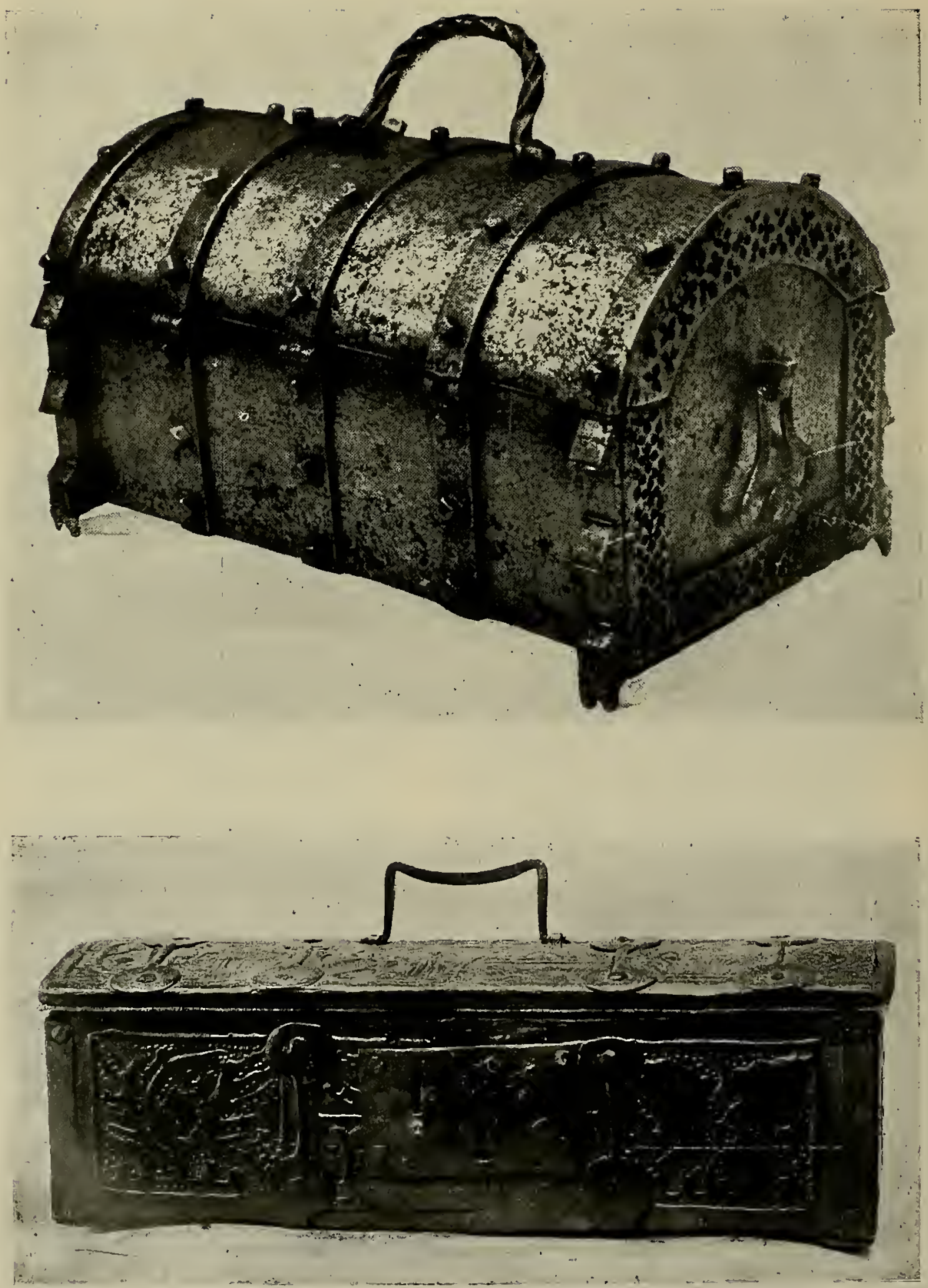

Figs. 103-104 








Figs. 106-107 


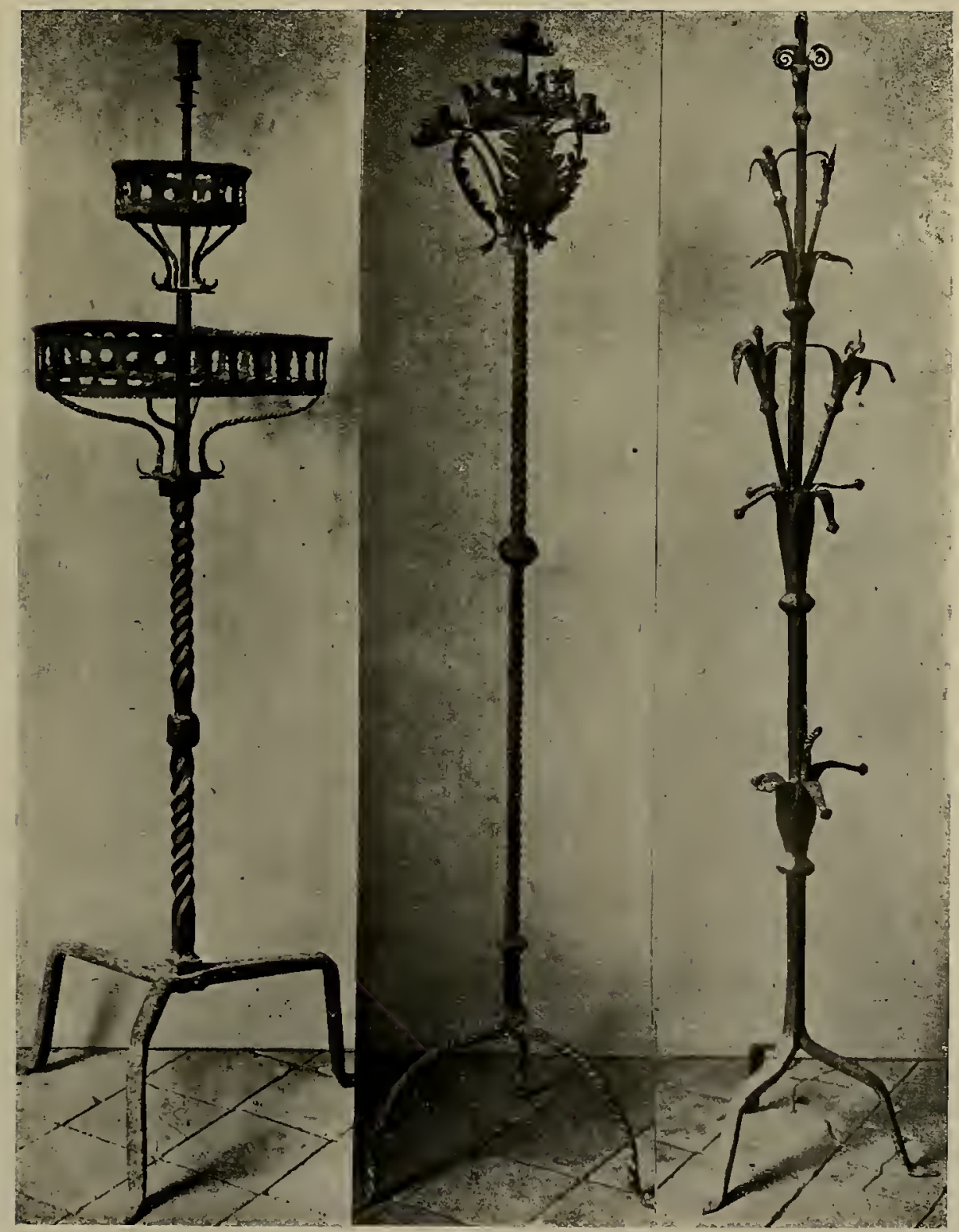

Fig. 108

Fig. 109

Fig. 110 


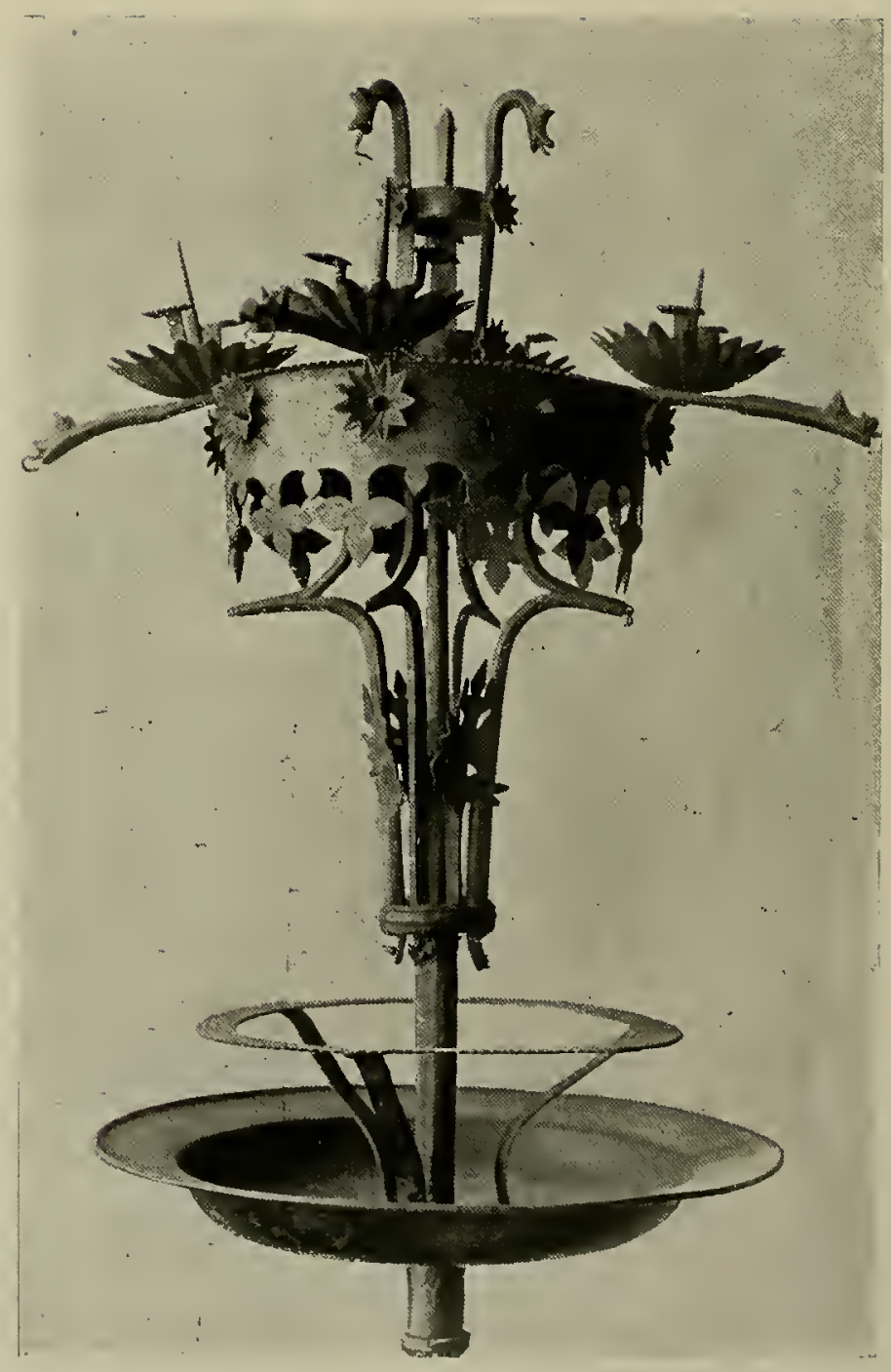

Fig. 111 




Fig. 112

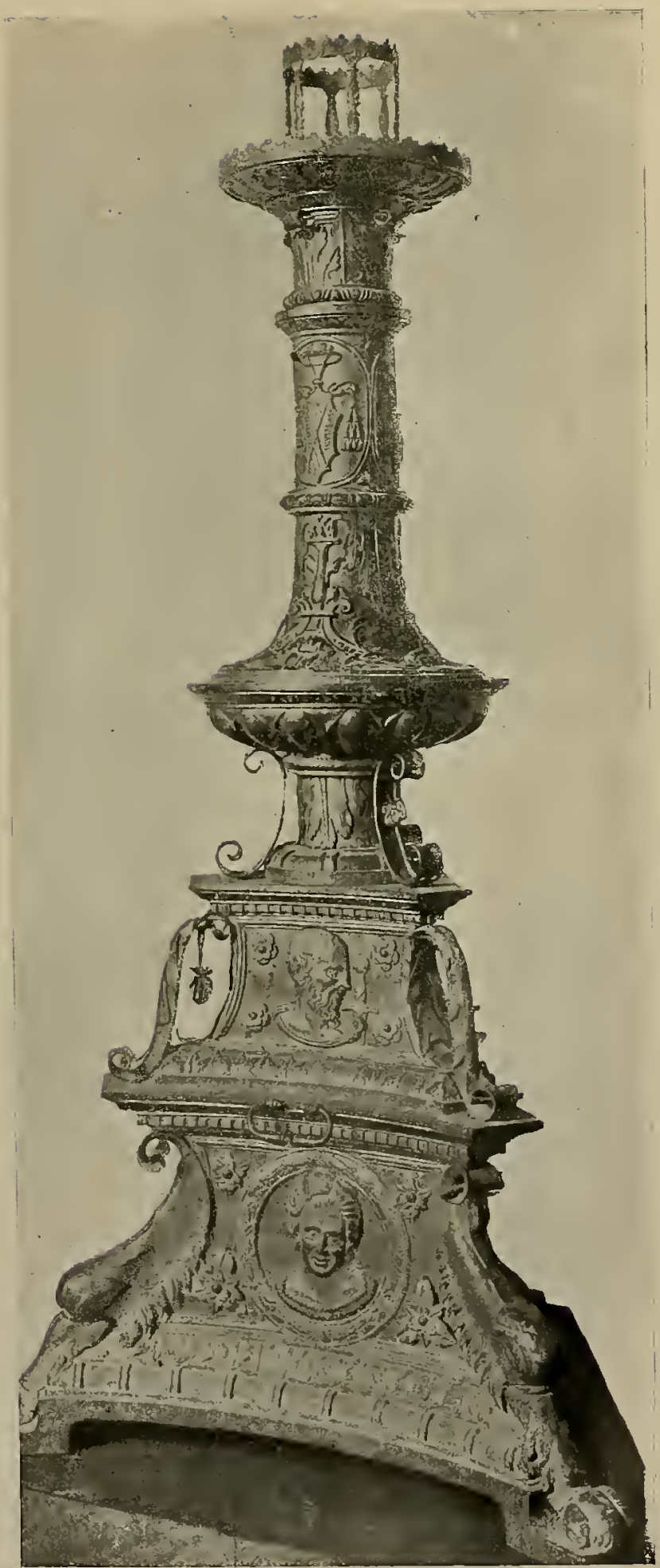

Fig, 113 

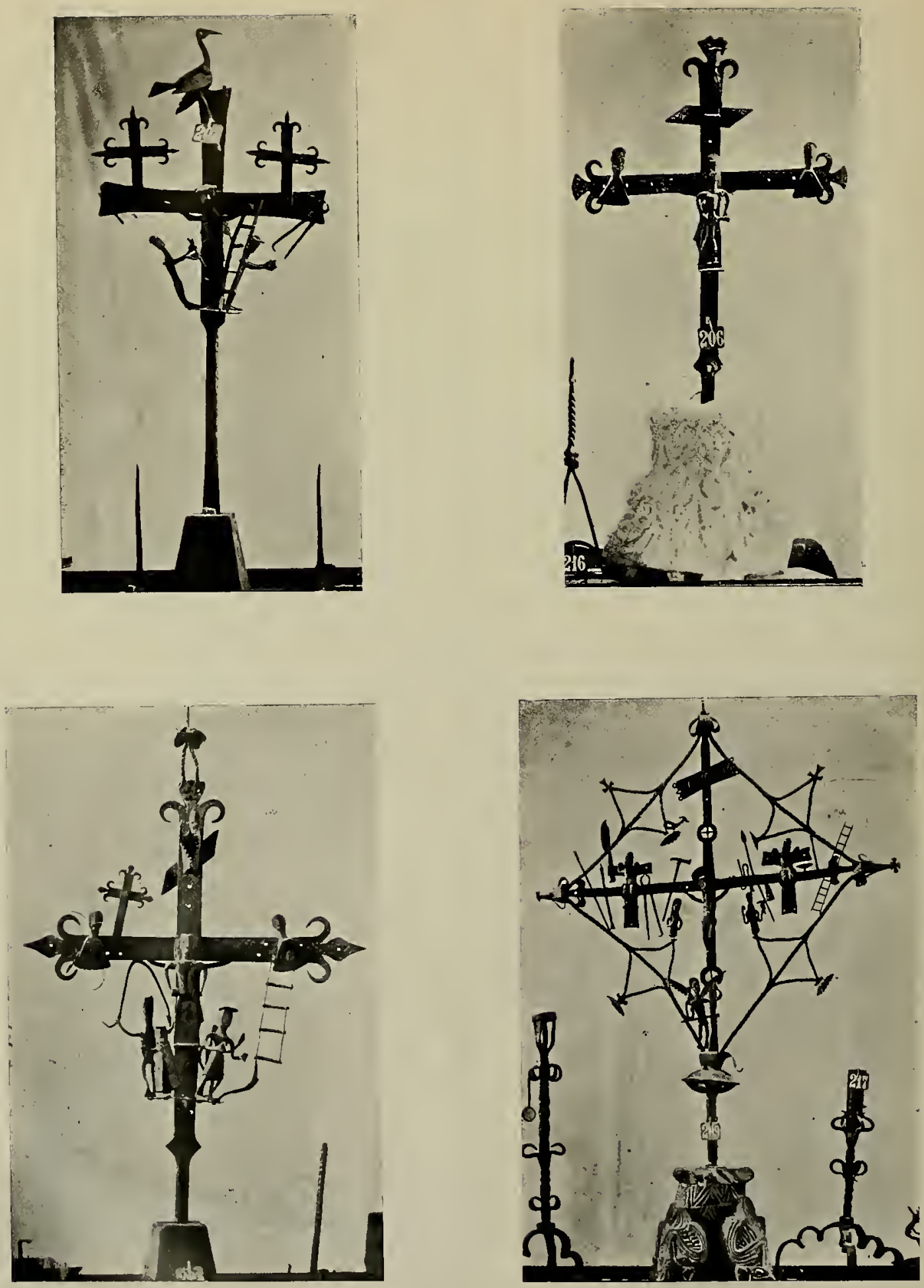

Figs. 114 a 117 


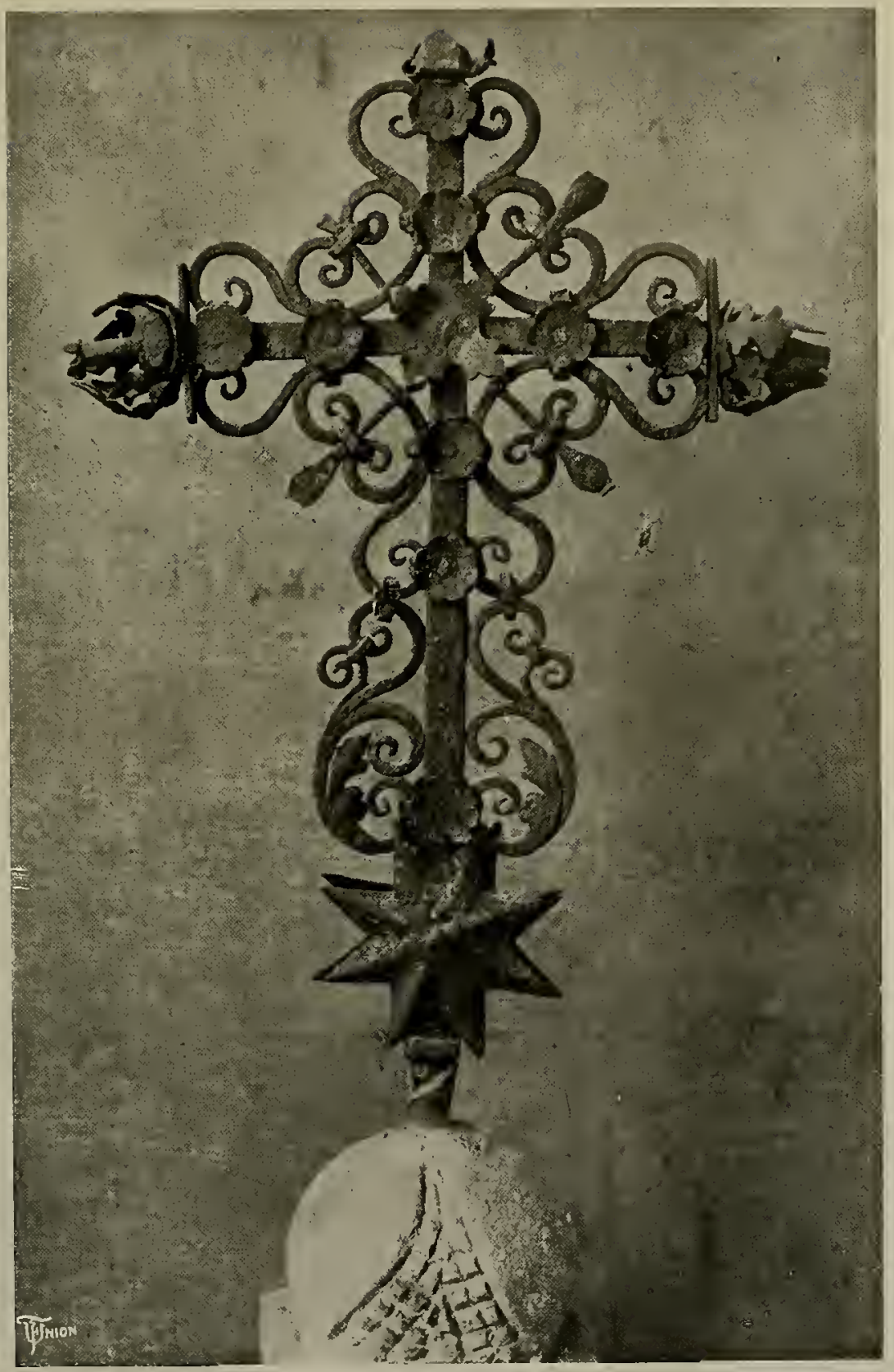

Fig. 118 

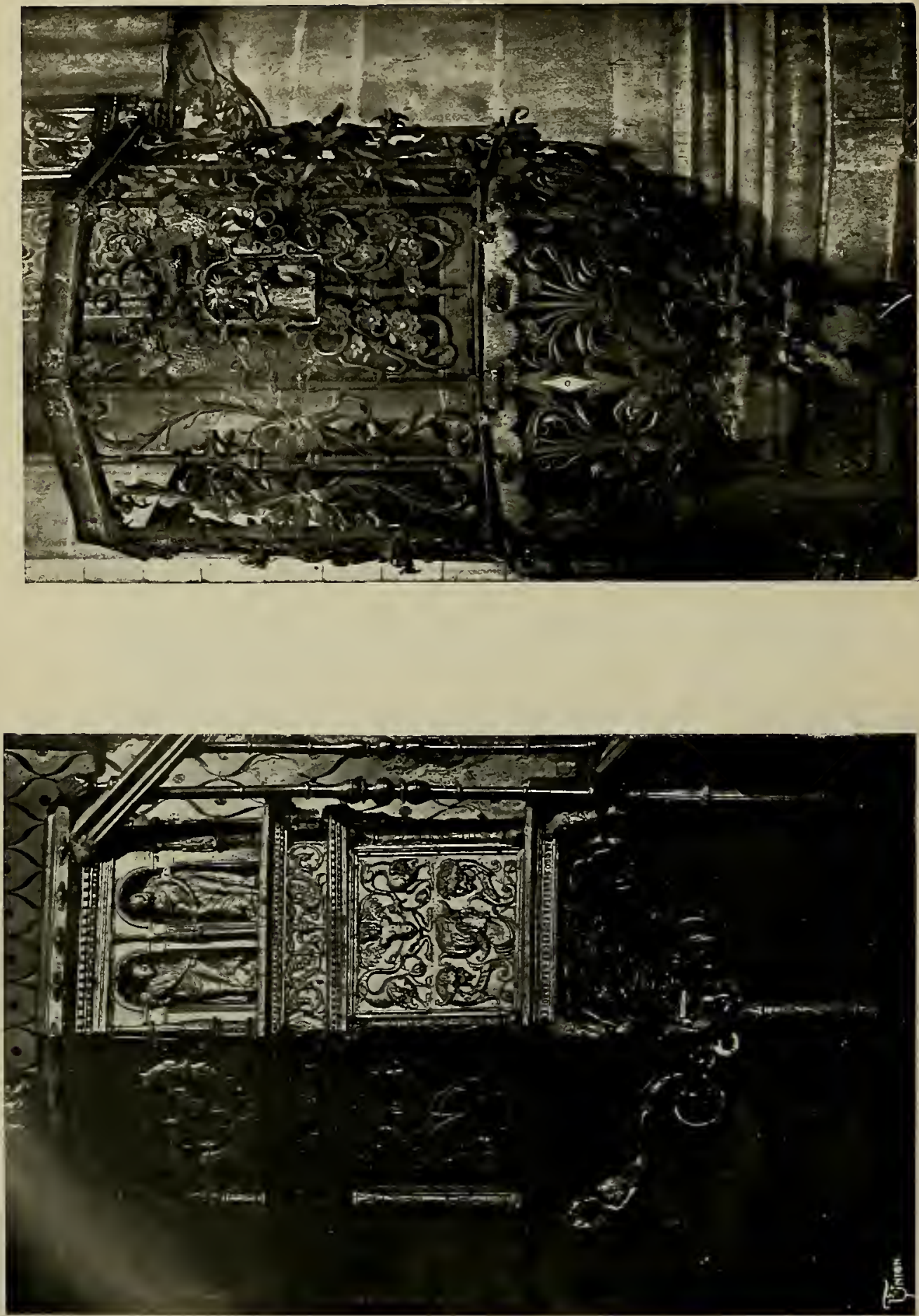



$\stackrel{\overrightarrow{3}}{\overrightarrow{3}}$ 


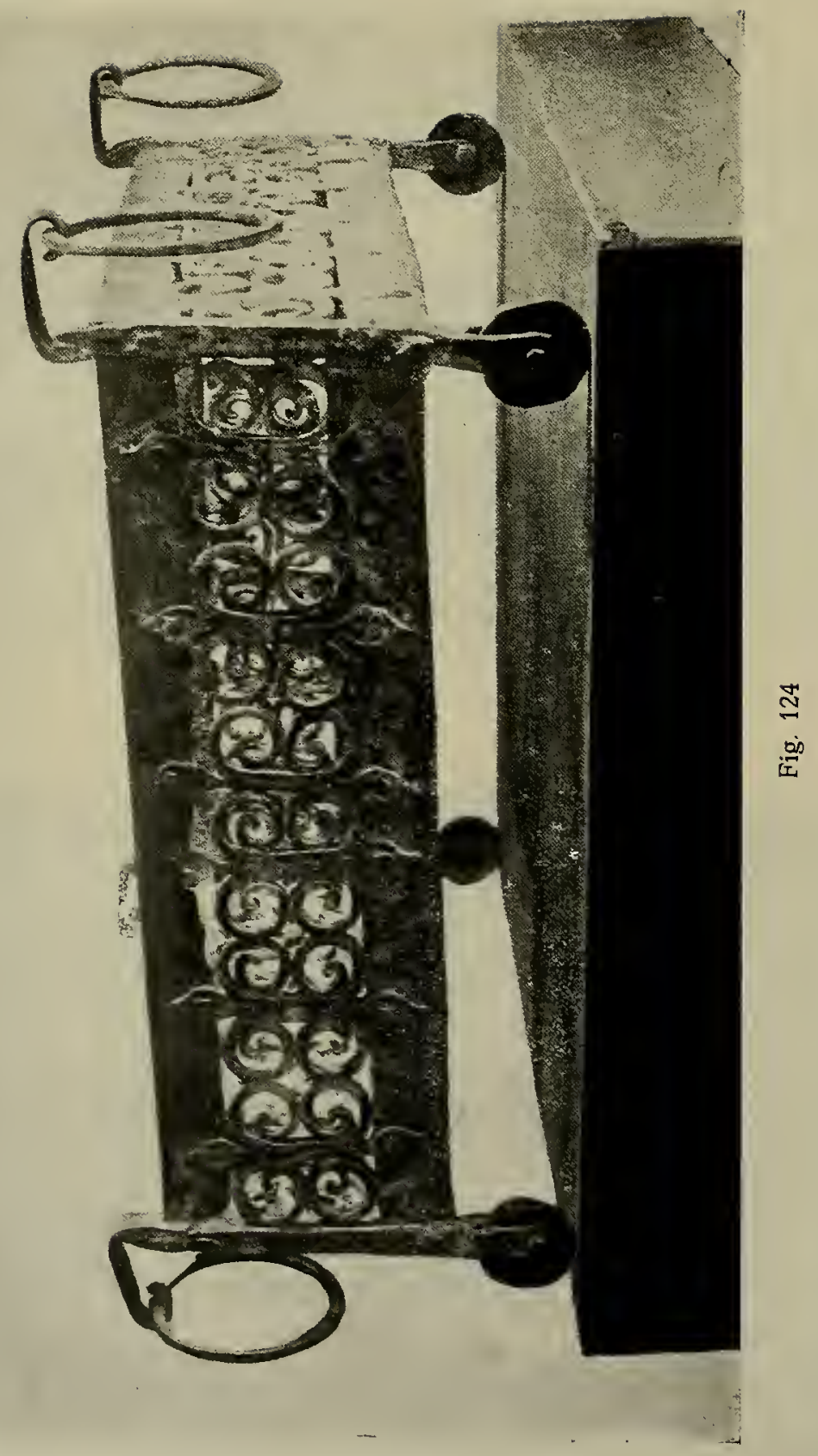




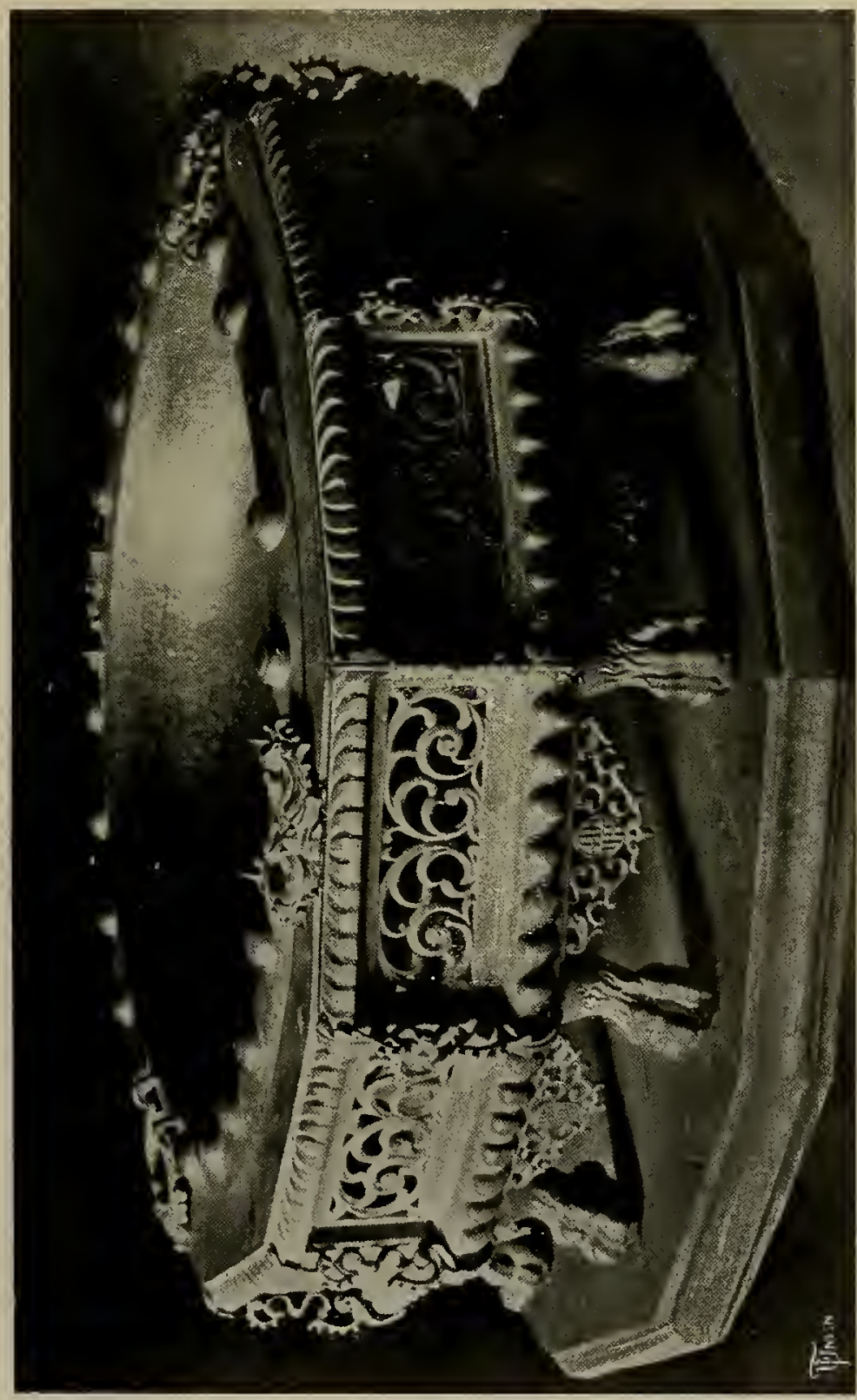

$\stackrel{ }{3}$

离 


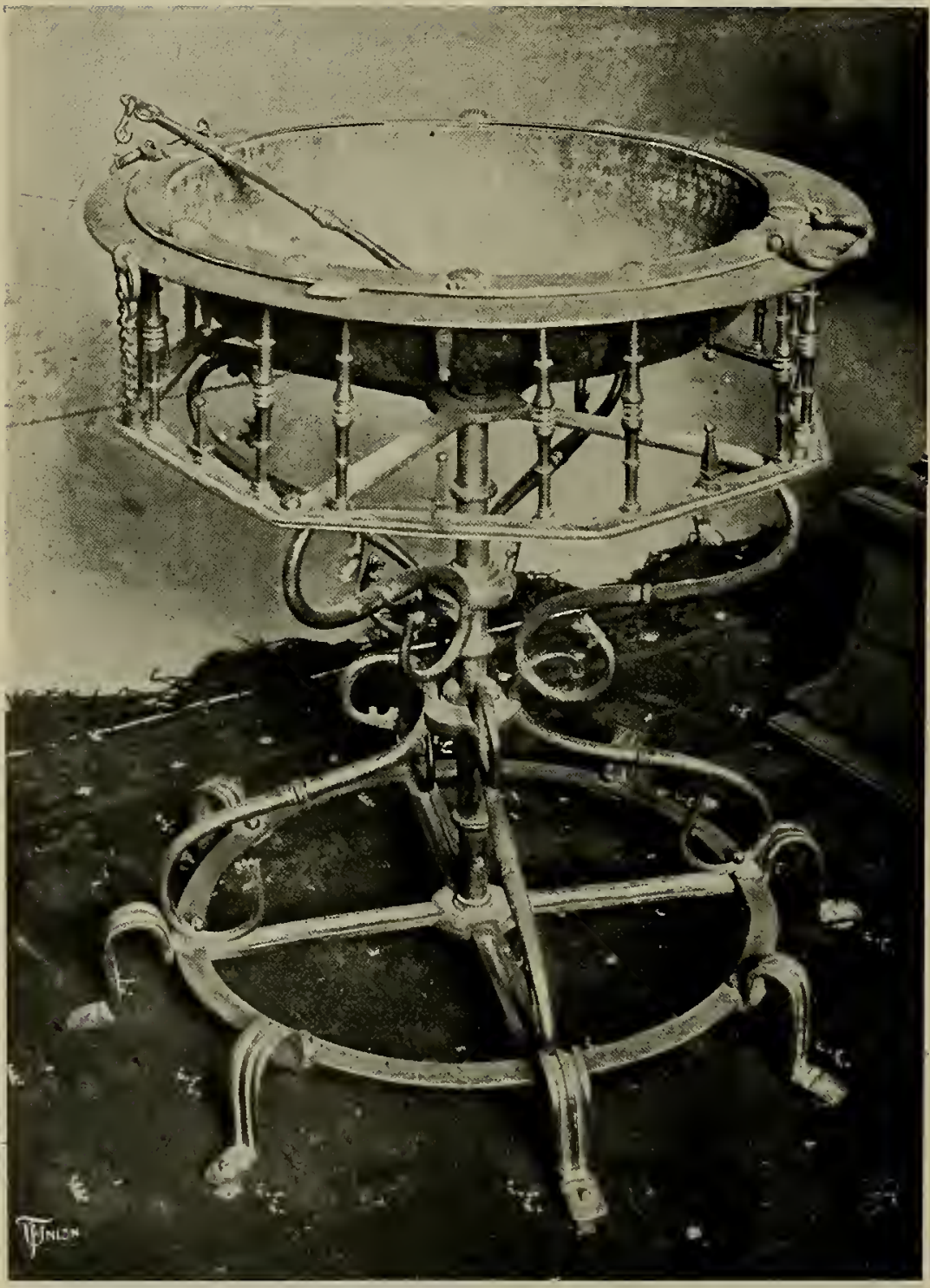

Fig. 126 


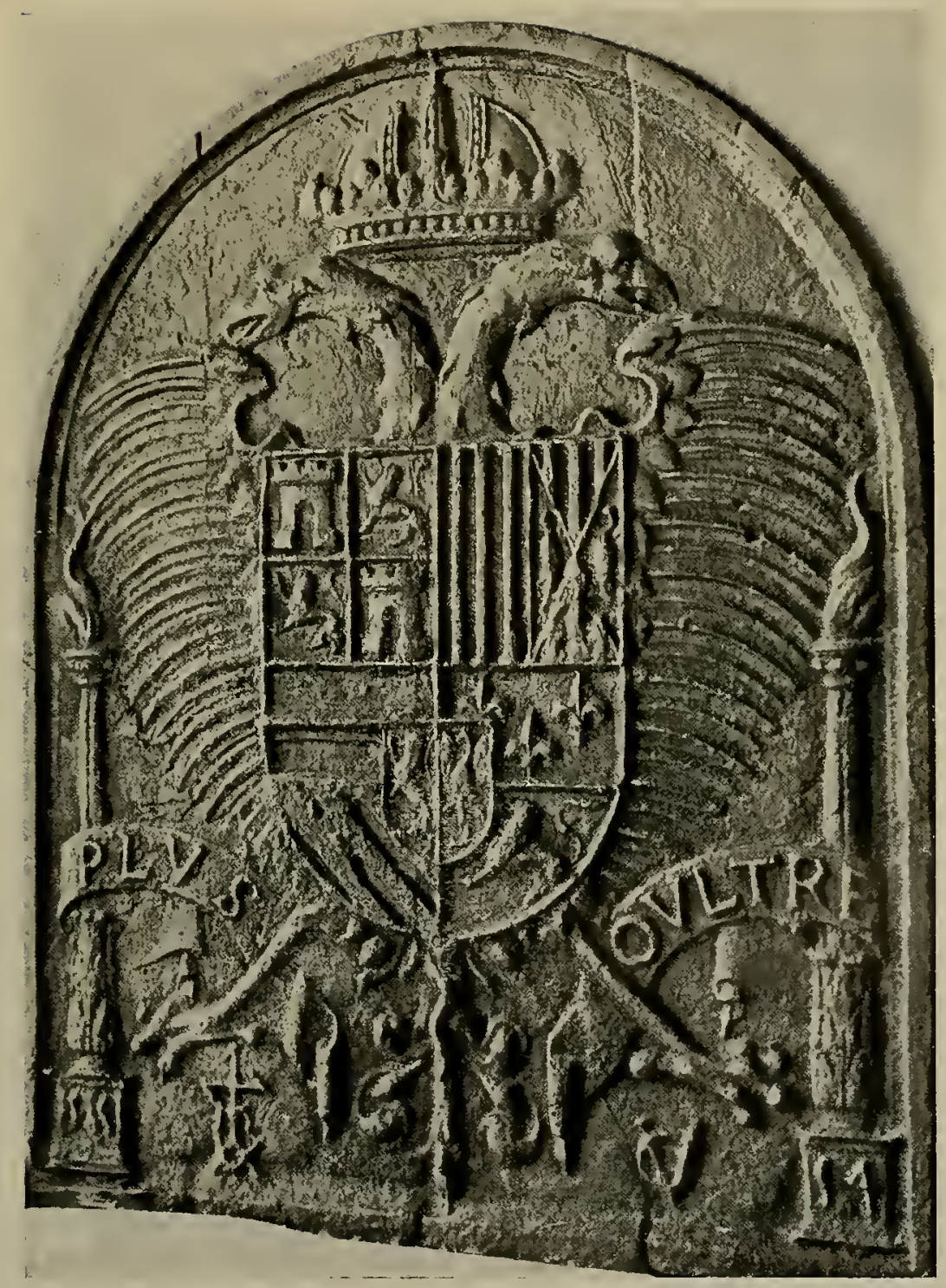

Fig. 127 


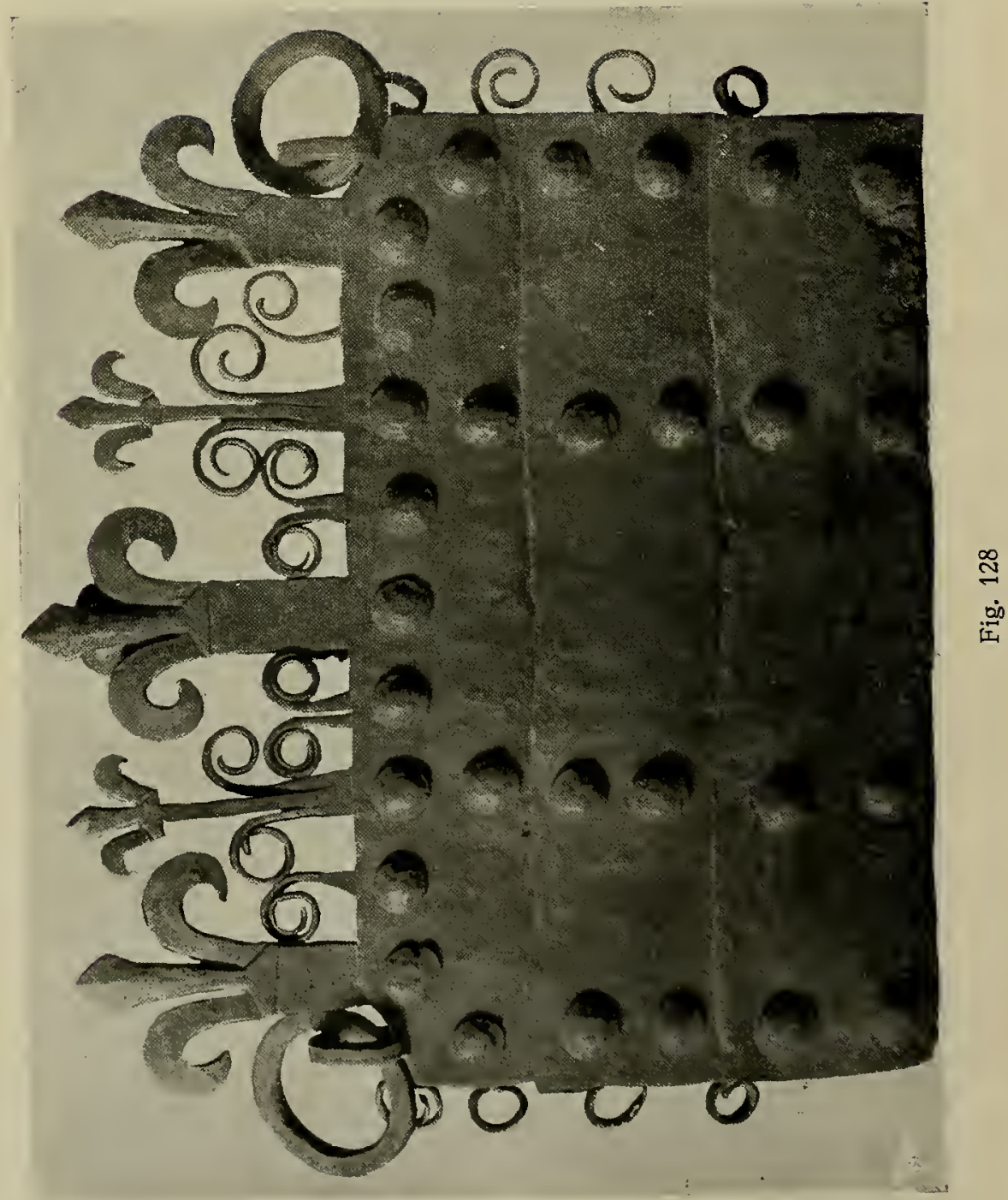



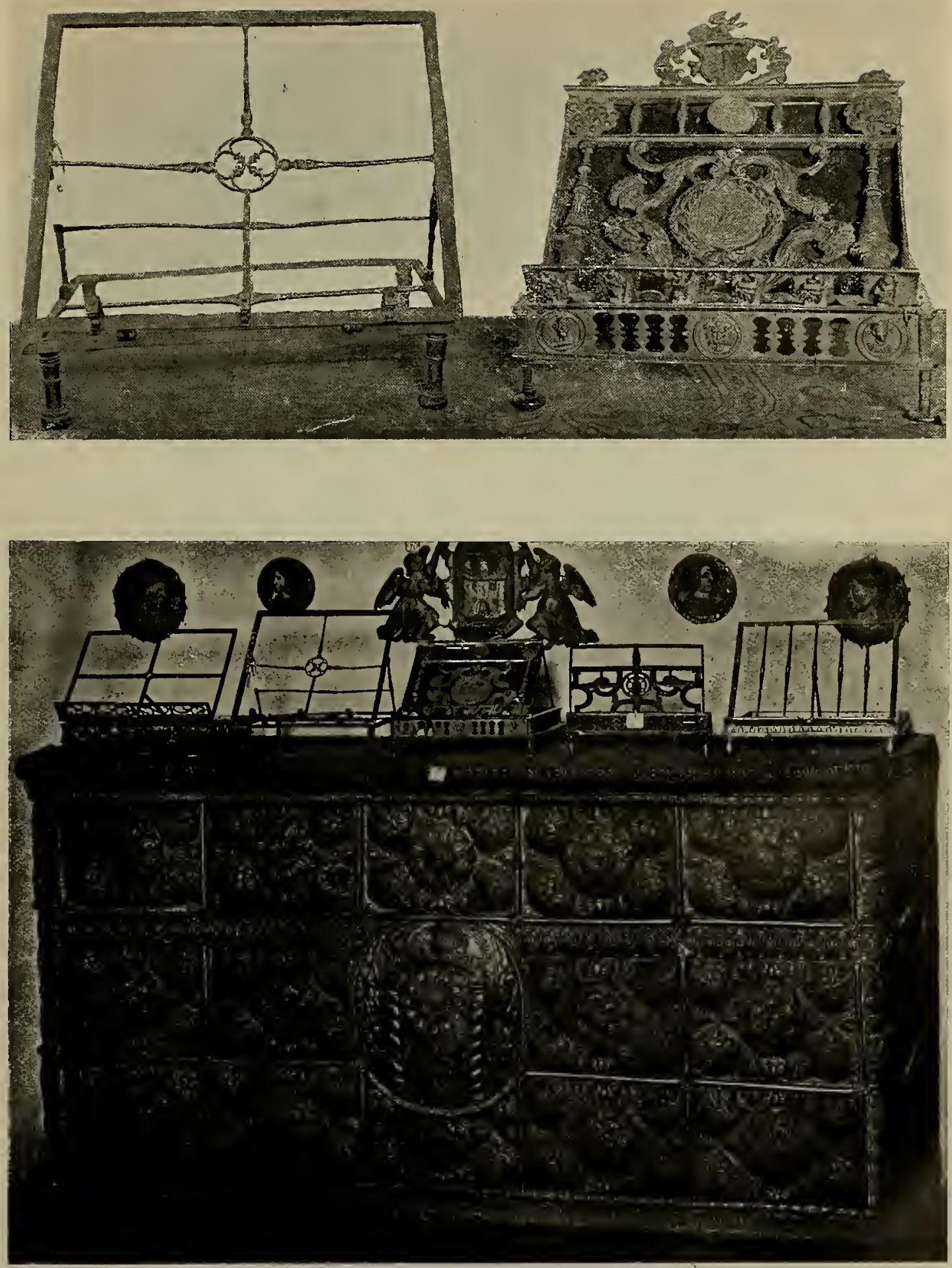

Figs. 129-130-131 


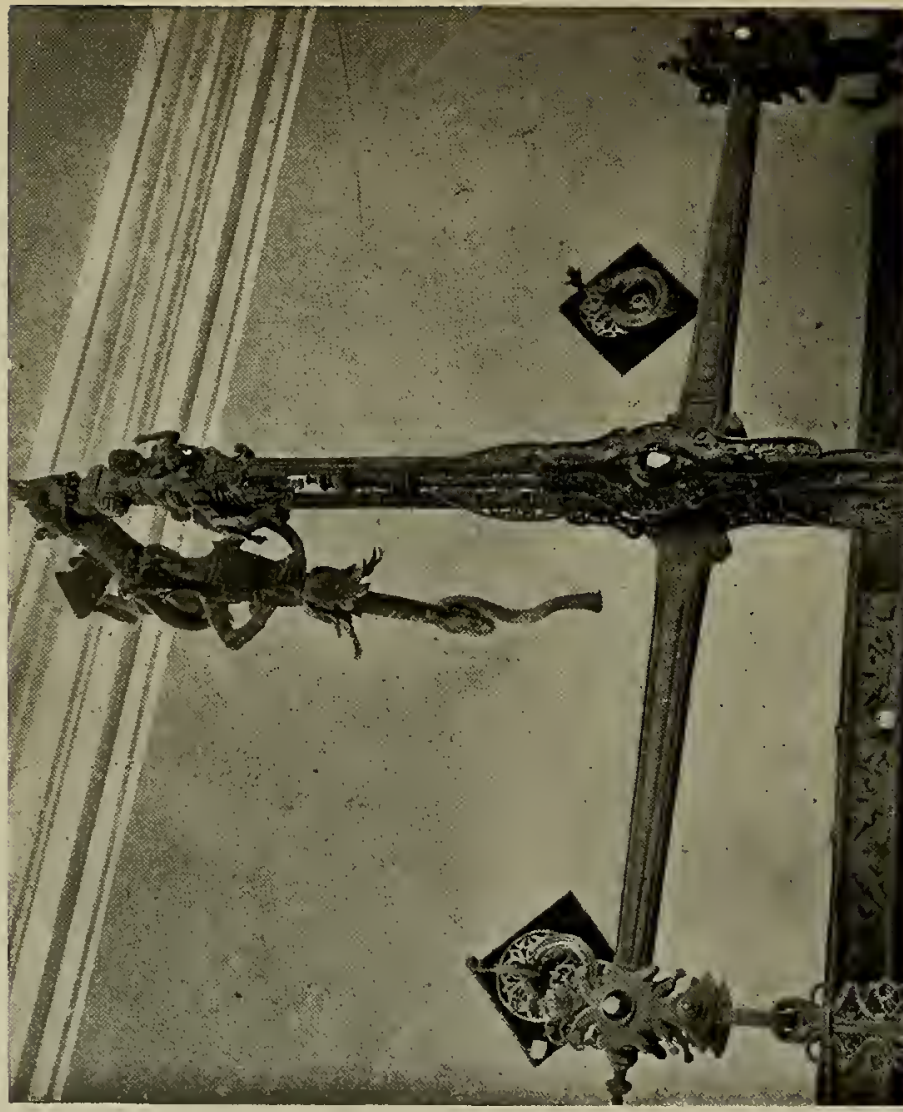

$\stackrel{m}{2}$

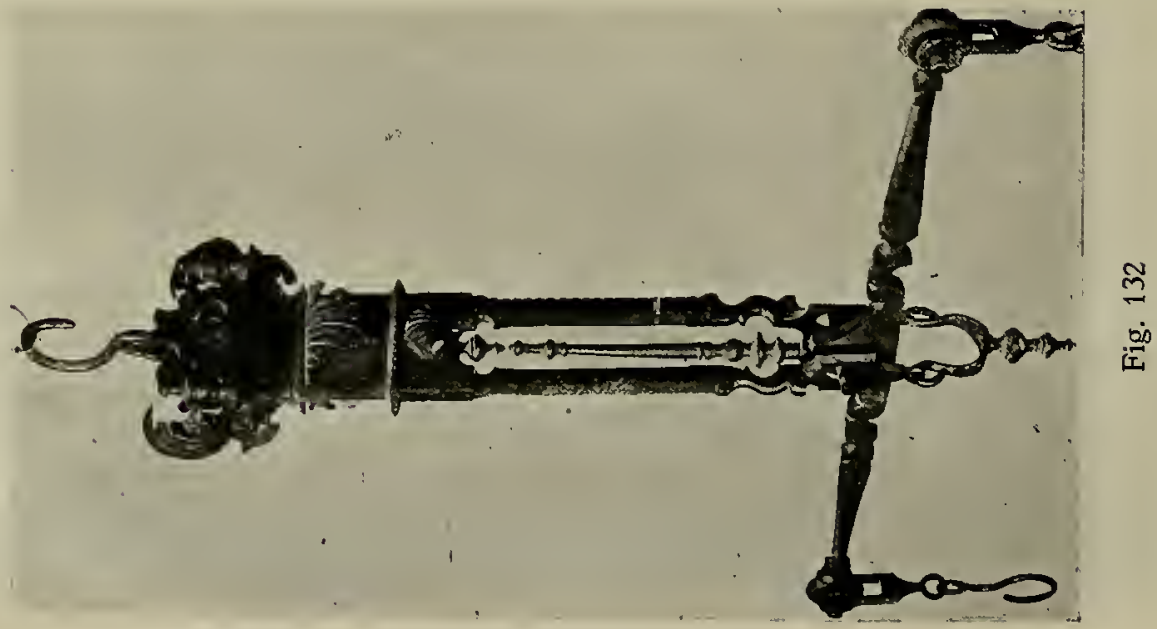




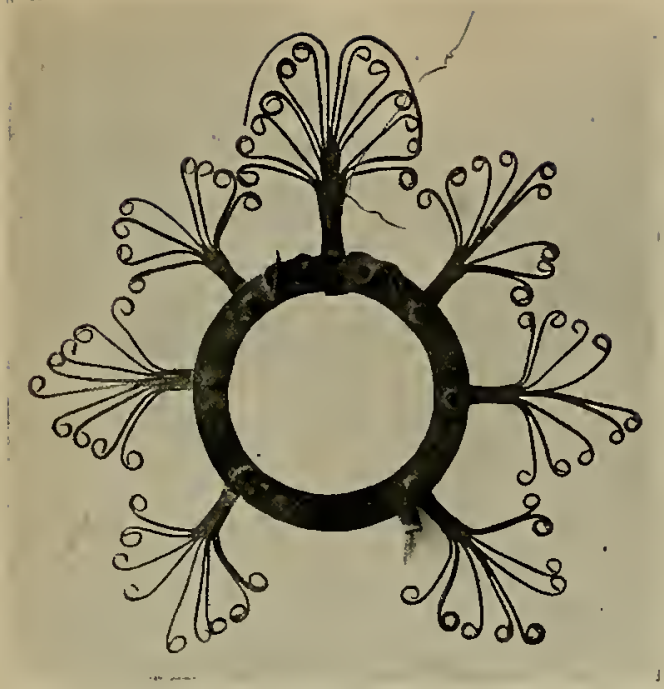

Fig. 134

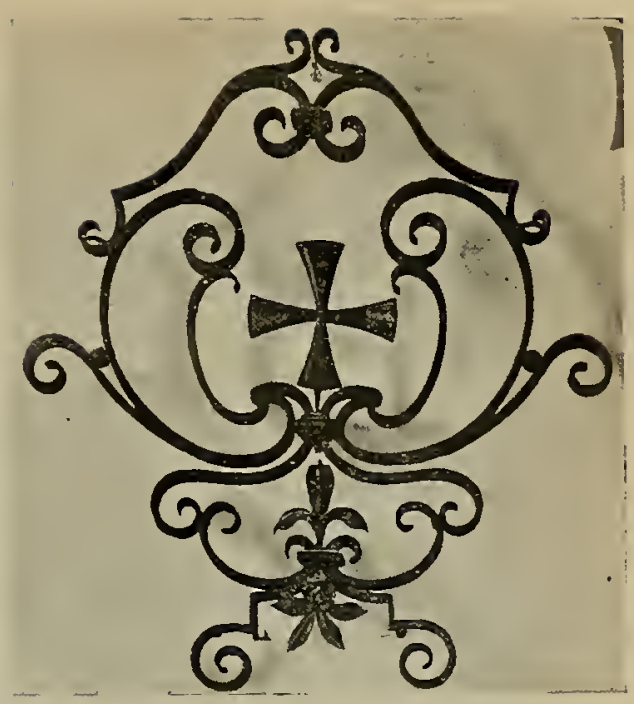

Fig. 135

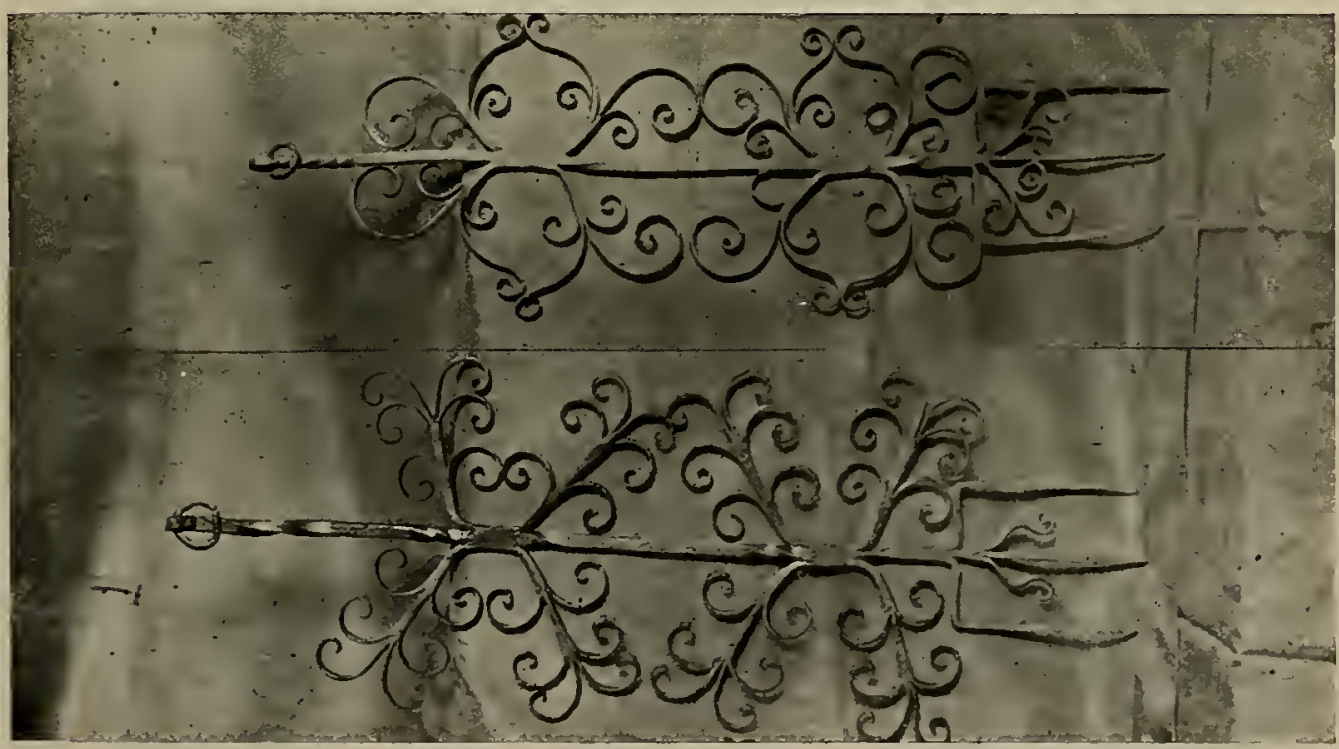

Fig. 136 




Fig. 137 

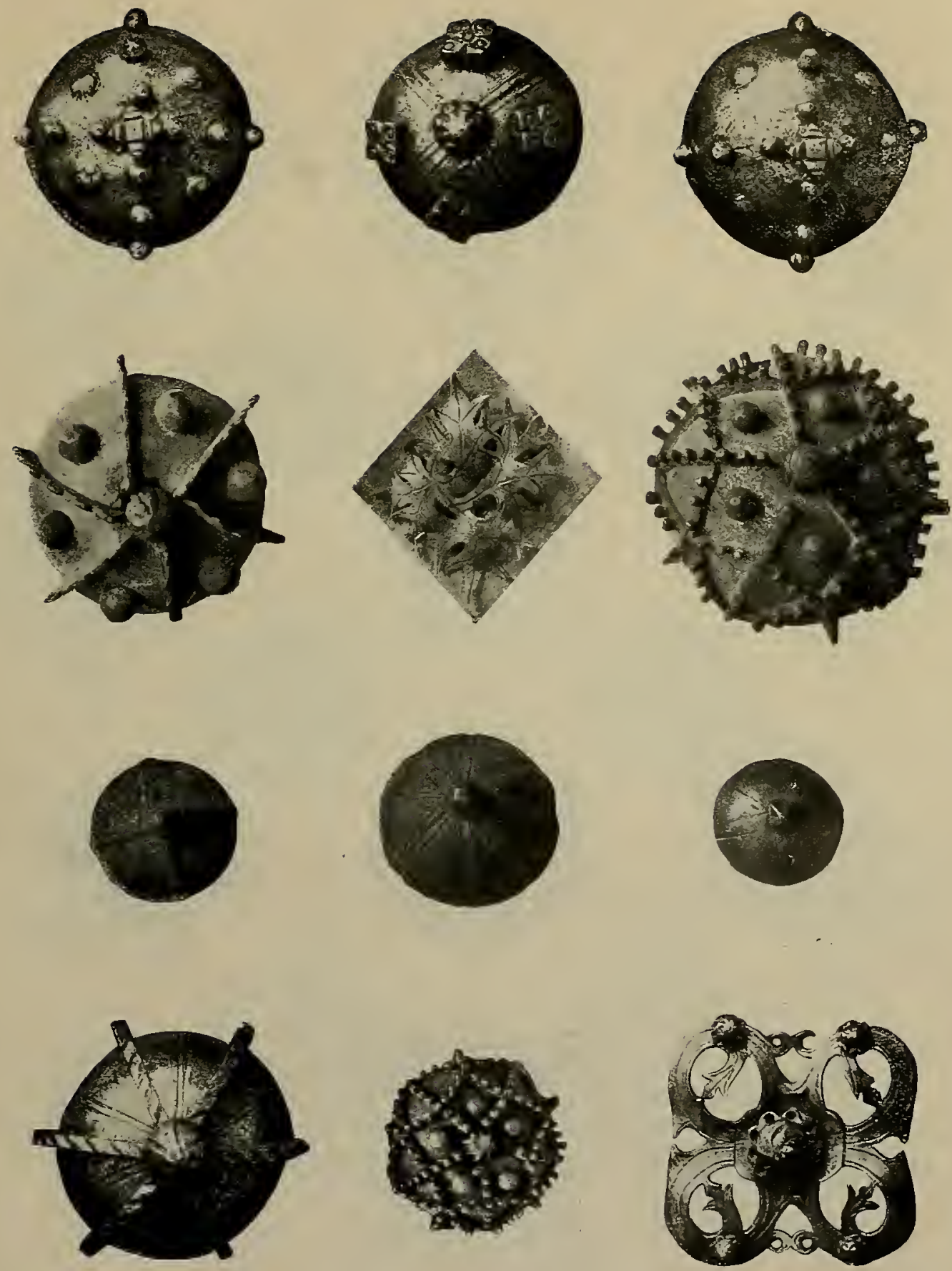

Figs. 138 a 149 

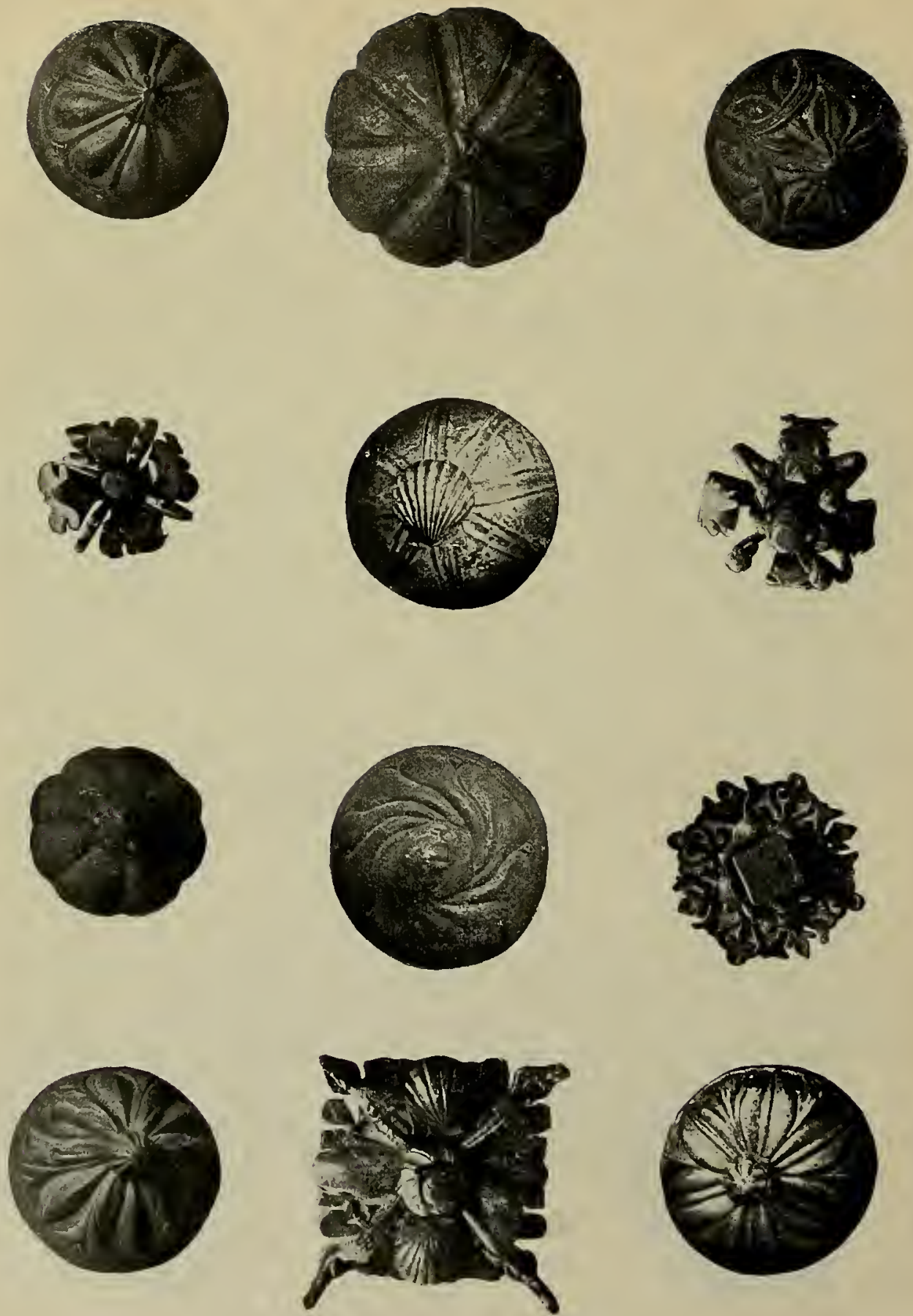

Figs. $=150$ a 161 


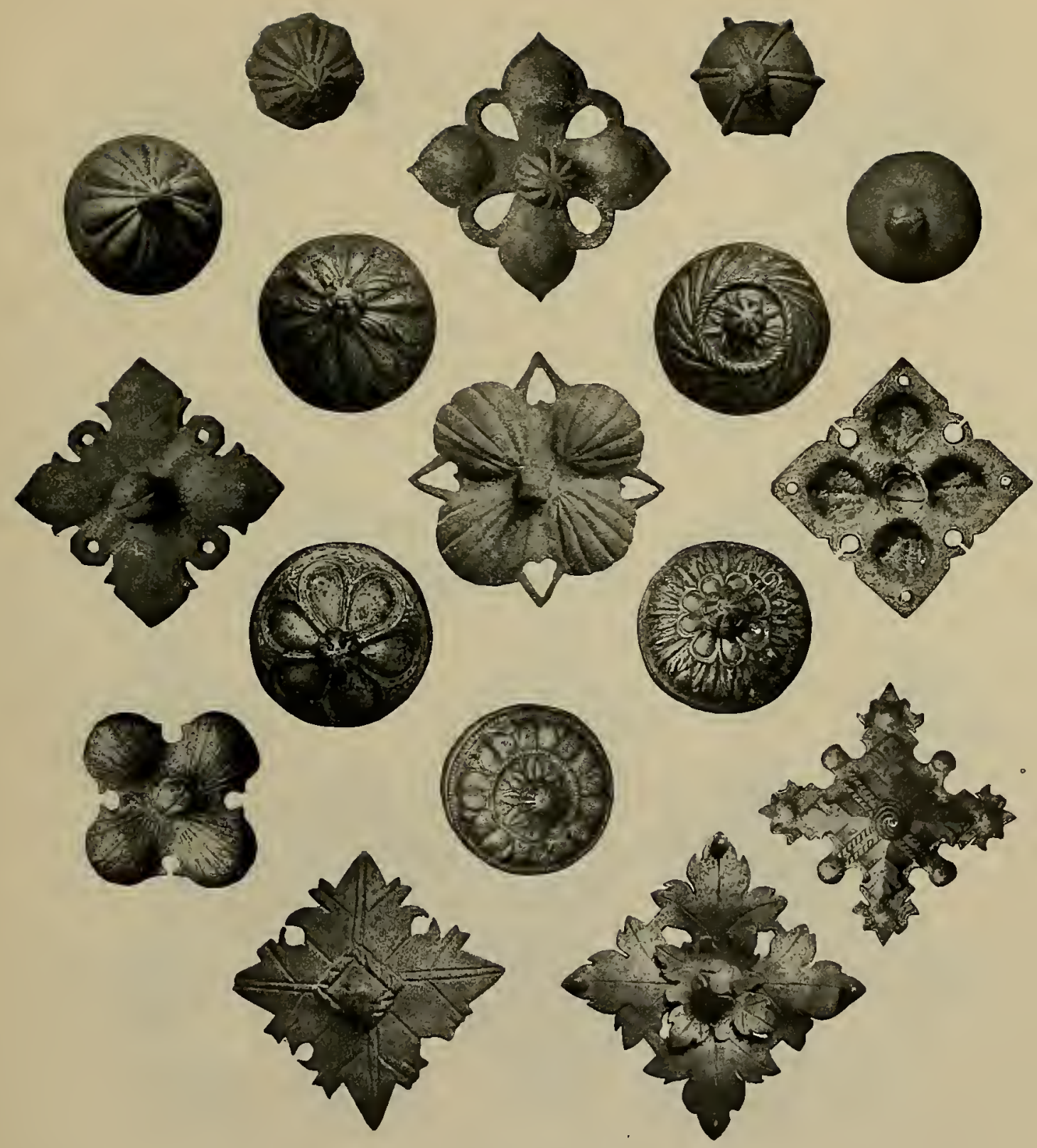

Figs. 162 a 178 


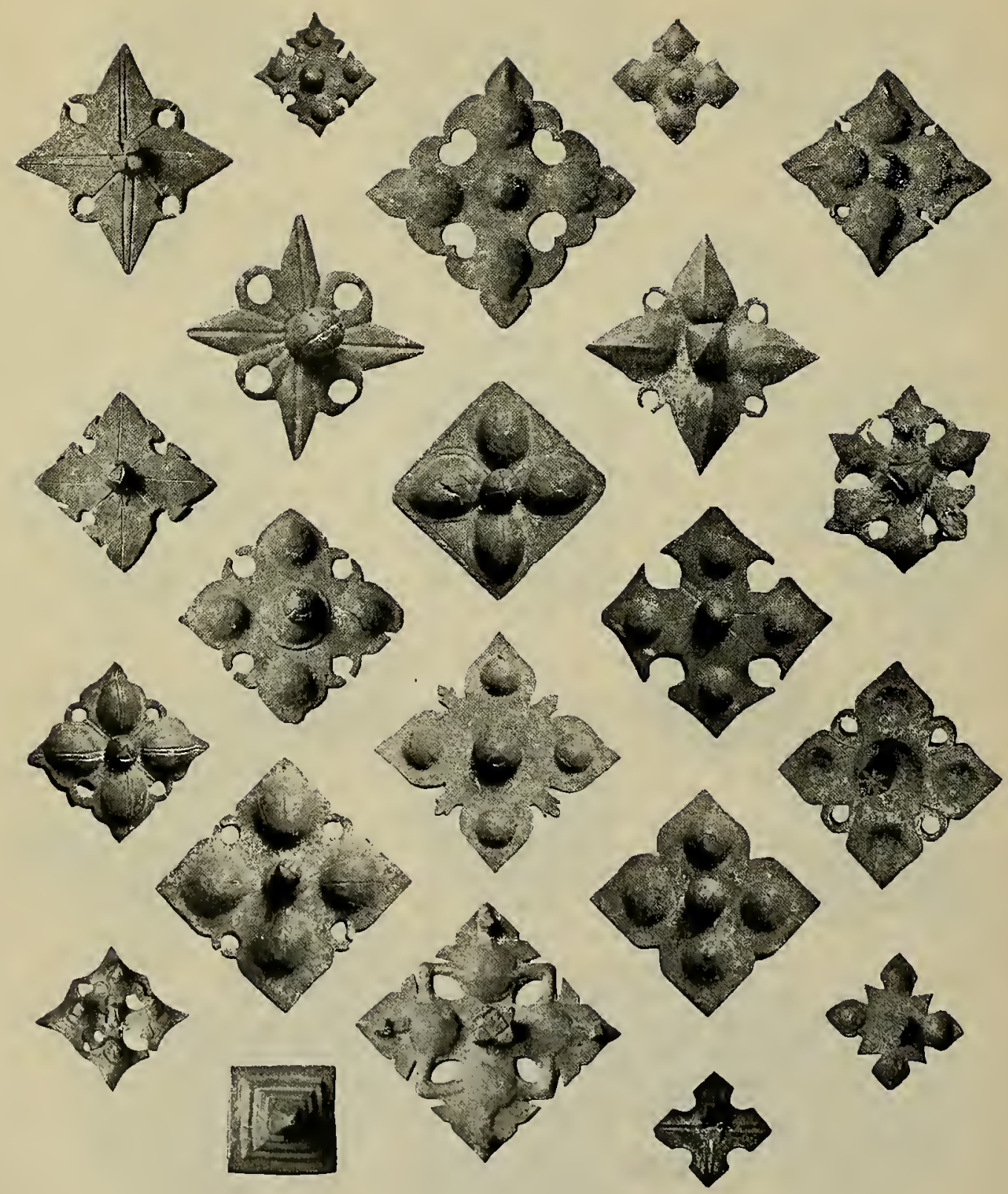

Figs. 179 a 200 


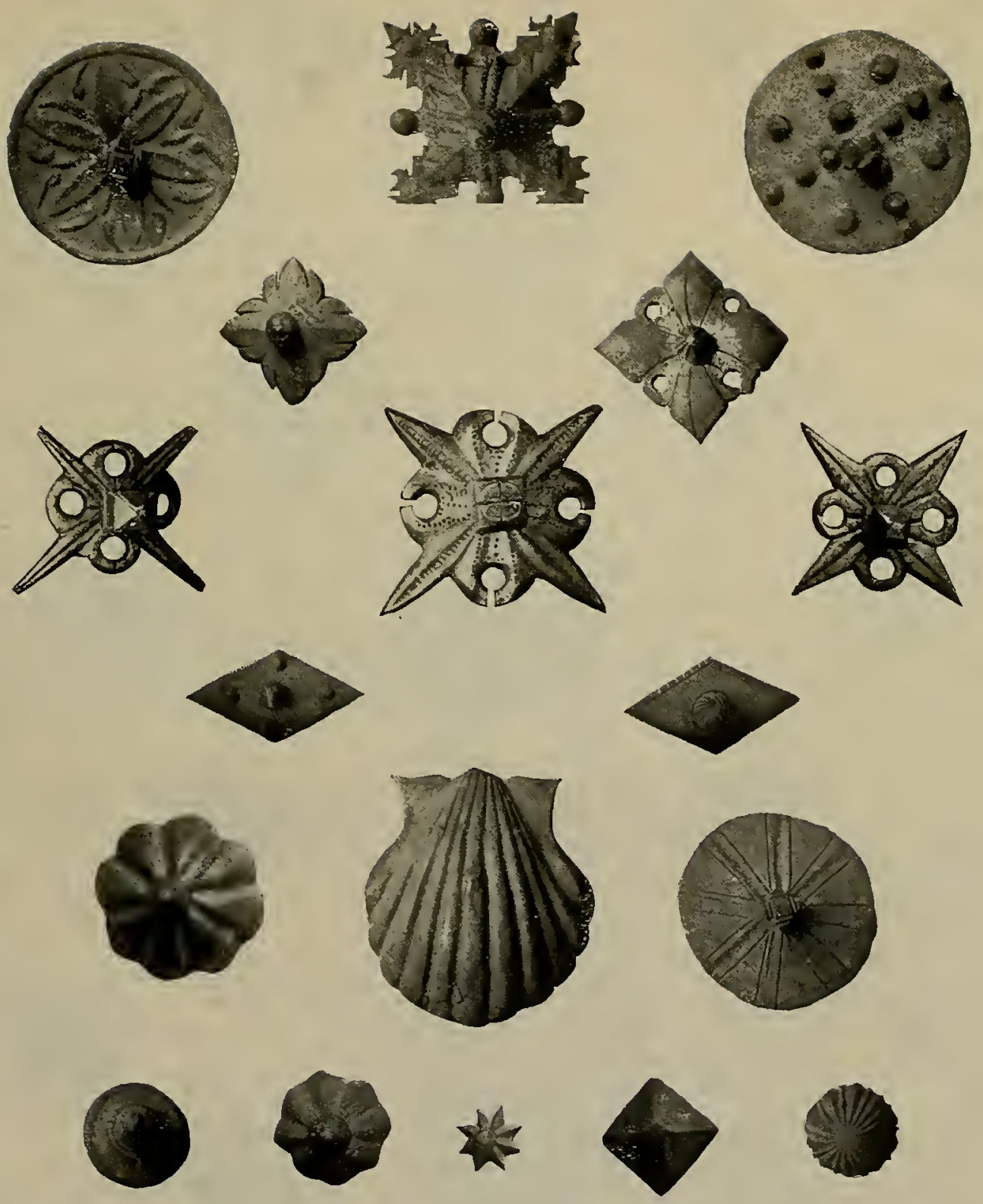

Figs. 201 a 218 


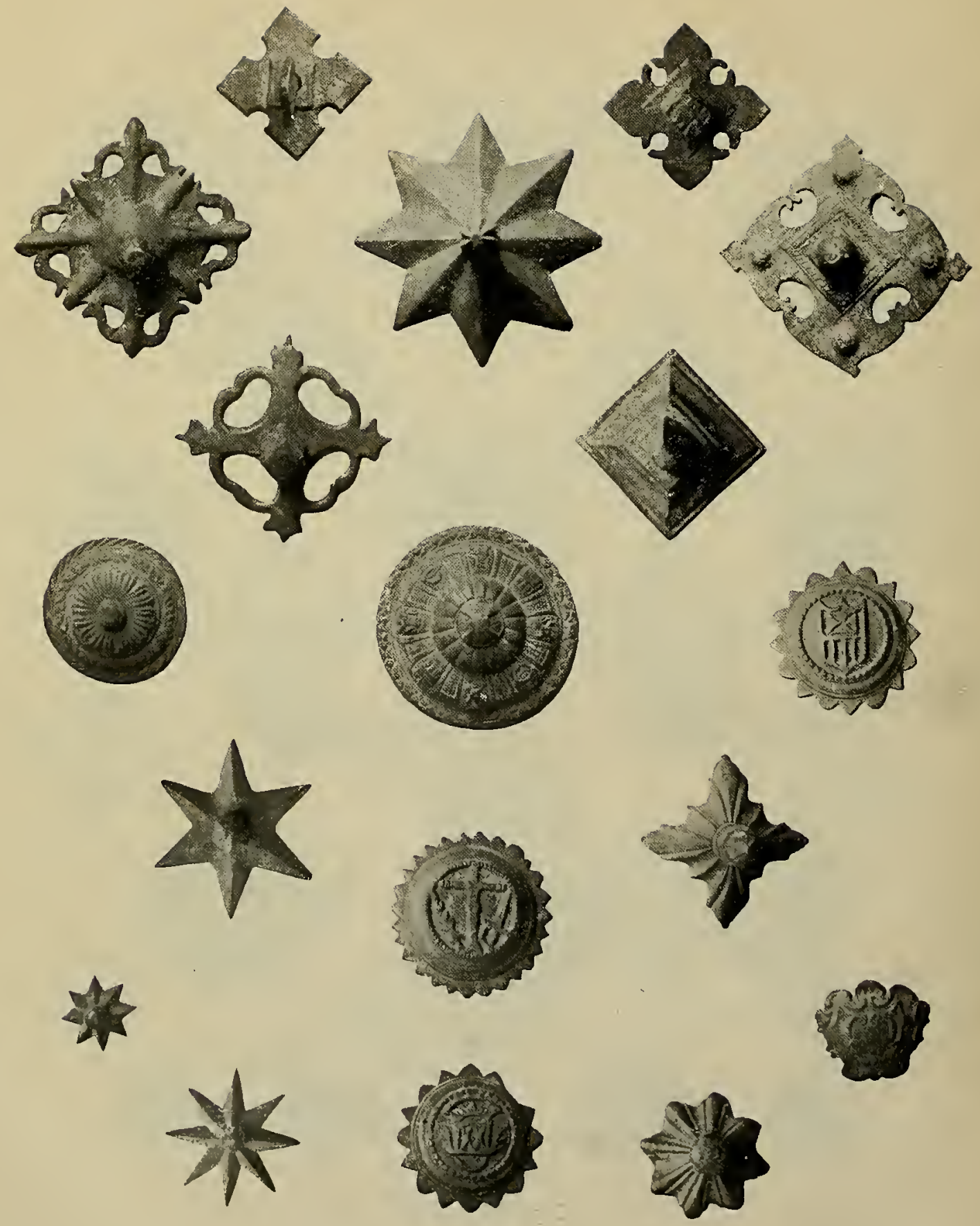

Figs. 219 a 236 


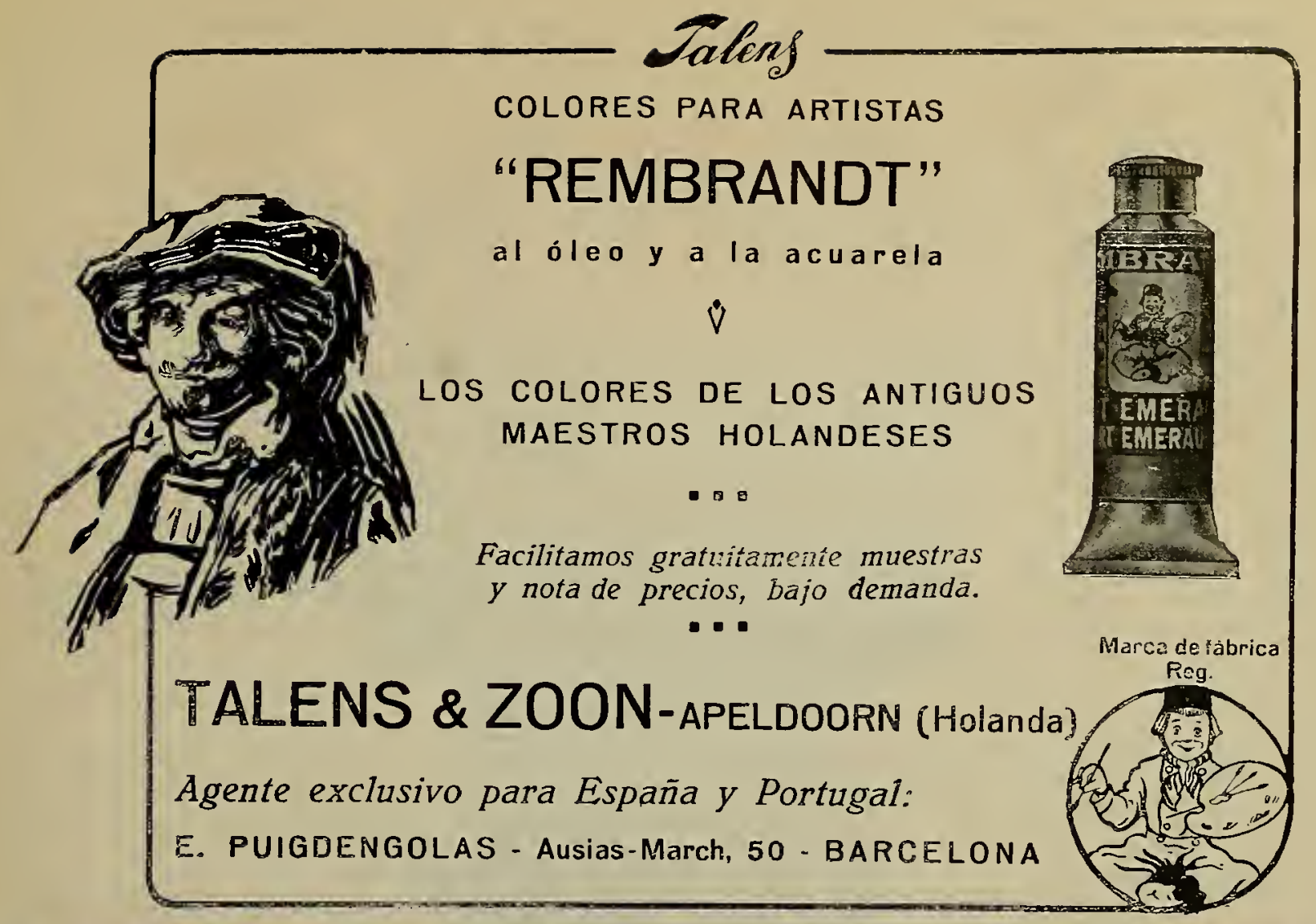

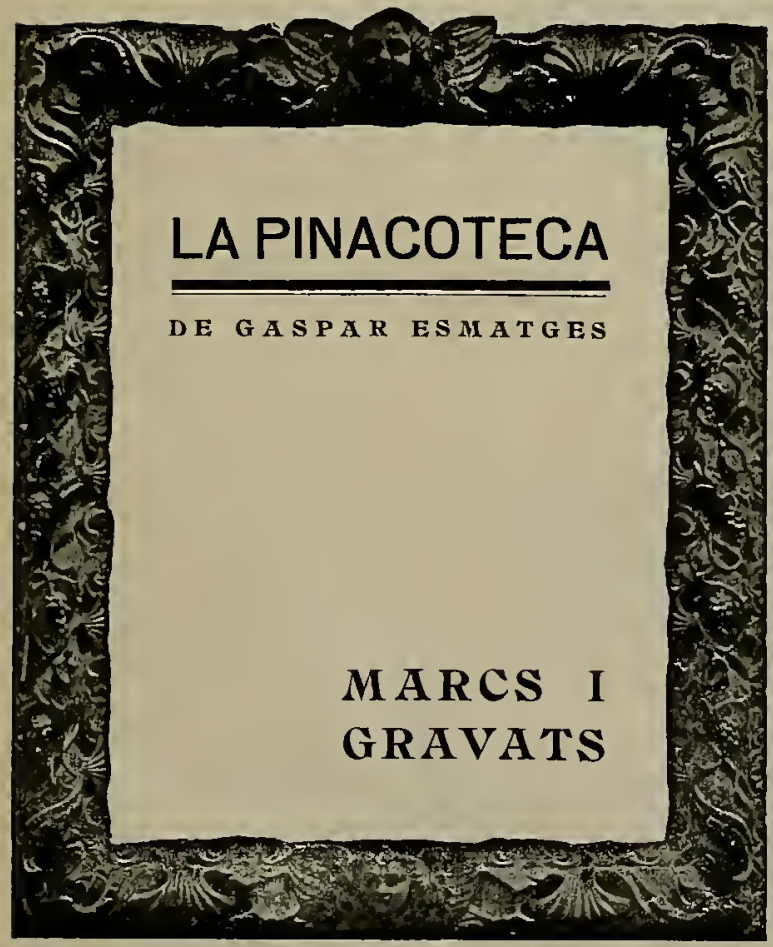

CORTS CATALANES, 644 BARCELONA : Telèion A. 5045 (Entre Passeig de Gràcia i Clarís)

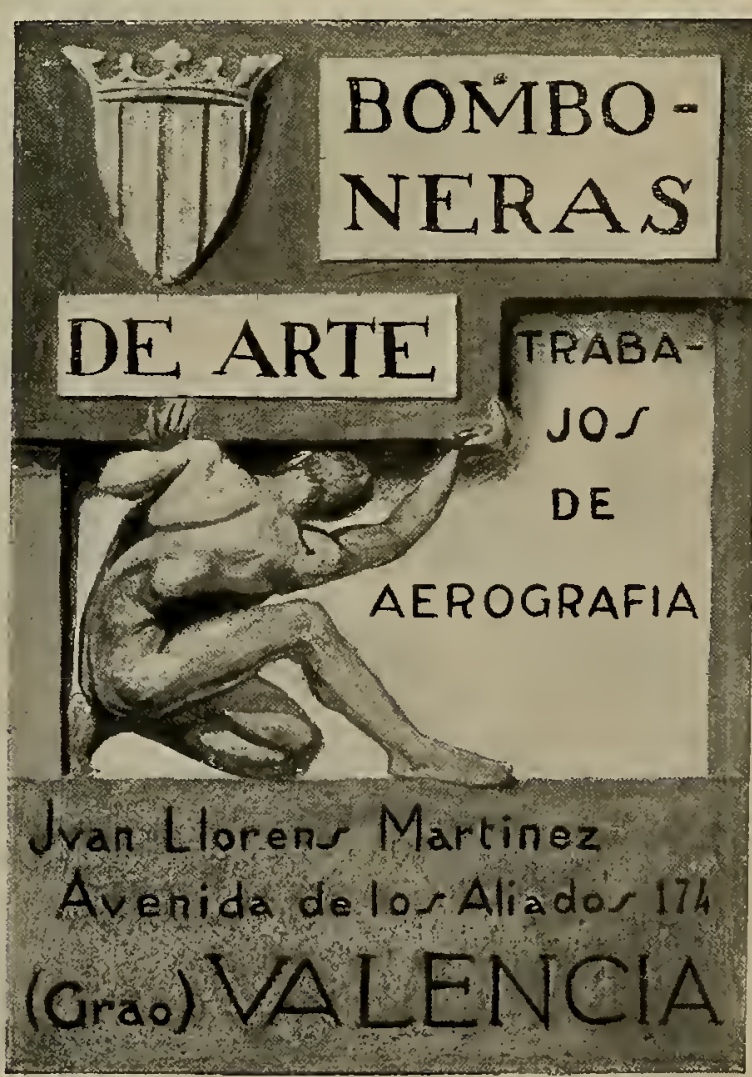




\section{FA I A N C

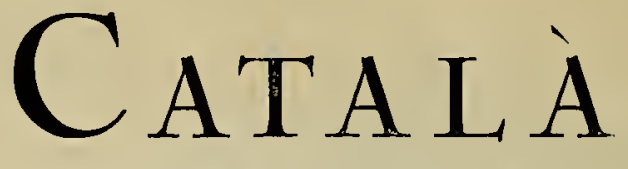

GR A N V I A , N ÚM. 615 : T ELE F N 1884 A.

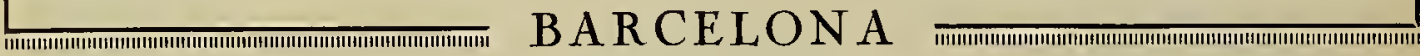

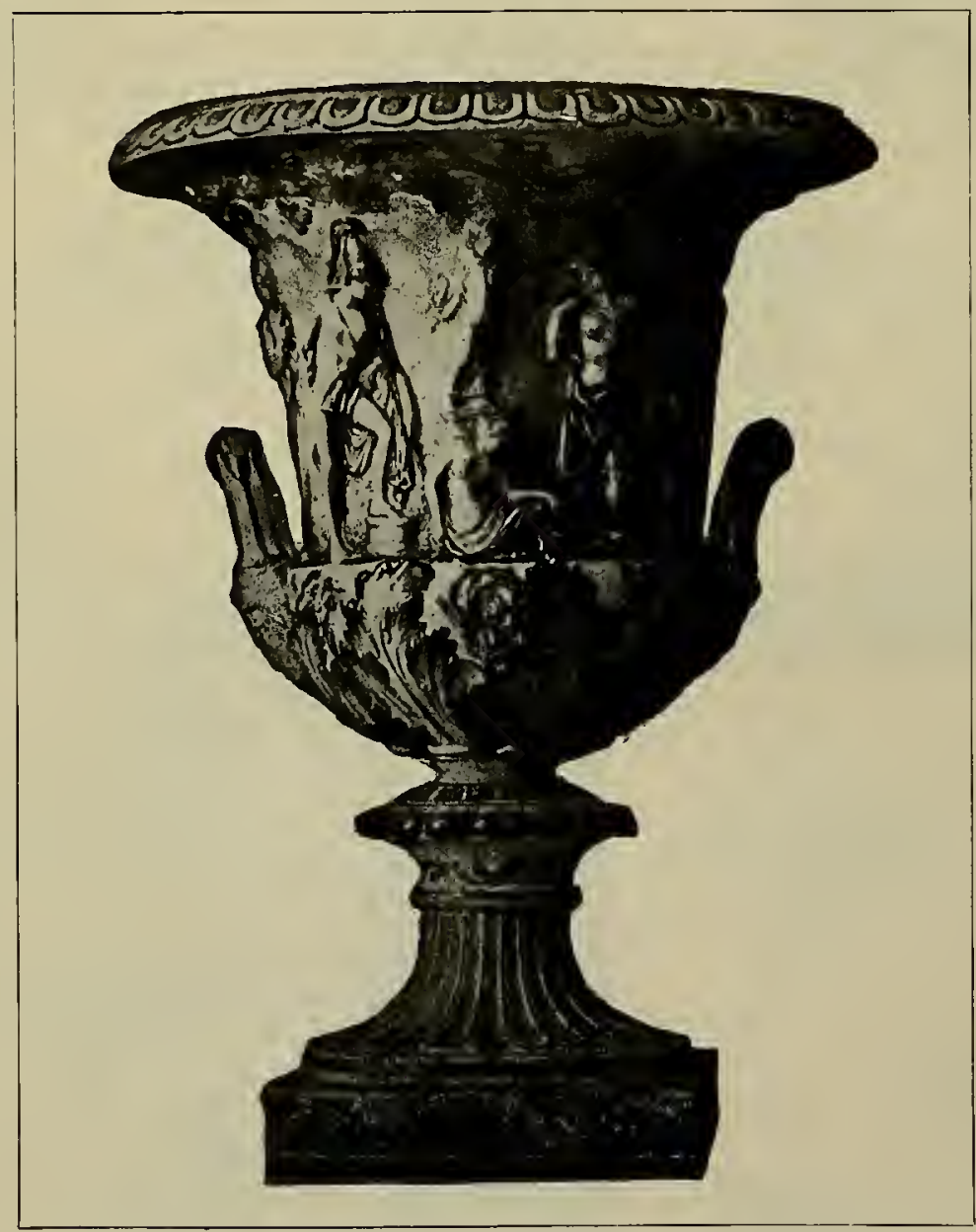

COPES PER A CONCURSOS - CISTELLS PER A LABORS - PORCELLANES OBJECTES PER A REGALS - PORTA-RETRATS • RELLOTGES D I VIATGE I SOBRE-TAULA - MARCS - CAIXETES PER A CIGARS - BRONZES D'ART, ETC.

VÍDUA DE SANTIAGO SEGURA, S. en C. 


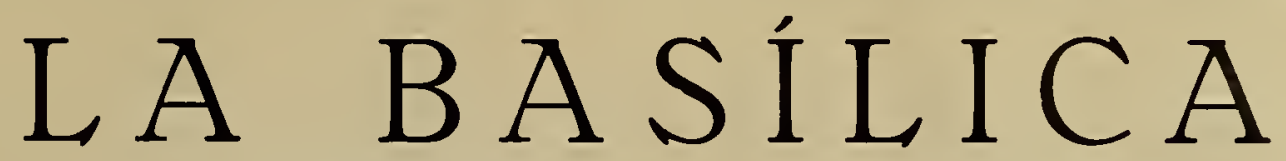

COMPRA I VENDA D'ANTIGUITATS

EL CENTRE MÉS

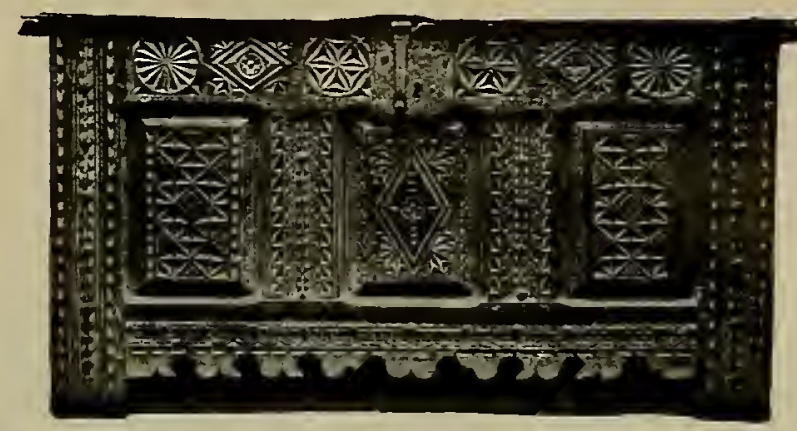

Situat darrera la Catedral, prop de

IMPORTANT DE

BARCELONA PER

A TOTA MENA

D'ANTIGUITATS

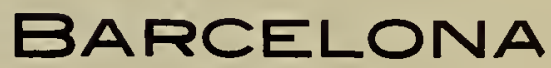

OBERT: DE 10 A 1 Y DE 3 A 7

PIETAT, NUM. 4

TELĖFON $4626 \mathrm{~A}$. l'Institut d'Estudis Catalans, el Palau de la Generalitat i l'Arxiu de la Corona d'Aragó

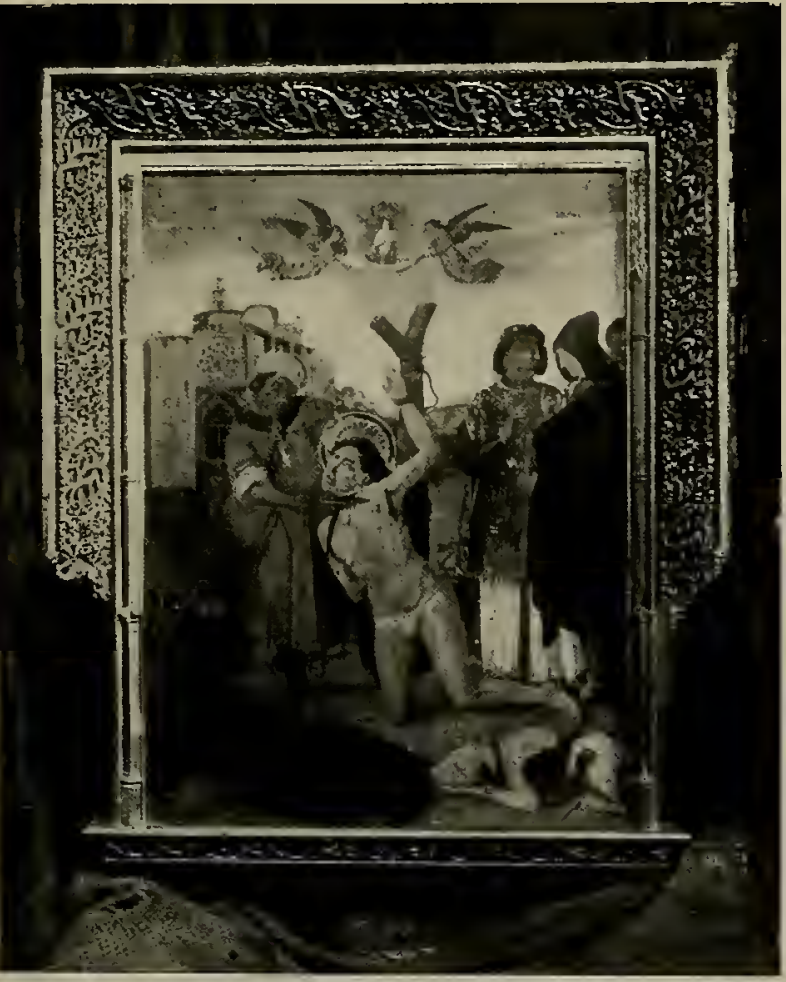

\section{Antiga Casa OLIVA \\ SUCCESSORS: \\ Priu i Simon \\ Consell de cent, 368 \\ BARCELONA}

TALLER DE DAURATS I POLICROMATS

\section{Altars : Imatges}

Decoració i reproducció en pasta, d'objectes d'Art : Nou procediment d'aquesta casa en la neteja dels daurats i policromats en objectes d'Art antic : Imitació de metalls, marfil, marbres, fustes, etc. : Secció especial per a conservació i restauració de retaules CASA FUNDADA L'ÁNY 1885 


\section{art et deconation}

La grande revue française d'art moderne

Recherchée pour ses nombreuses reproductions en noir et en couleurs.

Tous les arts et surtout la décoration intérieure de la maison.

\section{QUELQUES ARTICLES PARUS RÉCEMMEHT}

6 Etudes sur le Mobilier moderne : Quelques interprétations de la Flore : : Le Point de Nice (dentelles) : : L'Art chrétien moderne : : Médailles et plaquettes de la guerre : L'art de la carrosserie et l'auto-

mobile de luxe, etc., etc. : : : : : : : :

Chaque mois un numéro de 40 pages, avec environ 50 très belles reproductions en noir et en couleurs :: Chronique de l'actualité artistique, étudiant les villes, les monuments, les musées, les expositions, les ventes, les livres, etc.: : : : : : : : : :

Le numéro: France, 6 frs. - Etranger, 7 frs. L'abonnement: France, 60 frs. - Etranger, 70 frs.

Sur demande un specimen gratuit sera envoye Paris, 2, rue de l'Echelle et chez les libraires.

\section{Rassegna d'Arte Antica e Moderna}

Cette revue, publiée sous la direction de $\mathrm{M}$. Corrado Ricci, avec le concours des plus éminents critiques d'Italie, étıdie l'art rétrospectif et contemporain, les collections publiques et particulières, les objets artistiques que l'ltalie révèle à l'admiration des amateurs. La RASSEgNA D'ARTE ANTICA E MoDERNA parait chaque mois en livraison de 56 pages, in $4^{\circ}$, ornées d'un grand nombre d'illustrations dans le texte et hors texte, avec gravures au burin et à l'eau-forte, estampes en couleurs, lithographies, etc.

Bollettino del Reale Istituto di Archeologia e Storia dell'Arte di Roma

Bulletin dirigé por Corrado Ricci, bimensuel, avec illustrations en phototypie, de 32 pages; publication officielle de l'Institut d'Archéologie et d'Histoire de l'Art de Rome. Il donne le compte rendu de tous les livres d'art et des revues publiés en ltalie et à l'étranger. Le Bulletin est livré aux abonnés de Rassegna au prix annuel de L. 10, Fr. 10, à l'étranger; pour les non abonnés, il est livré au prixde L. 20, Fr. 20, à l'étranger. Chaque numéro vant L. 3`50, Fr. 3`50 à l'étranger.

Editori ALFIER1 \& LACROIX - Roma (11) - Via Zanardelli, 7

\section{Gazette des Beaux-Arts}

REVUE MENSUELLE ILLUSTREE

PRIX DE L'ABONNEMENT

Paris et départements $80 \mathrm{fr}$. II Étranger

Edition de luxe (papier du Japour)

100 ir.

$140 \mathrm{fr}$.

La Gazette des Beaux-Arts, publiée, sous la direction de M. ThÉodore Reinach, membre de l'Institut, avec le concours des plus éminents critiques de tous les pays, embrasse l'étude rétrospective et contemporaine de toutes les manifestations de l'art et de la curiosité (architecture, sculpture, peínture, gravure, arts decoratifs et industriels, musique), des collections publiques et particulieres, de la bibliographie artistique.

Chaque livraison, de 80 pages in $-4 .^{\circ}$ carré, est ornée d'un grand nombre d'illustrations dans le texte et de plusieurs planches hors texte: gravures au burin et à l'eau forte, gravures sur bois, lithographies, estampes en couleurs, hêliogravures, etc., dues a nos premiers artistes.

Les abonnés de la Gazette des Beaux-Arts reçoivent graLes abomn
tuitement

\section{LA ChPoHiloue des arts et de la curlosití}

Cette publication supplémentaire leur signale tous les quinze jours, les ventes, les expositions et concours artistiques, leur donne les nouvelles des musées, des collections particulières, des Académies, le compte rendu des livres d'art et des revues publiés en France et à l'étranger.

ON S'ABONNE : ALX BLREALX DE LA GAZETTE DES BEAUX-ARTS 106, Bd St GERMAIN, PAR1S

Teléphone: Gobelins 21-29

CHEZ LES PRINCIPAUX LIBRAIRES DE LA FRANCE ET DE L'ÉTRANGER

dans tous les Bureaux de Poste

PRIX D'UN NUMÉRO SPÉCIMEN : 5 Irancs

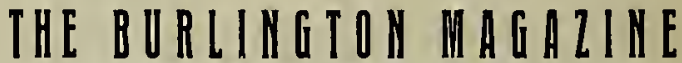 REVISTA MENSUAL IL-LUSTRADA D'ART}

Des de sa lundació (1903), THE BURLINGTON MAGAZINE ha prosperat constantment i compta entre sos collaboradors els critics d'art més competents, no solsament d'Anglaterra i Amèrica, sinó de França, Alemanya, ltàlia, Espanya, Bèlgica i Hol-landa. Si el conjunt de treballs publicats en el MAGAZINE forma una revista completa de les arts plastiques, la bellesa de ses il'lustracions posa al BURLINGTON MAGAZINE com el primer dels periodics artistics d'Europa i Amèrica. Els més importants descobriments d'aquets darrers temps, ja sobre art migeval i de la Ranaixença a Europa, ja temps, ja sobre art mahometá, sinic, hindu i altres llocs menys explorats, han sigut publicats i comentats en THE BURLINGTON MAGAZINE

Una llista, per ordre alfabètic, dels principals articles publicats, seria enviada gratuitament, essent demanada al nostre despatx principal a Londres, 17, Old Burlington Street, W.

Núms. 82-83 Cézanne, per Maurice Denis.

N. 208 Esmalts de l'escola de G. Glaise.

N. 209 Art modern francés, por F. R. Vanderpil.

N. 210 Georges Seurat, per A. Salmón.

N. 213 Pintura espanyola a Burlington House.

N. 214 Mobles italians, per H. C. Smith. Al demana'is es prega que s'indiqui el numero

Subscripció anyal: Número solt: 35 shillings 3 shillings

The Burlington Magazine Ltd. LONDON : 17, Old BurLington StreEt W. 1.

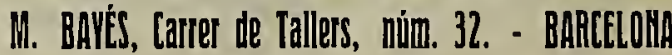




\section{GALERIES LAIETANES}

Granvia, núm. 613 : BARCELONA : Telèfon 4902 A.

\section{ANTIGUITATS}

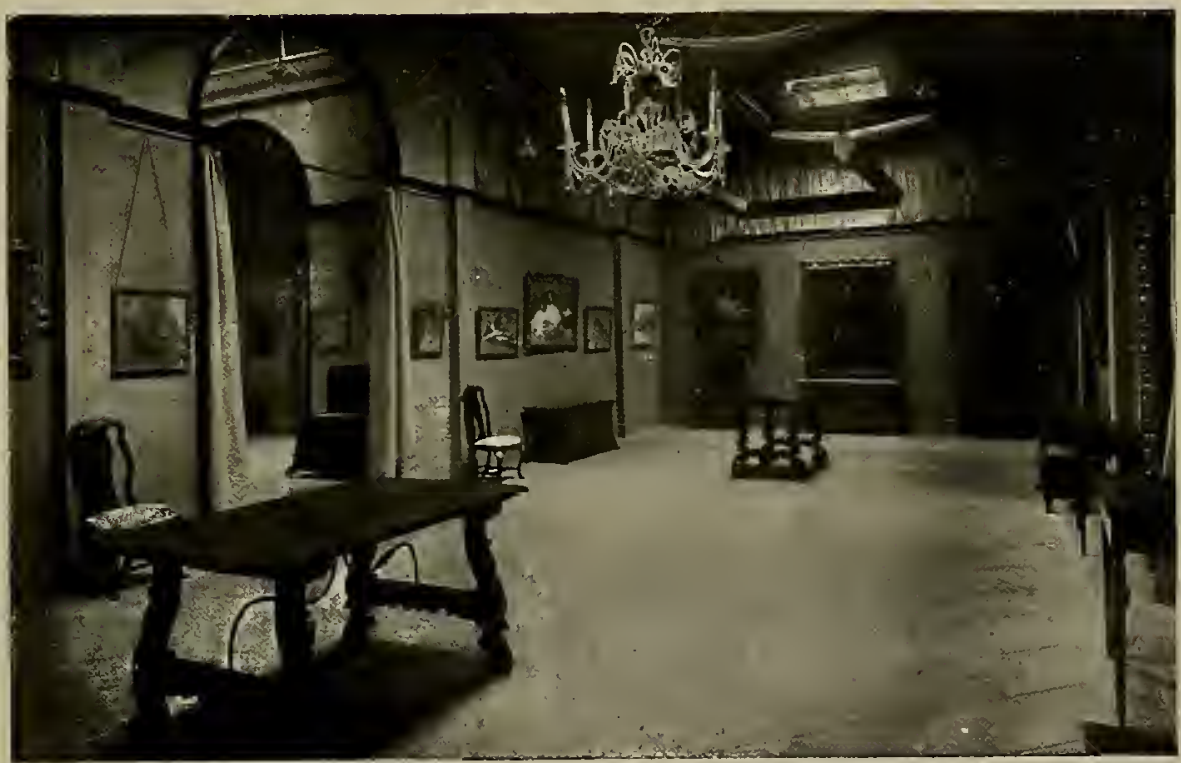

ART MODERN

CAMAFEUS :: BRODATS :: ALFOMBRES PERSES :: TAPISSOS $::::$ CORNuCÓPIES $::$ JOIES :: MOBLES D'ESTIL :: :: EXPOSICIONS CONSTANTMENT RENOVADES D'OBRES DEIS MÉS AFAMATS ARTISTES MODERNS 




CASA ESTABLERTA L'ANY 1852

Consell de Cent, nüm, 351 (tocant al Passeig de Gràcia)

Tallers: Enric Granados, 21 Telèfon A. 4438

$B \mathcal{R} C \& \& O N \mathcal{A}$

MOBLES : DECORACIÓ QUA DROS : LLIBR FS SALES I`EXPOSICIONS
CASA EDITRICE D'ARTE BESTETTI \& TUMMINELLI Milán, Roma, Florencia, Nápoles, Palermo, Génova, Venecia, Lugano


Revisla de Arte, baja la dirección de HUGO OJETTI

Esta Revista no es para los eruditos y estudiosos, sino que se dirige al vasto piblico de los enamorados del arte. lanto se ocupa de las artes menores, como del arte puro, del arte antiguo como del moderno; y aunque consagrando la mayor parte al italiano, no ignora el arte extranjero, aun el no europeo. Es un tipo de revista hasta ahora no existente en Italia.

Se publica en fasciculos mensuales de 70 paginas con numerosisimas ilustraciones y láminas aparte en negro y color.

La subscripción al año III empieza en 1. de Junio de 1922

Un fascículo . . . . . . . . frcs. 15

Doce fascículos, subscripción . . . frcs. 120 Dirección :

FLORENCIA : Palazzo dell'Arte della Lana Administración :

MILÁN: Viale Monforte, número 20

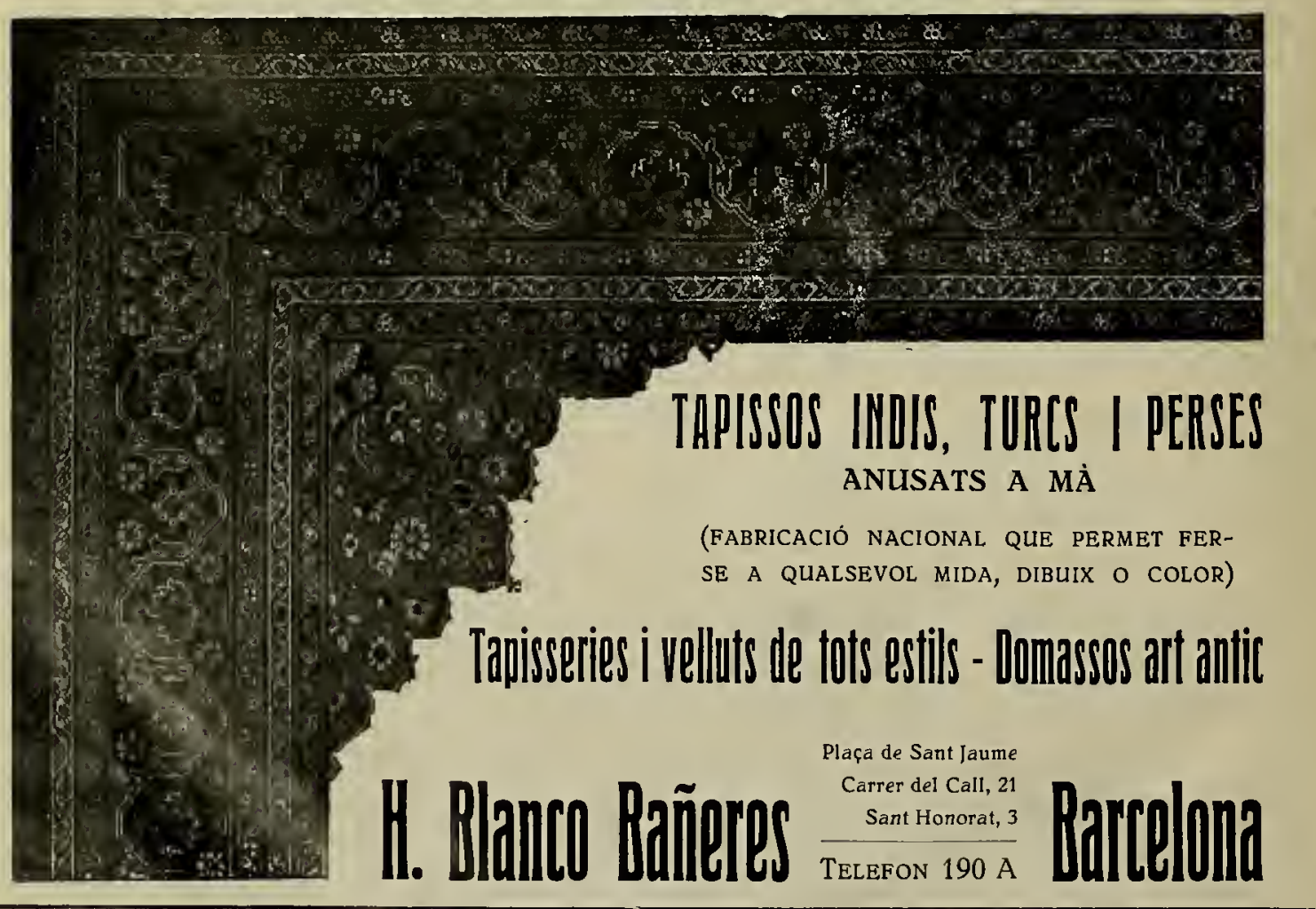




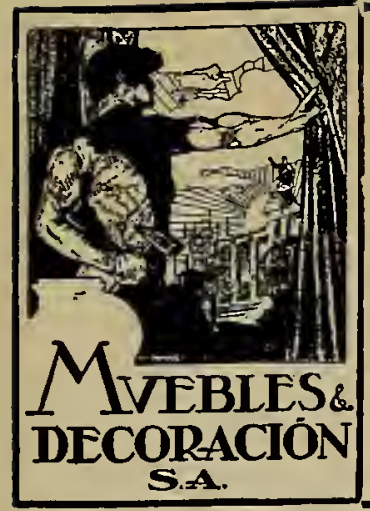

Mobles per a despatxs en tots istils; especialitat en el T IP O A MERICÁ; el més gran stock Instal-lacions completes d'oficines, bancs, tendes, clubs, etc.

AMB ELS SELS ENCẢRREGS, EL CLIENT

ESTALVIARÅ TEMPS, MOLESTIES I DINERS

Corts, 532/Teléfon A. $300 /$ BARCELONA
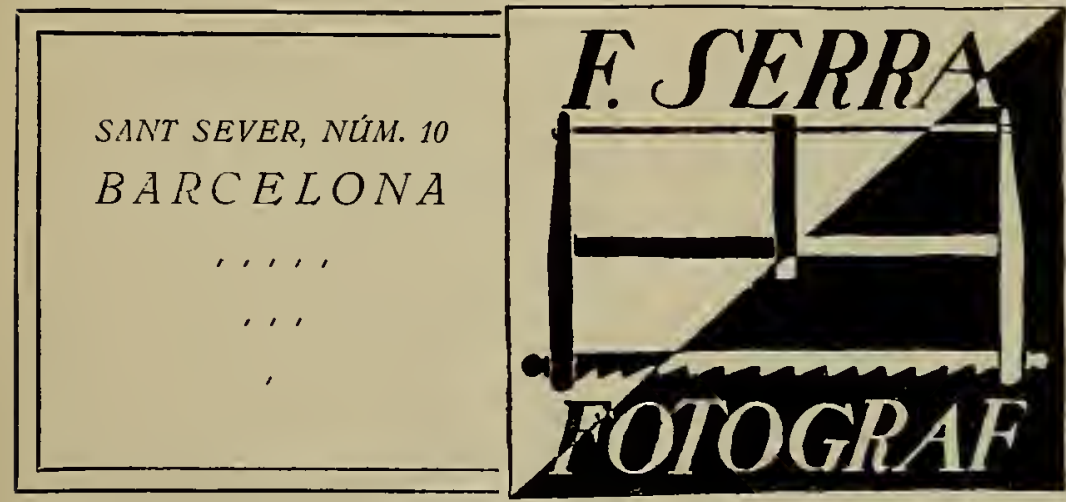

REPRODUCCIÓ

DE PINTURES

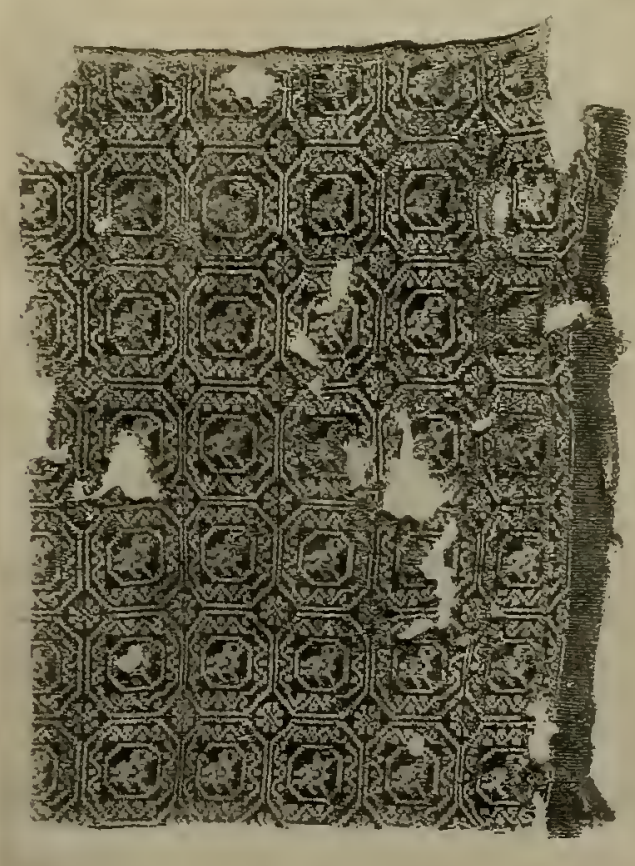

ANT IG ÜEDA DES

| M U E B L E S

L ÁMPARA S

DECORACIÓ N

Canuda, 4

Barcelona 


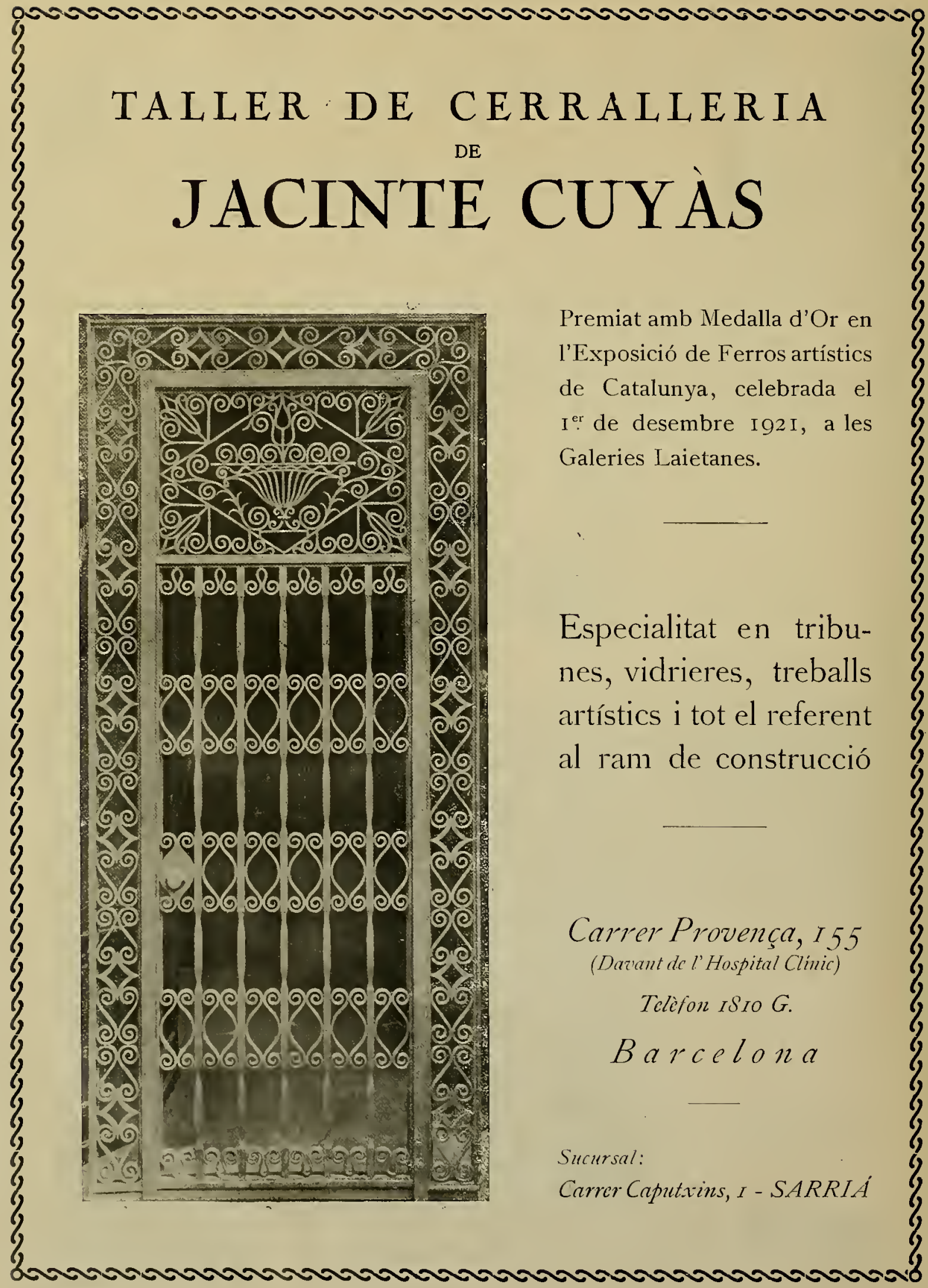





